\title{
Projeções multidimensionais para a análise de fluxos de dados
}

Tácito Trindade de Araújo Tiburtino Neves 

Assinatura:

\title{
Tácito Trindade de Araújo Tiburtino Neves
}

\section{Projeções multidimensionais para a análise de fluxos de dados}

\author{
Tese apresentada ao Instituto de Ciências \\ Matemáticas e de Computação - ICMC-USP, \\ como parte dos requisitos para obtenção do título \\ de Doutor em Ciências - Ciências de Computação e \\ Matemática Computacional. VERSÃO REVISADA \\ Área de Concentração: Ciências de Computação e \\ Matemática Computacional \\ Orientador: Prof. Dr. Fernando Vieira Paulovich
}


Ficha catalográfica elaborada pela Biblioteca Prof. Achille Bassi e Seção Técnica de Informática, ICMC/USP, com os dados fornecidos pelo(a) autor(a)

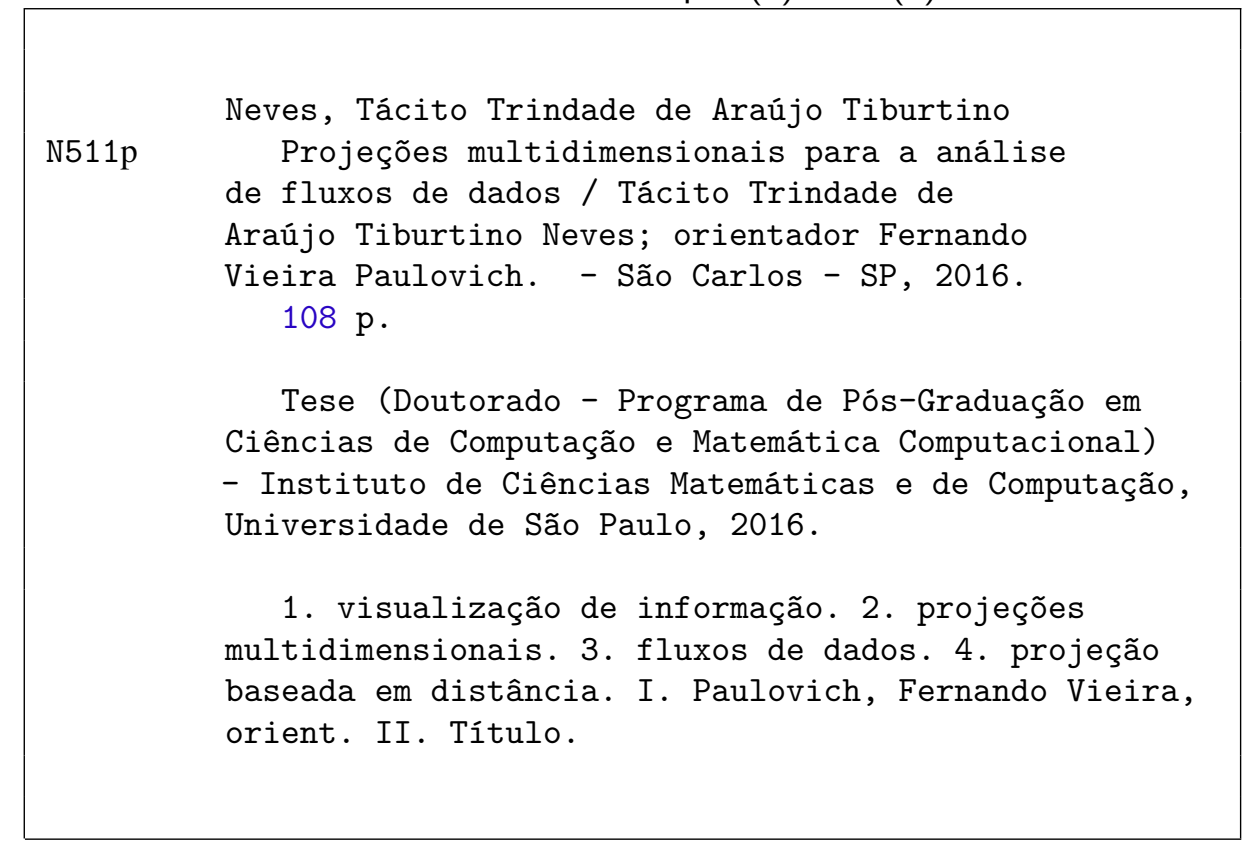


Tácito Trindade de Araújo Tiburtino Neves

\section{Multidimensional projections for data stream analysis}

Doctoral dissertation submitted to the Instituto de Ciências Matemáticas e de Computação - ICMCUSP, in partial fulfillment of the requirements for the degree of the Doctorate Program in Computer Science and Computational Mathematics. FINAL VERSION

Concentration Area: Computer Science and Computational Mathematics

Advisor: Prof. Dr. Fernando Vieira Paulovich 

Dedico esta tese aqueles que mais amo: meus pais, Hortogami e Girliane; meus irmãos, Theomar e Nívea; e minha noiva, Niedja. Sem vocês isso não seria possível. 



\section{AGRADECIMENTOS}

A Deus, por me dar paz, sempre estando em meu coração.

Aos meus pais, Hortogami e Girliane, e aos meus irmãos, Theomar e Nívea, por me darem colo, amor e força de continuar. Além de todos os meus familiares, especialmente a minha tia Eliane que ajudou diretamente na fase final do trabalho.

À minha noiva Niedja, amor da minha vida, pelo apoio e principalmente pela paciência. Por acreditar, às vezes mais do que eu, que isso seria possível. E por largar tudo e casar comigo ao final desse trabalho. Eu amo você.

Ao meu orientador, Dr. Fernando Vieira Paulovich, pelos ensinamentos, pela amizade e pelos churrascos (que foram poucos mas existiram). Saiba que você é um exemplo de profissional, e principalmente de ser humano. Espero que um dia sinta orgulho do seu ex-orientando, assim como sinto de ter sido seu aprendiz.

Aos demais professores que contribuíram com minha formação, seja no ensino mais básico, no CEFET-AL (atual IFAL), na UFAL ou aqui no ICMC-USP. De um modo muito especial ao Prof. Dr. Alejandro Frery, que foi o primeiro a me apresentar a pesquisa. Também à Prof. ${ }^{a}$ Dr. ${ }^{a}$ Maria Cristina Ferreira de Oliveira, por tudo que fez por mim desde o tempo em que me orientou no mestrado.

Aos amigos de São Carlos, que dividiram o mesmo teto ou apenas estiveram presentes nos momentos vividos por lá, Fernando Sá (Feu), Edgar Peixoto, Danilo, Maycon, Gabriel (Ceará), Cássio Prazeres, José Augusto (Tim), Flávio Dusse, Renato Rodrigues, David, Ricardo Rios, Guilherme (Baiano), Felipe (Mineiro), Karina, Nelson Ponce, Leonardo Martinussi, Pablo e todos os outros.

Aos amigos de longa data: Andrezza, Cícero, Daniel, Everson (Cabeção), Ericka, Higor, Jhonatan Guedes (Gaio), Jhonathan Gomes, Paulo Henrique, Rafael, Robson, aos amigos do Amparo e todos os outros que estiveram presentes em minha vida.

Aos colegas de trabalho e amigos de Rio Paranaíba, em especial a Marcelo Zorzan, João Mari, Rejane Nascentes, Vinícius Albano, Liziane, Guilherme Pena, Pablo Munhoz e Gabriela Mendonça.

Todos os colegas de curso e do laboratório do grupo de pesquisa em Visualização, Imagens e Computação Gráfica (VICG) do ICMC/USP. 
À banca que gentilmente aceitou o convite para essa defesa.

À Universidade Federal de Viçosa, mais especificamente ao campus de Rio Paranaíba, que apoiou e me liberou para finalizar o doutorado. E ao Instituto de Ciências Matemáticas e de Computação da Universidade de São Paulo, que me acolheu desde quando cheguei para o mestrado.

Ao CNPq, a CAPES e à FAPESP pelo apoio financeiro, direto ou indireto.

A todos que, direta ou indiretamente, contribuíram para que tudo isto fosse possível. 


\section{RESUMO}

TIBURTINO, TÁCITO. Projeções multidimensionais para a análise de fluxos de dados. 2016. 108 f. Tese (Doutorado em Ciências - Ciências de Computação e Matemática Computacional) - Instituto de Ciências Matemáticas e de Computação (ICMC/USP), São Carlos SP.

As técnicas de projeção multidimensional tornaram-se uma ferramenta de análise importante. Elas buscam mapear dados de um espaço multidimensional para um espaço visual, de menor dimensão, preservando as estruturas de distância ou de vizinhança no mapa visual produzido. Apesar dos recentes avanços, as técnicas existentes ainda apresentam deficiências que prejudicam a sua utilização como ferramentas exploratórias em certos domínios. Um exemplo está nos cenários streaming, nos quais os dados são produzidos e/ou coletados de forma contínua. Como a maioria das técnicas de projeção necessitam percorrer os dados mais de uma vez para produzir um layout final, e fluxos normalmente não podem ser carregados por completo em memória principal, a aplicação direta ou mesmo a adaptação das técnicas existentes em tais cenários é inviável. Nessa tese de doutorado é apresentado um novo modelo de projeção, chamado de Xtreaming, no qual as instâncias de dados são visitadas apenas uma vez durante o processo de projeção. Esse modelo é capaz de se adaptar a mudanças nos dados conforme eles são recebidos, atualizando o mapa visual para refletir as novas estruturas que surgem ao longo do tempo. Os resultados dos testes mostram que o Xtreaming é muito competitivo em termos de preservação de distâncias e tempo de execução se comparado com técnicas do estado-da-arte. Também é apresentada uma nova técnica de projeção multidimensional, chamada de User-assisted Projection Technique for Distance Information (UPDis), que foi projetada para permitir a intervenção do usuário exigindo apenas informações de distância entre as instâncias, e que é utilizada como parte do Xtreaming. Os resultados também mostram que a UPDis é tão rápida, precisa e flexível quanto as técnicas do estado-da-arte.

Palavras-chave: visualização de informação, projeções multidimensionais, fluxos de dados, projeção baseada em distância. 



\section{ABSTRACT}

TIBURTINO, TÁCITO. Projeções multidimensionais para a análise de fluxos de dados. 2016. 108 f. Tese (Doutorado em Ciências - Ciências de Computação e Matemática Computacional) - Instituto de Ciências Matemáticas e de Computação (ICMC/USP), São Carlos SP.

Multidimensional Projection techniques have become an important analytics tool. They map data from a multidimensional space into a visual space preserving the distance or neighborhood structures on the produced layout. Despite the recent advances, existing techniques still present drawbacks that impair their use as exploratory tools on certain domains. An example is the streaming scenario, in which data are captured or produced continuously. Since most projection techniques need to traverse the data more than once to produce a final layout, and streaming data typically cannot be completely loaded into the main memory, the direct use or even adaptation of the existing techniques in such scenarios is infeasible. In this dissertation, we present a novel projection model, called Xtreaming, wherein the data instances are visited only once during the projection process. This model is able to adapt itself to the changes in data as data is received, updating the visual layout to reflect the new structures that emerge over time. The tests show that Xtreaming is very competitive regarding distance preservation and running time when compared with state-of-the-art projection techniques. We also present a new multidimensional projection technique, called User-assisted Projection Technique for Distance Information (UPDis), that was designed to allow user intervention requiring only distance information between data instances. UPDis is used as part of the Xtreaming model. The results show that UPDis is as fast, accurate and flexible as state-of-the-art techniques.

Key-words: information visualization, multidimensional projections, data streams, distancebased projection. 



\section{LISTA DE ILUSTRAÇÕES}

Figura 1 - Classificação das técnicas de projeção multidimensional . . . . . . . . . . 33

Figura 2 - Visão geral da técnica UPDis . . . . . . . . . . . . . . 51

Figura 3 - Comparação de stress entre a abordagem aleatória e utilizando agrupamento 54

Figura 4 - Comparação stress vs. $\Lambda \ldots \ldots \ldots$. . . . . . . . . 57

Figura 5 - Boxplots dos resultados de stress e tempo de execução . . . . . . . . . 58

Figura 6 - Gráfico de dispersão das distâncias no espaço original e no espaço projetado 59

Figura 7 - Efetividade da manipulação realizada pelo usuário . . . . . . . . . . . 62

Figura 8 - Projeções variando a porcentagem de amostras representativas mais próximas 63

Figura 9 - Preservação de vizinhança vs. porcentagem de vizinhos mais próximos . . . 64

Figura 10 - Visão geral da técnica Xtreaming. . . . . . . . . . . . . . . . . 67

Figura 11 - Comparação entre técnicas de mapeamento para construir a função de projeção 69

Figura 12 - Ilustração do processo de re-projeção da Xtreaming . . . . . . . . . . . . 70

Figura 13 - Ilustração do teste de detecção de mudanças da Xtreaming . . . . . . . . 72

Figura 14 - Tamanho da amostra vs . partições recebidas . . . . . . . . . . . . 75

Figura 15 - Stress vs. partições recebidas . . . . . . . . . . . . . . . 76

Figura 16 - Boxplots de stress da técnica Xtreaming com diferentes ordenações de dados 77

Figura 17 - Boxplots de stress comparando a Xtreaming com outras técnicas . . . . . . 78

Figura 18 - Boxplots de stress com técnicas usando amostras produzidas pela Xtreaming 79

Figura 19 - Gráfico de dispersão distância original vs . distância projetada . . . . . . . 80

Figura 20 - Boxplots de tempo de execução . . . . . . . . . . . . . . . . . . 81

Figura 21 - Tempos de execução para grandes conjuntos de dados . . . . . . . . . . . 81

Figura 22 - Boxplots de stress com técnicas incrementais . . . . . . . . . . . . . . 82

Figura 23 - Ilustração do processo de recomendação de leituras . . . . . . . . . . . . 84

Figura 24 - Ilustração do cálculo da distância entre dois livros . . . . . . . . . . . . . 85

Figura 25 - Projeções dos livros escolhidos pelo usuário . . . . . . . . . . . . . . . 87

Figura 26 - Projeção final de todos os livros relacionados . . . . . . . . . . . . . . . . 88

Figura 27 - Projeção dos tweets coletados no dia 14/04/2016 . . . . . . . . . . . . . 93

Figura 28 - Projeção dos tweets coletados nos dias 14/04/2016, 15/04/2016 e 16/04/2016 93

Figura 29 - Evolução ao longo dos 30 dias que formam o período de coleta dos tweets . 94 



\section{LISTA DE ALGORITMOS}

Algoritmo 1 - User-assisted Projection Technique for Distance Information (UPDis) . . 55

Algoritmo 2 - Xtreaming . . . . . . . . . . . . . 73 



\section{LISTA DE TABELAS}

Tabela 1 - Conjuntos de dados utilizados nas comparações da UPDis . . . . . . . . . 56

Tabela 2 - Conjuntos de dados utilizados nas comparações da Xtreaming . . . . . . 74

Tabela 3 - Hashtags mais citadas durante o período de coleta . . . . . . . . . . . 90

Tabela 4 - Hashtags classificadas manualmente . . . . . . . . . . . 92 



\title{
LISTA DE ABREVIATURAS E SIGLAS
}

\author{
$k$-NNG $\ldots \quad k$-Nearest Neighbor Graph \\ $k$-NN $\ldots . . \quad k$-Nearest Neighbor \\ CMDS ..... Classical Multidimensional Scaling \\ CP ...... Componentes Principais \\ I-ISOMAP Incremental ISOMAP \\ I-PCA .... Incremental PCA \\ ISOMAP ... Isometric Feature Mapping \\ L-ISOMAP Landmarks ISOMAP \\ L-MDS .... Landmarks MDS \\ LAMP ..... Local Affine Multidimensional Projection \\ LLE ..... Local Linear Embedding \\ LSP ..... Least Square Projection \\ MDS ..... Multidimensional Scaling \\ NP ...... Neighborhood Preservation \\ PCA ..... Principal Component Analysis \\ PLMP ..... Part-Linear Multidimensional Projection \\ PLP ...... Piecewise Laplacian Projection \\ RNA ..... Redes Neurais Artificiais \\ S-PLMP ... Streaming PLMP \\ SVD ...... Singular Value Decomposition \\ t-SNE ... t-Distributed Stochastic Neighbor Embedding \\ UPDis ... User-assisted Projection Technique for Distance Information
}





\section{LISTA DE SÍMBOLOS}

$\mathbf{X}$ - Conjunto de instâncias no espaço $m$-dimensional.

$m$ — Dimensão do espaço original.

$\mathbf{x}_{i}$ - $i$-ésima instância do espaço original.

$\mathbf{Y}$ - Conjunto de pontos no espaço $p$-dimensional.

$p$ — Dimensão do espaço projetado.

$\mathbf{y}_{i}-i$-ésimo ponto do espaço projetado.

$n$ — Número de instâncias no espaço original e pontos no espaço projetado.

$\delta\left(\mathbf{x}_{i}, \mathbf{x}_{j}\right)$ - Dissimilaridade entre as instâncias $i$ e $j$ no espaço original.

$d\left(\mathbf{y}_{i}, \mathbf{y}_{j}\right)$ - Distância entre os pontos $i$ e $j$ no espaço projetado.

$\overline{\mathbf{X}}$ - Conjunto de amostras selecionadas em $\mathbf{X}$.

$\overline{\mathbf{x}}_{i}$ - $i$-ésima instância do conjunto de amostras.

$S_{1}$ - Função de stress de Kruskal.

$S_{2}$ — Função de stress de Sammon.

$M F$ — Parâmetro de otimização de convergência do algoritmo Pekalska.

maxDist $_{i}$ - Maior distância entre $\mathbf{x}_{i}$ e seus vizinhos mais próximos.

$V$ - Conjunto de instâncias vizinhas de $\mathbf{x}_{i}$.

$\Phi$ — Transformação linear da técnica PLMP.

NP — Métrica de avaliação de preservação de vizinhança chamada de Neighborhood Preservation.

$N_{k_{i}}^{m}-k$ vizinhos mais próximos de $\mathbf{x}_{i}$ no espaço $m$-dimensional.

$N_{k_{i}}^{p}-k$ vizinhos mais próximos de $\mathbf{x}_{i}$ no espaço $p$-dimensional.

$\Lambda$ - Parâmetro da UPDis que determina o valor mínimo de variância que se pretende capturar. $\|\cdot\|_{F}$ - Norma de Frobenius. 



\section{SUMÁRIO}

INTRODUÇÃO $\ldots \ldots \ldots \ldots \ldots \ldots \ldots \ldots$

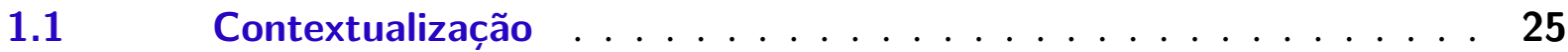

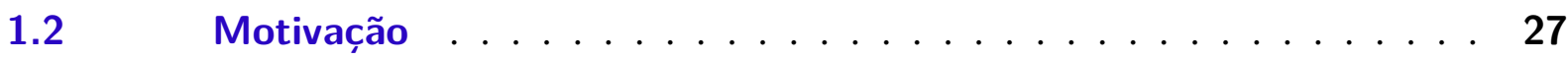

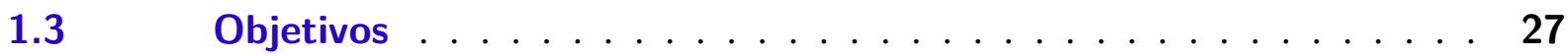

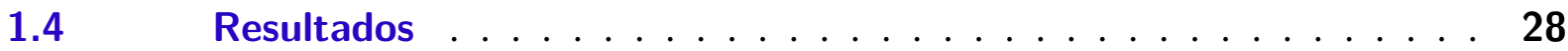

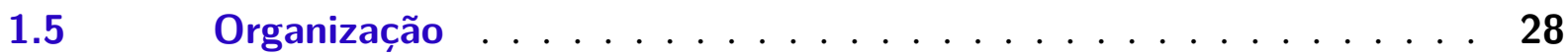

2 TÉCNICAS DE PROJEÇÃO MULTIDIMENSIONAL . . . . . 31

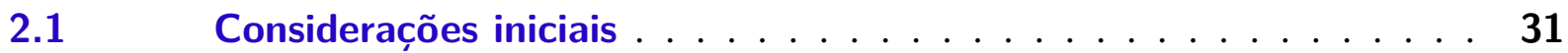

2.2 Técnicas não-incrementais . . . . . . . . . . . . . . . . 34

2.2.1 Principal Component Analysis (PCA) . . . . . . . . . . . . 34

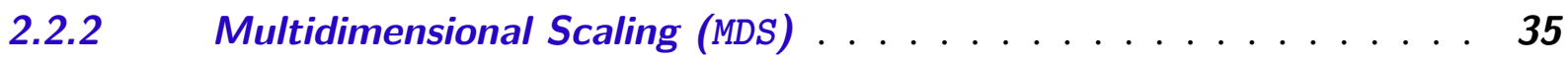

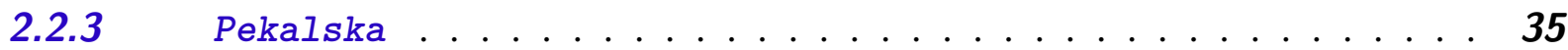

2.2.4 Modelo Hibrido de Chalmers . . . . . . . . . . . . . . . . . 36

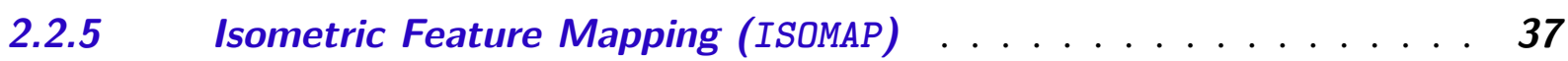

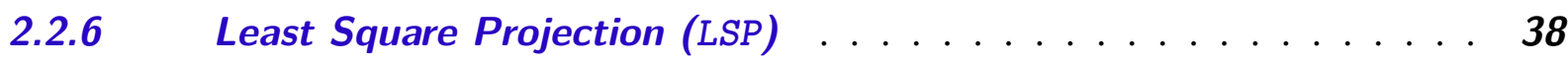

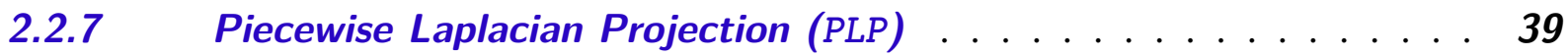

2.2.8 Part-Linear Multidimensional Projection (PLMP) . . . . . . . . . 40

2.2.9 Local Affine Multidimensional Projection (LAMP) . . . . . . . . 41

2.2.10 t-Distributed Stochastic Neighbor Embedding (t-SNE) . . . . . . 42

2.3 Técnicas incrementais . . . . . . . . . . . . . . . . 43

2.3.1 Incremental $P C A(I-P C A) \ldots \ldots \ldots \ldots \ldots$

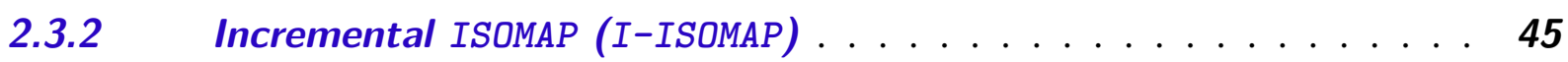

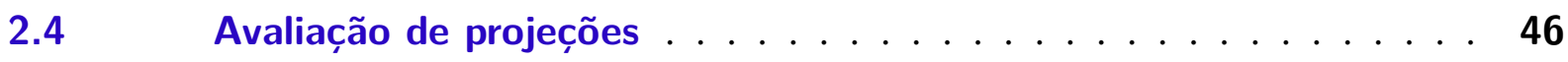

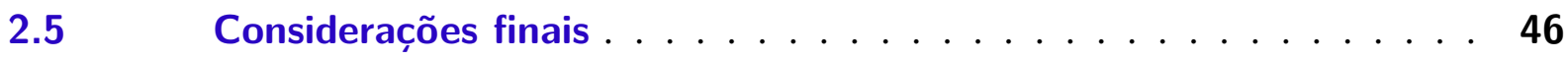

3 VISUALIZAÇÃO DE INFORMAÇÃO DE DISTÂNCIA POR MEIO DE PROJEÇÕES MULTIDIMENSIONAIS ASSISTIDAS . . . . . 49

$3.1 \quad$ Considerações iniciais . . . . . . . . . . . . . . . . 49

3.2 Descrição da técnica $\ldots \ldots \ldots \ldots \ldots \ldots$

3.2.1 Mapeando a informação de distância . . . . . . . . . . . 50

3.2.2 Criando a transformação afim . . . . . . . . . . . . . 52 


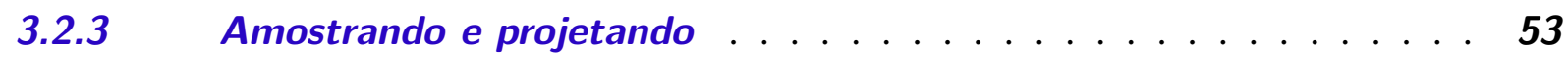

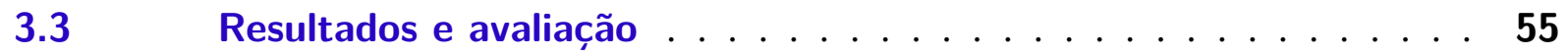

3.3.1 Análise do parâmetro lambda $(\Lambda) \ldots \ldots \ldots \ldots$

3.3.2 Análise de tempo e stress . . . . . . . . . . . . . . . 56

3.3.3 Manipulação realizada pelo usuário . . . . . . . . . . . 58

$3.4 \quad$ Considerações finais . . . . . . . . . . . . . . . . 61

4 VISUALIZAÇÃO DE FLUXOS DE DADOS POR MEIO DE PROJEÇÕES MULTIDIMENSIONAIS . . . . . . . . . . . . . 65

$4.1 \quad$ Considerações iniciais . . . . . . . . . . . . . . . . 65

4.2 Descrição da técnica . . . . . . . . . . . . . . 66

4.2.1 Construindo a função de projeção . . . . . . . . . . . . . . 67

4.2.2 Re-projeção . . . . . . . . . . . . . . . . . 68

4.2.3 Detecção de mudanças . . . . . . . . . . . . . . . . . 71

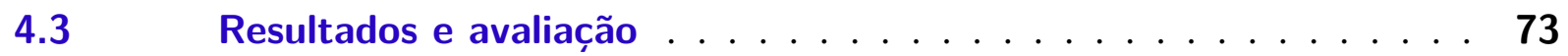

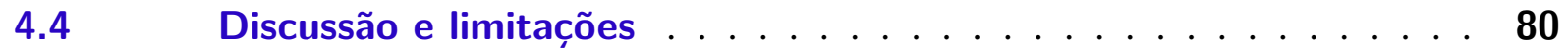

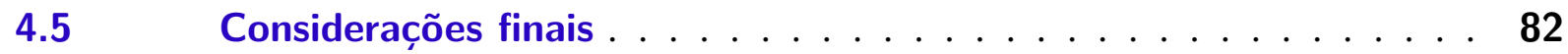

$5 \quad$ APLICAÇÕES $\ldots \ldots \ldots \ldots \ldots \ldots \ldots \ldots \ldots \ldots$

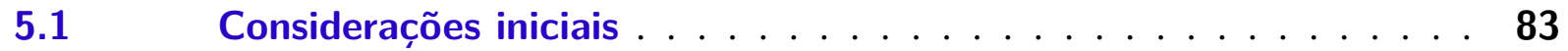

$5.2 \quad$ Organização de coleções de livros . . . . . . . . . . . . 83

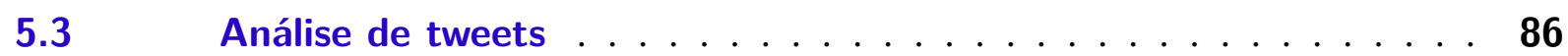

$5.4 \quad$ Considerações finais . . . . . . . . . . . . . . . . . . . 92

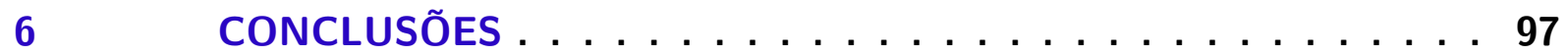

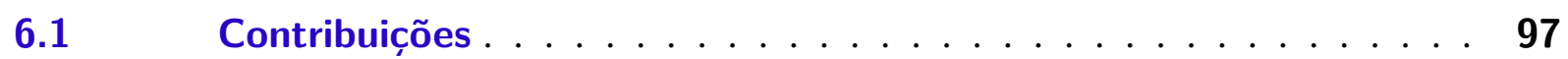

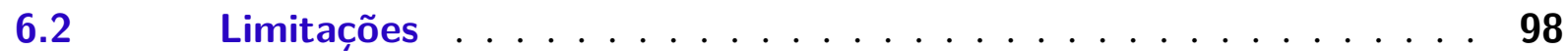

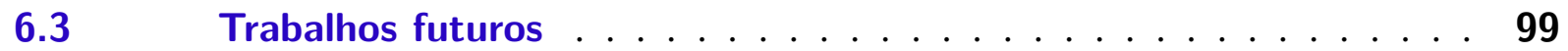

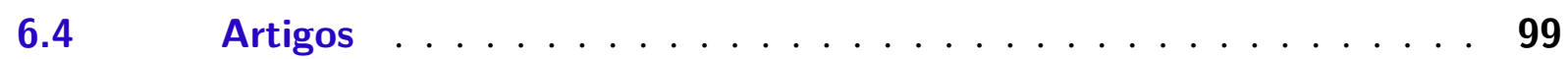

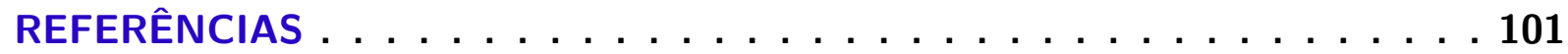




\section{1}

\section{INTRODUÇÃO}

\subsection{Contextualização}

A quantidade crescente da produção, coleta e divulgação de dados, muitas vezes de forma contínua, está se tornando um obstáculo para o processo analítico de dar sentido à informação obtida. Os sistemas tradicionais, que geralmente coletam esses dados e os armazenam em arquivos para um processamento posterior, não conseguem extrair informação de forma adequada por conta das limitações de tempo e memória (DOMINGOS; HULTEN, 2000). Essa característica promoveu o surgimento de novos desafios referentes à análise de dados, entre eles a necessidade de métodos sofisticados, muitas vezes em tempo real (MUTHUKRISHNAN, 2005).

Esses dados continuamente coletados ou produzidos são chamados de fluxos de dados e são provenientes de aplicações como monitoramento de redes, transações financeiras, sensoriamento, simulações científicas, entre outras (HAO et al., 2009). A análise desse tipo de dados busca detectar fraudes, invasões, atividades anormais, assim como permitir a observação de tendências, classificar dados e outras atividades associadas ao processo de exploração de grandes coleções. Entretanto, devido à natureza dessas aplicações, esse processo deve ser feito quase que em tempo real e, portanto, os métodos tradicionais não se aplicam.

Um fluxo de dados contínuo é uma sequência de itens de dados que são ordenados pelo tempo. Geralmente são multidimensionais, produzidos a altas taxas e contêm grandes volumes de informação (HAO et al., 2009). Basicamente existem dois tipos de fluxos de dados (GUHA et al., 2003). Um deles tem como principal característica a grande quantidade de dados acumulados. Nesse caso, dados são armazenados em memórias secundárias, caracterizadas por baixa taxa de transferência, cujo acesso deve ser linear. No outro tipo, os dados são coletados a altas taxas e quantidades, o que impossibilita seu armazenamento e exige seu descarte após processamento.

Técnicas tradicionais de análise de dados, como os algoritmos de agrupamento ou classificação, têm demonstrado sérias limitações quando aplicados para a compreensão de diversos 
fenômenos que exigem a rápida coleta e processamento de grandes volumes de dados (GUHA et al., 2003; PAVLIDIS et al., 2011).

Extrair conhecimento de fluxos de dados contínuos é, então, um dos grandes desafios da atualidade (GAMA; GABER, 2007). Diversas abordagens computacionais têm sido desenvolvidas para lidar com essa tarefa desafiadora (DOMINGOS; HULTEN, 2000; BABCOCK et al., 2002; GAMA et al., 2010; BIFET et al., 2011; FISCHER; MANSMANN; KEIM, 2012; GAMA, 2012; NGUYEN; WOON; NG, 2015), sendo a visualização uma das candidatas. A visualização se baseia em criar representações visuais interativas dos dados, permitindo o emprego da capacidade visual do ser humano.

Diferentes ferramentas e abordagens de visualização estão disponíveis. Grinstein, Trutschl e Cvek (2001) citam como exemplos mais clássicos: scatterplots 2D e 3D (CLEVELAND, 1993), matrizes de scatterplots (ANDREWS, 1972), table lens (RAO; CARD, 1994), técnicas iconográficas (CHERNOFF, 1973; PICKETT; GRISTEIN, 1988; BEDDOW, 1990; ROSE; WONG, 2000), técnicas orientadas a pixel (KEIM; KREIGEL, 1994; KEIM; KRIEGEL, 1996; KEIM, 2000), coordenadas paralelas (INSELBERG, 1985; INSELBERG; DIMSDALE, 1990; INSELBERG, 1997), RadViz (HOFFMAN, 1999), GrandTour (ASIMOV, 1985), mapas autoorganizáveis de Kohonen (KOHONEN, 1998), etc. Muitas dessas são similares ou estão relacionadas (GRINSTEIN; TRUTSCHL; CVEK, 2001). Um estudo sobre essas técnicas pode ser encontrado em (OLIVEIRA; LEVKOWITZ, 2003).

Um outro conjunto de técnicas que vêm ganhando destaque na área de visualização é o conjunto das técnicas de projeção multidimensional (TEJADA; MINGHIM; NONATO, 2003), sendo essa uma abordagem que alcançou relativo sucesso em processos analíticos que envolvem a identificação de padrões, tendências ou outliers considerando estruturas de similaridade. Neves et al. (2015) apresentam um estudo sobre algumas dessas técnicas, entre elas: Sammon's Mapping (SAMMON, 1969), LLE (ROWEIS; SAUL, 2000), ISOMAP (TENENBAUM; SILVA; LANGFORD, 2000), Random Projection (ACHLIOPTAS, 2003), LSP (PAULOVICH et al., 2008), Glimmer (INGRAM; MUNZNER; OLANO, 2009), PLMP (PAULOVICH; SILVA; NONATO, 2010), NeRV (VENNA et al., 2010), PLP (PAULOVICH et al., 2011), LAMP (JOIA et al., 2011) e LoCH (FADEL et al., 2014). Em geral, o resultado de uma técnica multidimensional é um conjunto de pontos que estão posicionados no plano, no qual cada elemento corresponde a uma instância no conjunto original de dados. Muitas técnicas de projeção multidimensional têm sido propostas.

Tendo em vista as características dos fluxos de dados, de forma mais específica o grande volume e a alta dimensionalidade, o emprego de projeções multidimensionais pode ser bastante efetivo no processo de interpretação desses dados, dando suporte a uma análise que permita uma rápida extração de informação relevante para o cenário streaming. 


\subsection{Motivação}

Embora as projeções multidimensionais sejam um mecanismo eficiente para a extração de informação de interesse em grandes conjuntos de dados, a maioria das técnicas existentes não está apta a lidar com fluxos de dados, sendo o objetivo principal desse trabalho de doutorado tratar esse problema.

A principal diferença entre o cenário streaming e o cenário estático é que, no primeiro, a distribuição que gera os dados pode se alterar com o passar do tempo. No cenário estático, os algoritmos supõem que os dados não se alteram com o tempo e, uma vez criado o modelo de projeção, não há necessidade de alterá-lo. Para o cenário streaming, os algoritmos devem considerar a necessidade de alteração no modelo de projeção, caso mudanças ocorram nas características dos dados.

No cenário streaming, o modelo de criação dos mapas visuais implementado por muitos algoritmos de projeção é muitas vezes impraticável, pois necessitam armazenar todos os dados em memória principal. Essa alta quantidade de dados produzidos ou coletados, que são apresentados para projeção, traz a necessidade de desenvolvimento de novas estratégias. Os algoritmos precisam criar os mapas visuais de forma online, ou incremental, processando os dados à medida em que estes se tornam disponíveis, uma vez que logo em seguida são descartados.

No caso de fluxo de dados, um grande desafio é a preservação do mapa visual buscando evitar distorções temporais ou espaciais, com a chegada de novos eventos. Muitas mudanças no layout podem distrair o usuário, tornando a exploração muito difícil.

\subsection{Objetivos}

De forma a prover uma solução para os problemas citados anteriormente, considerando o cenário streaming, os objetivos desse trabalho de doutarado são:

Definir novas técnicas e abordagens, baseadas no conceito de projeção multidimensional, que possam oferecer suporte a análise exploratória de fluxos de dados. Para isso, elas devem possibilitar ao usuário identificar tendências, padrões e acontecimentos presentes em fluxos. Em outras palavras, o presente trabalho busca oferecer soluções de projeções que sejam capazes de gerar mapas visuais para conjuntos de dados que evoluem ao longo do tempo sem a necessidade de revisitar todas as instâncias de dados já processadas. Busca-se também definir uma estratégia que permita a atualização do mapa visual gerado, minimizando as distorções causadas pela inserção ou remoção de instâncias, como forma de evitar a perda de contexto ao longo do processo de projeção. 
A seguir é fornecido um resumo dos resultados alcançados ao longo desse projeto de doutorado.

\subsection{Resultados}

O principal resultado apresentado por este trabalho é um arcabouço para projeção de fluxos dados que emprega uma estratégia de projeção chamada de Xtreaming. Essa estratégia realiza a construção do mapa visual de forma incremental, à medida em que os dados são produzidos ou coletados e apresentados para serem projetados. Para isso, um mecanismo monitora a distribuição dos dados e, na detecção de uma mudança significativa, atualiza o modelo de projeção vigente. Como forma de garantir que a alteração do modelo de projeção reflita no posicionamento de pontos que representam instâncias já processadas, a informação de distância no espaço transformado é utilizada como entrada para o novo modelo de projeção. Os resultados dos testes comparativos mostraram que a técnica incremental é capaz de processar os dados de forma online e ainda obter uma boa precisão.

Além dessa técnica, um outro trabalho foi desenvolvido com o objetivo de fornecer uma abordagem que fosse capaz de realizar projeções quando apenas a informação de dissimilaridade entre as instâncias de dados fosse conhecida. A User-assisted Projection Technique for Distance Information (UPDis) é uma adaptação da técnica Local Affine Multidimensional Projection (LAMP) (JOIA et al., 2011) que possibilita a projeção quando apenas a informação de dissimilaridade é encontrada e permite a intervenção do usuário no processo de projeção. A avaliação comparativa coloca essa técnica no mesmo nível das técnicas estado-da-arte.

\subsection{Organização}

O restante deste texto está organizado da seguinte maneira:

- No Capítulo 2 são apresentadas algumas técnicas de projeção multidimensional tradicionais e incrementais (online), a fim de identificar suas limitações em relação ao cenário streaming, servindo de base para o desenvolvimento das soluções desenvolvidas nesse trabalho.

Os demais capítulos detalham as principais contribuições desse trabalho.

- No Capítulo 3, a técnica UPDis é descrita. Ela permite a realização de projeções em situações nas quais apenas a informação de dissimilaridade entre as instâncias é conhecida, além de possibilitar a intervenção do usuário durante o processo de projeção.

- No Capítulo 4, uma abordagem voltada para a criação incremental de mapas visuais provenientes de fluxos de dados é apresentada e discutida. Ao identificar uma mudança na distribuição que representa os dados já processados, uma atualização no modelo de 
projeção é realizada e uma manipulação nos pontos anteriormente inseridos no espaço transformado faz com que esses pontos respeitem essa atualização. Dessa forma, as relações de distâncias existentes no espaço original são aproximadas no espaço transformado à medida que novas instâncias são apresentadas para projeção.

- No Capítulo 5, dois estudos de caso que ilustram possíveis aplicações para as técnicas desenvolvidas são descritos.

- No Capítulo 6, as conclusões dessa tese são apresentadas, descrevendo as principais contribuições para o processo de análise de fluxos de dados, as limitações das abordagens desenvolvidas, elencando possíveis trabalhos futuros. 



\section{TÉCNICAS DE PROJEÇÃO MULTIDIMENSIONAL}

\subsection{Considerações iniciais}

A quantidade de informação produzida ou coletada continua crescendo tanto em volume quanto em complexidade. Apesar de muita informação não relevante poder ser filtrada, a geração de informação útil ainda continua sendo muito maior do que a capacidade das ferramentas de interpretação vigentes, tornando necessário o desenvolvimento de métodos e ferramentas capazes de fornecer meios eficientes de interpretação desses dados.

Uma abordagem que tem sido aplicada com sucesso na análise de tais dados são as técnicas de Projeção Multidimensional (TEJADA; MINGHIM; NONATO, 2003). Uma técnica de projeção multidimensional mapeia as instâncias de dados em elementos gráficos num espaço geralmente bidimensional, preservando alguma informação sobre as relações de distância ou similaridade entre elas de forma a revelar as estruturas existentes. O resultado de uma projeção multidimensional tipicamente é um conjunto de pontos posicionados no plano, no qual cada elemento representa uma instância de dados. Numa projeção de boa qualidade, pontos projetados próximos indicam instâncias similares, e os distantes, as não correlacionadas de acordo com alguma medida de similaridade.

Formalmente, seja $\mathbf{X}$ um conjunto de $n$ instâncias de dados em $\mathbb{R}^{m}$ com $\delta: \mathbb{R}^{m} \times \mathbb{R}^{m} \rightarrow \mathbb{R}$ um critério de proximidade entre instâncias em $\mathbb{R}^{m}$, e $\mathbf{Y}$ um conjunto de pontos em $\mathbb{R}^{p}$, com $p=\{1,2,3\}$, e $d: \mathbb{R}^{p} \times \mathbb{R}^{p} \rightarrow \mathbb{R}$ um critério de proximidade em $\mathbb{R}^{p}$. Uma técnica de projeção multidimensional pode ser descrita como uma função $f: \mathbf{X} \rightarrow \mathbf{Y}$ que visa tornar $\left|\boldsymbol{\delta}\left(\mathbf{x}_{i}, \mathbf{x}_{j}\right)-d\left(f\left(\mathbf{x}_{i}\right), f\left(\mathbf{x}_{j}\right)\right)\right|$ o mais próximo possível de zero, $\forall \mathbf{x}_{i}, \mathbf{x}_{j} \in \mathbf{X}$ (TEJADA; MINGHIM; NONATO, 2003).

As técnicas de projeção multidimensionais têm sido classificadas de diferentes formas, 
segundo algum critério que rege seu comportamento. Algumas classificações são apresentadas a seguir.

Uma das primeiras formas utilizadas para diferenciar as técnicas de projeção multidimensionais está relacionada com a função que realiza o mapeamento das instâncias, sendo as técnicas ditas lineares ou não-lineares. As técnicas lineares projetam os dados utilizando transformações lineares, enquanto que as técnicas não-lineares projetam os dados por meio de transformações não-lineares buscando preservar informações locais (YAN et al., 2006). Segundo Law e Jain (2006), métodos lineares são fáceis de entender e simples de implementar, mas a linearidade não leva a bons resultados em muitos cenários reais. Isso motivou o desenvolvimento de métodos não-lineares.

Outra possível classificação das técnicas de projeção multidimensional é a que faz divisão entre técnicas globais e técnicas locais (FADEL et al., 2014). Técnicas globais buscam aproximar $\delta\left(\mathbf{x}_{i}, \mathbf{x}_{j}\right)$ de $d\left(\mathbf{y}_{i}, \mathbf{y}_{j}\right)$, para todo $i \neq j$, enquanto que técnicas locais buscam preservar as distâncias considerando pequenas vizinhanças (FADEL et al., 2014).

De forma geral, se o objetivo é preservar a média das distâncias, técnicas globais são a melhor escolha. Entretanto, essas técnicas falham na preservação dos relacionamentos de vizinhanças, principalmente quando são considerados espaços de alta dimensão esparsos. Nesses espaços, normalmente as instâncias pertencem a variedades locais e são relacionadas a poucas instâncias que pertencem à mesma variedade (MARTIN-MERINO; MUNOZ, 2004). Ou seja, a maioria das instâncias são muito dissimilares entre si com apenas algumas poucas compartilhando propriedades comuns (MARTIN-MERINO; MUNOZ, 2004).

Caso o objetivo seja a preservação das vizinhanças, é preferível utilizar técnicas locais. As técnicas locais buscam preservar as distâncias em pequenas vizinhanças alcançando melhores resultados quando se trata de preservação das relações de vizinhança estabelecidas no espaço original. Se o objetivo da análise for a separação de grupos e a definição de suas fronteiras, as técnicas locais representam a melhor escolha, principalmente para conjuntos de dados de alta dimensionalidade (FADEL et al., 2014). No entanto, a maioria das técnicas locais possui como característica a tendência de formar aglomerados compactos, quando a distribuição das distâncias define grupos bem distintos nos dados. Isso pode dificultar a exploração visual, devido à grande sobreposição das instâncias no espaço visual.

Quando as técnicas se diferenciam entre considerar ou não uma amostra em um passo inicial, a classificação é feita em técnicas in-sample ${ }^{1}$ ou técnicas out-of-sample. ${ }^{2}$ As técnicas in-sample consideram o conjunto total de instâncias no processo de projeção. Por outro lado, as técnicas out-of-sample são realizadas por meio de uma abordagem em dois passos, na qual o primeiro passo consiste em projetar um pequeno conjunto de amostras. Em seguida, as instâncias restantes são posicionada no mapa visual por meio de interpolações.

1 Não foi encontrada uma tradução adequada para o termo in-sample.

2 Não foi encontrada uma tradução adequada para o termo out-of-sample. 
Em termos de precisão, ou seja, de preservação das distâncias e dos relacionamentos de distância, normalmente as técnicas in-sample alcançam melhores resultados. Entretanto, em termos de escalabilidade computacional, as técnicas out-of-sample são capazes de lidar com conjuntos de dados muito maiores e em tempos muito menores. Assim, caso o problema seja pequeno, técnicas in-sample são mais adequadas pois garantem uma melhor precisão, caso o conjunto apresente um grande volume de dados e uma pequena perda de precisão seja aceitável, técnicas out-of-sample são a melhor escolha.

Por fim, as técnicas podem construir o mapa visual de forma estática ou podem ir atualizando esse mapa à medida que novas instâncias são apresentadas ao modelo de projeção. As técnicas estáticas são geralmente chamadas de não-incrementais, enquanto que as técnicas capazes de processar os dados, à medida que são produzidos ou coletados, são chamadas de técnicas incrementais. A maioria dos algoritmos encontrados na literatura é do tipo nãoincremental. $\mathrm{O}$ atual cenário, chamado de streaming, no qual o volume de dados é muito grande para ser armazenado inteiro em memória principal ou é caracterizado por um fluxo ilimitado de dados, trouxe a necessidade de adaptação dessas técnicas ou do desenvolver novas outras.

Outras formas de classificação das técnicas de projeção multidimensionais podem ser encontradas na literatura. Sendo este trabalho diretamente relacionado com o cenário streaming, as técnicas explicadas nesse capítulo foram divididas em incrementais e não-incrementais, seguidas de uma classificação em lineares e não-lineares. A Figura 1 ilustra a classificação das técnicas apresentadas a seguir, de acordo com as regras descritas acima. Os retângulos representam as classes e sub-classes das técnicas e os retângulos com cantos arredondados contém os nomes das técnicas.

Figura 1 - Classificação das técnicas de projeção multidimensional apresentadas nesse capítulo.

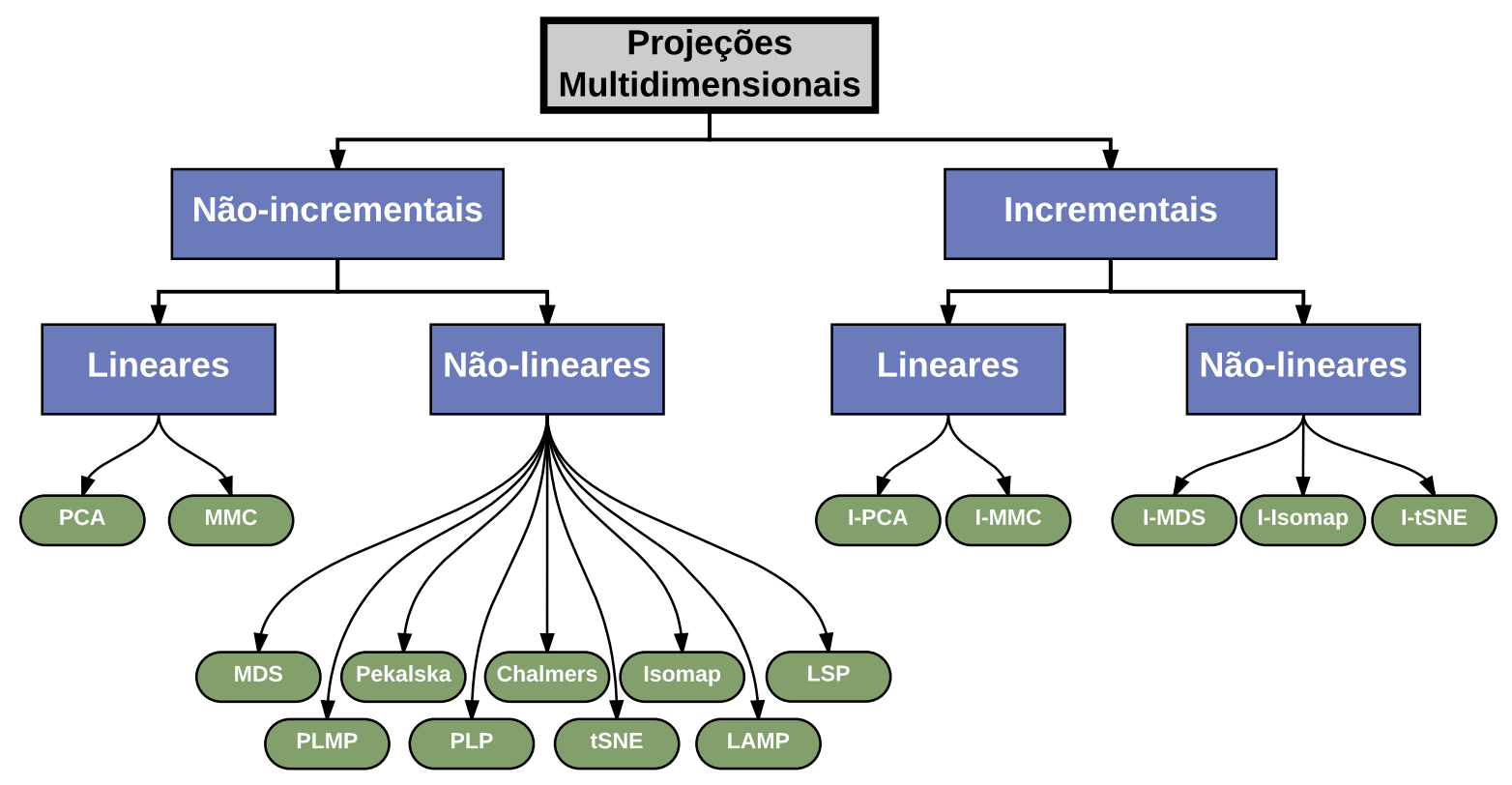

Fonte: Elaborada pelo autor. 


\subsection{Técnicas não-incrementais}

O primeiro conjunto de técnicas que será apresentado corresponde às não-incrementais. As técnicas desse grupo realizam o processo de projeção em lote, ou seja, processam todas as instâncias. Para isso, necessitam que todas as instâncias estejam armazenadas na memória principal ou realizam mais de um acesso sobre o conjunto de dados armazenados em memória secundária. A seguir, algumas dessas técnicas são descritas.

\subsubsection{Principal Component Analysis (PCA)}

A técnica Principal Component Analysis (PCA) (JOLLIFFE, 2005) busca realizar o mapeamento no espaço de baixa dimensionalidade por meio de uma combinação entre as dimensões originais dos dados.

A ideia da PCA é encontrar as combinações lineares ortogonais que melhor representam a variabilidade dos dados, os chamados Componentes Principais (CP). A quantidade de CPs existentes é determinada pela dimensionalidade (número de dimensões) dos dados. Entretanto, os primeiros componentes capturam a maior parte da variância dos dados.

O algoritmo do PCA começa calculando uma matriz de covariância dos atributos de $\mathbf{X} \in \mathbb{R}^{m}$, representada por $C_{m \times m}$, na qual $c_{i j}=\operatorname{cov}\left(a_{i}, a_{j}\right)$ representa a covariância entre os atributos $a_{i}$ e $a_{j}$ dada por

$$
\operatorname{cov}\left(a_{i}, a_{j}\right)=\frac{1}{n-1} \sum_{k=1}^{n}\left(a_{i_{k}}-\overline{a_{i}}\right)\left(a_{j_{k}}-\overline{a_{j}}\right)
$$

no qual $\overline{a_{i}}$ e $\overline{a_{j}}$ são as médias de $a_{i}$ e $a_{j}$ respectivamente.

De posse da matriz $C$, uma decomposição espectral é realizada a fim de obter os seus autovetores. Escrevendo $C$ na forma

$$
C=U \Lambda U^{T}
$$

onde $\Lambda=\operatorname{diag}\left(\lambda_{1}, \ldots, \lambda_{m}\right)$ é uma matriz diagonal dos autovalores ordenados de forma crescente e $U$ é uma matriz $m \times m$ ortogonal contendo os autovetores.

Assim, o calculo dos componentes se dá por

$$
S=\mathbf{X} \times\left[u_{1}, u_{2}, \ldots, u_{p}\right],
$$

sendo $u_{i}$ as colunas de $U$ e $p$ corresponde à dimensionalidade do espaço transformado.

Algumas das vantagens da PCA são a tendência de identificar padrões relevantes nos dados, capturar variabilidade com poucas dimensões e eliminar parte do ruído existente. Entre os problemas encontrados na aplicação da PCA como técnica de projeção multidimensional está o fato de que esta tende a ter problemas quando os dados apresentam relações não-lineares, já que é baseada em combinações lineares. 


\subsubsection{Multidimensional Scaling (MDS)}

As técnicas denominadas Multidimensional Scaling (MDS) atingiram uma grande popularidade (COX; COX, 2000). As técnicas MDS buscam realizar um mapeamento das instâncias pertencentes a um espaço $m$-dimensional em pontos no espaço $p$-dimensional buscando-se preservar relações de distância. A forma como essa preservação de distância é realizada determina diferentes técnicas MDS.

Uma das técnicas mais conhecidas é chamada de Classical Scaling (YOUNG; HOUSEHOLDER, 1938). Nela, busca-se uma transformação linear que mapeie $\mathbf{X}$ num espaço Euclidiano no qual as dissimilaridades $\delta\left(\mathbf{x}_{i}, \mathbf{x}_{j}\right)$ se aproximam das distâncias $\left\|\mathbf{y}_{i}-\mathbf{y}_{j}\right\|$. Essa transformação é encontrada fazendo-se a decomposição espectral da matriz de dissimilaridades. Quando as dissimilaridades são Euclidianas existem garantias para se encontrar um espaço no qual elas podem ser representadas sem perdas, porém, na prática, são necessárias mais de 3 dimensões.

Kruskal (1964) apresentou outras técnica MDS tratando o problema como uma questão de otimização. O processo busca encontrar uma configuração de pontos que minimiza a diferença quadrática entre as dissimilaridades estabelecidas no espaço original e as distâncias calculadas no espaço transformado. Essa função ficou conhecida como stress e é definida por:

$$
S_{1}=\sqrt{\frac{\sum_{i<j}\left(\boldsymbol{\delta}\left(\mathbf{x}_{\mathbf{i}}, \mathbf{x}_{\mathbf{j}}\right)-d\left(\mathbf{y}_{\mathbf{i}}, \mathbf{y}_{\mathbf{j}}\right)\right)^{2}}{\sum_{i<j} \boldsymbol{\delta}\left(\mathbf{x}_{\mathbf{i}}, \mathbf{x}_{\mathbf{j}}\right)^{2}}}
$$

A minimização é um processo iterativo utilizando o método de gradientes descendentes. Após a $t$-ézima iteração, a minimização é obtida pela resolução de:

$$
\mathbf{x}(t+1)=\mathbf{x}(t)-\frac{\partial S_{1}(t)}{\partial x(t)} /\left|\frac{\partial S_{1}(t)}{\partial x(t)}\right| \times s l,
$$

na qual as coordenadas das instâncias de $\mathbf{X}$ são colocadas no vetor $\mathbf{x}=\left(x_{11}, \ldots, x_{1 m}, \ldots, x_{n m}\right)^{T} \mathrm{e}$ $s l$ define o tamanho do passo de otimização em cada iteração.

Os métodos MDS originais são muito precisos em termos de preservação da distância global, mas são computacionalmente caros. Como forma de melhorar essa complexidade, mas ainda buscando uma boa qualidade em termos de preservação da distância, algumas estratégias foram propostas, tais como a Landmarks MDS (L-MDS) (SILVA; TENENBAUM, 2004) e a Pivot MDS (BRANDES; PICH, 2007).

\subsubsection{Pekalska}

Ainda entre as técnicas MDS, outra abordagem que busca minimizar uma funçaõ de perda é conhecida como Sammon's Mapping (SAMMON, 1969). Nela, uma configuração dos pontos é buscada de forma que $\left\|\mathbf{y}_{i}-\mathbf{y}_{j}\right\| \approx g\left(\delta\left(\mathbf{x}_{i}, \mathbf{x}_{j}\right)\right)$ por meio da minimização de uma função de perda, sendo $g$ uma função de transformação. 
A cada iteração, são calculadas as distâncias entre todos os pares de elementos do conjunto no espaço projetado, como forma de observar se as distâncias no espaço original foram preservadas, por meio da Equação (2.6). Caso o valor do erro $S_{2}$ fique acima de um certo limiar, o posicionamento dos elementos é alterado buscando diminuir esse erro.

$$
S_{2}=\frac{1}{\sum_{i<j} \delta\left(\mathbf{x}_{i}, \mathbf{x}_{j}\right)} \sum_{i<j} \frac{\left(d\left(\mathbf{x}_{i}, \mathbf{x}_{j}\right)-\delta\left(\mathbf{x}_{i}, \mathbf{x}_{j}\right)\right)^{2}}{\delta\left(\mathbf{x}_{i}, \mathbf{x}_{j}\right)}
$$

Para a minimização da função de perda, um método iterativo não-linear que emprega o gradiente dessa função é utilizado para se encontrar um mínimo local (PEKALSKA et al., 1999). A $t$-ésima iteração desse método é definida pela equação abaixo:

$$
\mathbf{y}_{p q}(t+1)=\mathbf{y}_{p q}(t)-M F \times \Delta_{p q}(t)
$$

na qual $\mathbf{y}_{p q}$ corresponde a coordenada $q$ do ponto $p$ e

$$
\Delta_{i j}(t)=\frac{\partial S_{2}(t)}{\partial \mathbf{y}_{i j}(t)} /\left|\frac{\partial^{2} S_{2}(t)}{\partial \mathbf{y}_{i j}^{2}(t)}\right|
$$

onde $0<M F \leq 1$ é um "fator mágico" que serve para otimizar a convergência do algoritmo, sendo determinado originalmente como $0.3 \leq M F \leq 0.4$.

Assim como o Classical Scaling e o método apresentado por Kruskal, a técnica Sammon's Mapping apresenta uma complexidade computacional $O\left(n^{2}\right)$. Buscando melhorar essa complexidade, Pekalska et al. (1999) apresentam algumas estratégias, sendo a principal delas projetar um subconjunto de amostras e interpolar o restante das instâncias. Como sugestão de interpolação, os autores apresentam: Triangulação (BISWAS; JAIN; DUBES, 1981), Mapeamento de Distâncias (PEKALSKA et al., 1999) e Redes Neurais Artificiais (RNA) (RIDDER; DUIN, 1997).

A interpolação proposta por Pekalska et al. (1999), chamada de Mapeamento de Distâncias, busca uma transformação linear da matriz de distância no espaço multidimensional que alcance a configuração da Sammon's Mapping no espaço transformado. Após encontrar esse operador, basta aplicá-lo a matriz de distância contendo os pontos que não compõem a amostra já projetada pela Sammon's Mapping.

\subsubsection{Modelo Hibrido de Chalmers}

Entre os modelos mais simples utilizados para a geração de mapas visuais, encontram-se os modelos baseados em molas. Esses modelos buscam um estado de equilíbrio para objetos conectados por molas (EADES, 1984). As forças no sistema são proporcionais às diferenças entre as dissimilaridades definidas no espaço original e as distâncias calculadas no espaço transformado. Para cada instância a ser projetada, a abordagem de Chalmers (CHALMERS, 1996) busca preservar no espaço transformado as distâncias para duas listas diferentes de 
instâncias, uma contendo os vizinhos mais próximos no espaço original e outra com instâncias escolhidas de forma aleatória.

A cada iteração, instâncias são selecionadas para serem inseridas na segunda lista de $\mathbf{x}_{i}$. Para cada instância selecionada, a dissimilaridade $\delta\left(\mathbf{x}_{i}, \mathbf{x}_{j}\right)$ é calculada e, caso $\delta\left(\mathbf{x}_{i}, \mathbf{x}_{j}\right)<$ maxDist ${ }_{i}$, sendo maxDist $_{i}$ a maior distância entre $\mathbf{x}_{i}$ e seus vizinhos mais próximos, então $\mathbf{x}_{j}$ é inserida na lista de vizinhos mais próximos e não na lista de instâncias aleatórias. Esse procedimento é repetido até que a lista de instâncias aleatórias atinja uma quantidade máxima de instâncias predeterminada. Quando isso ocorrer, o posicionamento de $\mathbf{x}_{i}$ é calculado.

Embora consiga uma melhor preservação das distâncias em pequenas vizinhanças, a abordagem apresentada por Chalmers é cara computacionalmente, $O\left(n^{2}\right)$. Para minimizar esse problema, Morrison, Ross e Chalmers (2002) apresentam uma abordagem que projeta um conjunto de amostras e interpola as demais (essa abordagem foi estendida por Morrison e Chalmers (2004)).

As amostras são projetadas utilizando o método proposto por Chalmers. Em seguida, no processo de interpolação, primeiro encontra-se um parente no conjunto de amostras para cada instância remanescente no conjunto original. O parente é a amostra que apresenta menor distância no espaço multidimensional. Então, define-se um raio em torno do parente, proporcional à distância no espaço multidimensional entre a instância e o parente. A instância é posicionada, inicialmente, em algum lugar sobre a circunferência formada por esse raio. Finalmente, para determinar o posicionamento final dessa instância, minimiza-se a equação:

$$
\sum_{1<z<n^{1 / 4}}\left|d\left(\overline{\mathbf{x}}_{z}, \mathbf{x}_{i}\right)-\delta\left(\overline{\mathbf{x}}_{z}, \mathbf{x}_{i}\right)\right|
$$

na qual as instâncias $\overline{\mathbf{x}}_{z}$ pertencem ao conjunto de amostras.

\subsubsection{Isometric Feature Mapping (ISOMAP)}

Outra variante da Classical Scaling foi apresentada por Tenenbaum, Silva e Langford (2000). Dado um conjunto de instâncias de dados num espaço $m$-dimensional, $\mathbf{X} \in \mathbb{R}^{m}$, a técnica Isometric Feature Mapping (ISOMAP) (TENENBAUM; SILVA; LANGFORD, 2000) assume que os dados encontram-se em uma variedade e realiza o mapeamento de $\mathbf{x}_{i}$ para $\mathbf{y}_{i}$ no espaço $p$-dimensional, de tal maneira que a distância geodésica entre $\mathbf{x}_{i}$ e $\mathbf{x}_{j}$ seja o mais próximo possível da distância Euclidiana entre $\mathbf{y}_{i}$ e $\mathbf{y}_{j}$ em $\mathbb{R}^{p}$. A distância geodésica entre duas instâncias de dados é definida como o comprimento da curva mais curta na variedade que liga as duas instâncias.

O algoritmo ISOMAP pode ser divido em três etapas. Na primeira delas, um grafo de vizinhança é construído e, para isso, é necessário uma definição de vizinhança. Seja $\Delta_{i j}$ a distância euclidiana entre $\mathbf{x}_{i}$ e $\mathbf{x}_{j}$. Um exemplo de definição de vizinhança pode ser: $\mathbf{x}_{i}$ e $\mathbf{x}_{j}$ são vizinhos se $\Delta_{i j}$ for menor do que um parâmetro $\varepsilon$. Um outro exemplo é a utilização do algoritmo 
$k$-Nearest Neighbor ( $k$-NN) para definir essa vizinhança. Definida a vizinhança de uma instância, um grafo não direcionado ponderado $G=(V, E)$ com o vértice $v_{i} \in V$ correspondente a $\mathbf{x}_{i}$ é construído. Uma aresta $e(i, j)$ entre $v_{i}$ e $v_{j}$ existe se $\mathbf{x}_{i}$ é um vizinho de $\mathbf{x}_{j}$. O peso de $e(i, j)$, representado por $w_{i j}$, é aplicado a $\Delta_{i j}$.

A seguir, uma estimativa das distâncias geodésicas é encontrada buscando-se o caminho mais curto entre os vértices correspondentes no grafo de vizinhança. Os caminhos mais curtos podem ser encontradas utilizando um algoritmo como o algoritmo de Dijkstra, por exemplo. Finalmente, a ISOMAP recupera $\mathbf{y}_{i}$ utilizando a técnica Classical Scaling sobre as distâncias geodésicas.

Uma versão mais eficiente da ISOMAP utiliza a abordagem de amostragem e interpolação para reduzir o número de distâncias calculadas. Essa abordagem é conhecida como Landmarks ISOMAP (L-ISOMAP) (SILVA; TENENBAUM, 2002), e possibilita que grandes conjuntos de dados sejam processados.

\subsubsection{Least Square Projection (LSP)}

Um exemplo de técnica que apresenta boa precisão em termos de preservação de relações locais de vizinhança é a Least Square Projection (LSP) (PAULOVICH et al., 2008). Os passos realizados pela LSP podem ser resumidos em três. Primeiro, um grafo de vizinhanças entre as instâncias de $\mathbf{X}$ é definido. Em seguida, seleciona-se um subconjunto $\overline{\mathbf{X}} \subset \mathbf{X}$ (com $|\overline{\mathbf{X}}|=c$ ), chamados de pontos de controle, e gera-se a projeção destes com uma técnica convencional, como a Classical Scaling. Por fim, as instâncias restantes são projetadas por meio de interpolação, para isso busca-se a solução de um sistema de equações lineares. Este sistema é montado de forma a estabelecer restrições de posicionamento que respeitem as relações de vizinhanças descritas pelo grafo encontrado no primeiro passo. Seja $V_{i}=\left\{\mathbf{x}_{i_{1}}, \ldots, \mathbf{x}_{i_{k_{i}}}\right\}$ o conjunto de $k_{i}$ pontos vizinhos de $\mathbf{x}_{i}$. Na LSP o posicionamento de cada $\mathbf{y}_{i}$ é dado pela seguinte equação

$$
\mathbf{y}_{i}-\sum_{\mathbf{x}_{j} \in V_{i}} \alpha_{i j} \mathbf{y}_{j}=0, \quad 0 \leq \alpha_{i j} \leq 1, \sum_{\mathbf{x}_{j} \in V_{i}} \alpha_{i j}=1
$$

Se resolvermos a Equação (2.10) para todas as instâncias de $\mathbf{X}$, cada $\mathbf{x}_{i}$ será mapeado no fecho convexo formado pelas instâncias em $V_{i}$. Particularmente, quando $\alpha_{i j}=\frac{1}{k_{i}}$ temos $\mathbf{y}_{i}$ no centroide das instâncias em $V_{i}$ (TUTTE, 1963; FLOATER, 1997). A Equação (2.10) resulta em um conjunto de sistemas lineares que torna possível o cálculo das coordenadas $\mathbf{y}_{i}: L x_{1}=0, L x_{2}=0, \ldots, L x_{p}=0$, onde $\mathrm{x}_{1}, \mathrm{x}_{2}, \ldots, \mathrm{x}_{p}$ são vetores contendo as coordenadas cartesianas dos pontos e $L$ é uma matriz Laplaciana $n \times n$, cujas entradas são dadas por

$$
l_{i j}=\left\{\begin{aligned}
1, & \text { se } i=j \\
-\alpha_{i j}, & \text { se } \mathbf{x}_{j} \in V_{i} \\
0, & \text { caso contrário. }
\end{aligned}\right.
$$


Os pontos de controle são, então, utilizados para adicionar informação geométrica ao sistema. Eles são inseridos no sistema linear como novas equações na matriz. As coordenadas cartesianas dos pontos de controle são adicionadas do lado direito do sistema, levando a um vetor não-nulo. Assim é possível re-escrever a Equação (2.10) da seguinte forma: $A \mathrm{x}=b$, onde $A$ é uma matriz $(n+n c) \times n$ dada por

$$
A=\left(\begin{array}{l}
L \\
C
\end{array}\right), c_{i j}= \begin{cases}1, & \mathbf{x}_{j} \in \overline{\mathbf{X}} \\
0, & \text { caso contrário }\end{cases}
$$

e $b$ é o vetor

$$
b_{i}=\left\{\begin{array}{rl}
0 & i \leq n \\
\mathbf{y}_{c_{i} k} & n<i \leq n+c
\end{array}\right.
$$

onde $\mathbf{y}_{c_{i} k}$ é uma das coordenadas cartesianas do ponto de controle $\mathbf{x}_{c_{i}}$.

Embora a LSP apresente bons resultados em termos de preservação de vizinhança, o operador Laplaciano necessita da solução de um sistema linear com $n$ variáveis, o que a torna computacionalmente impraticável para grandes conjuntos de dados.

\subsubsection{Piecewise Laplacian Projection (PLP)}

Como forma de contornar esse problema, Paulovich et al. (2011) apresentam a técnica Piecewise Laplacian Projection (PLP). A ideia da PLP é resolver pequenos sistemas lineares, ao invés de apenas um muito grande. Isso é feito particionando o conjunto de dados em pequenos grupos e aplicando a LSP para cada um desses conjuntos de forma independente. A coerência geométrica entre as projeções desses grupos é alcançada projetando os pontos de controle desses grupos em conjunto.

A PLP começa selecionando um pequeno subconjunto de instâncias. Para cada uma dessas instâncias, um grafo de vizinhança é construído e um conjunto de pontos de controle é escolhido. $\mathrm{O}$ grafo e os pontos de controle associados a uma dada amostra são utilizados para construir o sistema Laplaciano. A ideia é ter um conjunto de pontos de controle e um grafo de vizinhança para cada amostra de instâncias. Os pontos de controle guiam o posicionamento das instâncias no espaço visual. As instâncias projetadas no espaço visual podem ser manipuladas pelo usuário, melhorando o agrupamento de instâncias similares. Dessa forma, os pontos de controle e os grafos de vizinhança são atualizados dinamicamente, modificando as matrizes Laplacianas e as projeções resultantes.

Para a construção do grafo de vizinhança, considere $\mathscr{S}=\left\{\mathbf{s}_{1}, \ldots, \mathbf{s}_{l}\right\}$ um subconjunto de amostras provenientes de $\mathbf{X}$. Essa amostras são utilizadas para dividir $\mathbf{X}$ em $l$ subconjuntos $\mathbf{X}=\mathbf{X}_{1}, \ldots, \mathbf{X}_{l}$, onde cada subconjunto $\mathbf{X}_{i}$ contém as instâncias em $\mathbf{X}$ mais próximas a $\mathbf{s}_{i}$ do que a qualquer outra amostra $\mathbf{s}_{j}, i \neq j$. O número de instâncias $l$ é dado por $l=\sqrt{n}$, visto que este é o limite superior para o número de grupos em um conjunto de dados (PAL; BEZDEK, 1995). O grafo de vizinhança $N X_{i}$ correspondente a $\mathbf{X}_{i}$ é definido utilizando o $k$-Nearest Neighbor Graph 
( $k$-NNG). Cada nó em $N X_{i}$ representa uma instância em $\mathbf{X}_{i}$. Dois nós em $N X_{i}$ estão conectados por uma aresta se pelo menos um deles está entre os $k$-vizinhos mais próximos do outro. Para os pontos de controle de cada $\mathbf{X}_{i}$, são escolhidos $\sqrt{l}$ instâncias de $\mathbf{X}_{i}$ de forma aleatória.

De posse dos pontos de controle e dos grafos de vizinhança, é possível construir um sistema linear para cada subconjunto $\mathbf{X}_{i}$. A construção do sistema linear acontece de forma semelhante a construção apresentada na LSP.

Com essa subdivisão em sistemas lineares menores, a PLP apresenta custo computacional menor quando comparada com a LSP. No entanto, perde em termos de preservação de vizinhança.

\subsubsection{Part-Linear Multidimensional Projection (PLMP)}

Também visando lidar com grandes conjuntos de dados, uma técnica que busca uma maior velocidade no processo de projeção é a Part-Linear Multidimensional Projection (PLMP) (PAULOVICH; SILVA; NONATO, 2010). Na PLMP, inicialmente uma projeção $\overline{\mathbf{Y}} \subset \mathbb{R}^{p}$ é construída para um subconjunto de instâncias representativas $\overline{\mathbf{X}} \subset \mathbb{R}^{m}$ e essa informação é usada para a construção de uma transformação linear $\Phi: \mathbb{R}^{m} \rightarrow \mathbb{R}^{p}$ para o posicionamento das outras instâncias não projetadas. A transformação $\Phi$ pode ser aproximada de forma eficiente resolvendo um sistema linear $\Phi \overline{\mathbf{X}}=\overline{\mathbf{Y}}$ por meio de mínimos quadrados. Uma vez que $\Phi$ for determinada, a projeção do conjunto de dados passa a ser a transformação de cada $\mathbf{x}_{i} \notin \overline{\mathbf{X}}$ por $\Phi$, uma operação pouco custosa. De uma maneira mais formal, a PLMP busca satisfazer a equação

$$
\Phi=\underset{\hat{\Phi} \in \mathscr{L}_{m, p}}{\operatorname{argmin}}\left\{\frac{1}{\sum_{i j} d\left(\mathbf{x}_{i}, \mathbf{x}_{j}\right)^{2}} \sum_{i j}\left(d\left(\mathbf{x}_{i}, \mathbf{x}_{j}\right)-d\left(\hat{\Phi}\left(\mathbf{x}_{i}\right), \hat{\Phi}\left(\mathbf{x}_{j}\right)\right)\right)^{2}\right\}
$$

na qual $\mathscr{L}_{m, p}$ é o espaço de transformações lineares de $\mathbb{R}^{m}$ para $\mathbb{R}^{p}$.

Entretanto, se a quantidade de instâncias do conjunto de dados for elevada, resolver essa equação é impraticável. Para resolver esse problema é utilizada uma aproximação de $\Phi$ que considera o conjunto de amostras. Mais especificamente, essa proximação é obtida por

$$
\begin{array}{r}
\phi_{11} \overline{\mathbf{x}}_{1,1}+\cdots+\phi_{1 m} \overline{\mathbf{x}}_{1, m}=\overline{\mathbf{y}}_{1,1} \\
\phi_{11} \overline{\mathbf{x}}_{2,1}+\cdots+\phi_{1 m} \overline{\mathbf{x}}_{2, m}=\overline{\mathbf{y}}_{2,1} \\
\vdots \\
\phi_{11} \overline{\mathbf{x}}_{k, 1}+\cdots+\phi_{1 m} \overline{\mathbf{x}}_{k, m}=\overline{\mathbf{y}}_{k, 1}
\end{array}
$$

com $k$ sendo o tamanho do conjunto de amostras e $\phi_{1, i}, i=1, \ldots, m$ são as entradas da primeira linha da matriz que representa $\Phi$. Esse sistema pode ser escrito na forma $\mathbf{L} \phi=b$, no qual $\mathbf{L}$ é a matriz correspondente as amostras representativas, $\phi$ é a transposta da primeira linha de $\Phi$ e $b$ é um vetor contendo as primeiras coordenadas das $\overline{\mathbf{y}}_{j}, j=1, \ldots, k$. A aproximação completa é obtida repetindo-se o processo para todas as linhas de $\Phi$.

Na PLMP, a qualidade do mapeamento linear depende basicamente da seleção das instâncias representativas e do posicionamento delas no espaço visual. A possibilidade de mudança 
interativa do posicionamento das instâncias representativas é uma das características mais interessantes da PLMP, tornando-a um mecanismo verdadeiramente interativo para análise visual de dados. Entre as limitações da técnica está a necessidade de que o número de instâncias representativas seja maior do que o número de dimensões dos dados, o que pode dificultar o uso da técnica em situações nas quais os dados estão em um espaço dimensional muito alto.

A PLMP só precisa conhecer as amostras representativas e seu posicionamento no espaço projetado para realizar a projeção das demais instâncias. Se existe algum conhecimento a priori dos dados as amostras podem ser "fabricadas", como afirmam os autores, sem a necessidade de percorrer os dados, permitindo a aplicação da PLMP como uma técnica streaming. Nesse documento, essa abordagem será chamada de Streaming PLMP (S-PLMP). A ideia parte do pressuposto de que as instâncias do conjunto de dados estão em um hipercubo $H=\left[\alpha_{1} \beta_{1}\right] \times\left[\alpha_{2} \beta_{2}\right] \times \cdots \times\left[\alpha_{m} \beta_{m}\right] \subset \mathbb{R}^{m}$ de fronteiras $\left[\alpha_{i} \beta_{i}\right]$ conhecidas. Dessa forma é possível escolher aleatoriamente instâncias que estejam dentro desse hipercubo para compor o conjunto de amostras. Se o número de amostras for grande o bastante para garantir que cada instância do hipercubo possui uma amostra representativa, um bom resultado será alcançado ao projetar o conjunto real de dados.

\subsubsection{Local Affine Multidimensional Projection (LAMP)}

Outra técnica que faz uso de instâncias representativas em um passo anterior para a geração da projeção final é a Local Affine Multidimensional Projection (LAMP) (JOIA et al., 2011). Essa técnica, além de possuir custo computacional baixo e boa precisão em termos de preservação de dissimilaridades nos mapeamentos, possibilita a manipulação dos pontos de controle no espaço visual pelo usuário. Partindo de uma projeção gerada para uma amostra dos conjuntos de dados, o usuário pode manipular os elementos no espaço visual mudando as relações de similaridade. A projeção dos demais elementos é gerada a partir destes elementos.

Para o mapeamento de cada instância, uma função linear é encontrada pela LAMP. O problema é definido em termos das coordenadas de posicionamento das instâncias representativas, e o mapeamento de cada $\mathbf{x}_{i}$ é a transformação $f_{\mathbf{x}_{i}}(\mathbf{x})=\mathbf{x} M+\mathbf{t}$ que otimiza

$$
\begin{aligned}
\min _{f_{\mathbf{x}_{i}}} & \sum_{j=1}^{c} \alpha_{j}\left\|f_{\mathbf{x}_{i}}\left(\mathbf{x}_{j}^{\prime}\right)-\mathbf{y}_{j}^{\prime}\right\|^{2} \\
\text { sujeito a } & M^{T} M=I,
\end{aligned}
$$

na qual $\alpha_{j}=\frac{1}{\left\|\mathbf{x}_{j}^{\prime}-\mathbf{x}_{i}\right\|^{2}}$ são pesos adicionados para que instâncias representativas mais similares influenciem mais no mapeamento de $\mathbf{x}_{i}$, enquanto que as menos similares irão influenciar menos.

A solução para a minimização da Equação (2.13) é reescrevê-la em forma de matriz, dando origem a um problema de Procrustes Ortogonal (GOWER; DIJKSTERHUIS, 2004), o qual possui solução conhecida. Basta tornar a derivada parcial de $\mathbf{t}$ igual a zero e reescrever $\mathbf{t}$ em 
termos de $M$ com $\mathbf{t}=\overline{\mathbf{y}}^{\prime}-\overline{\mathbf{x}}^{\prime} M$, onde

$$
\overline{\mathbf{x}}^{\prime}=\frac{\sum_{j=1}^{c} \alpha_{j} \mathbf{x}_{j}^{\prime}}{\sum_{j=1}^{c} \alpha_{j}}, \quad \overline{\mathbf{y}}^{\prime}=\frac{\sum_{j=1}^{c} \alpha_{j} \mathbf{y}_{j}^{\prime}}{\sum_{j=1}^{c} \alpha_{j}} .
$$

De volta a Equação (2.13), temos

$$
\begin{aligned}
\min _{f_{\mathbf{x}_{i}}} & \sum_{j=1}^{c} \alpha_{j}\left\|f_{\mathbf{x}_{i}}\left(\hat{\mathbf{x}}_{j}\right)-\hat{\mathbf{y}}_{j}\right\|^{2} \\
\text { sujeito a } & M^{T} M=I,
\end{aligned}
$$

onde $\hat{\mathbf{x}}_{j}=\mathbf{x}_{j}^{\prime}-\overline{\mathbf{x}}^{\prime}$ e $\hat{\mathbf{y}}_{j}=\mathbf{y}_{j}^{\prime}-\overline{\mathbf{y}}^{\prime}$. Por fim, escrevendo a Equação (2.14) na forma matricial, temos

$$
\begin{aligned}
\text { minimizar } & \|A M-B\|_{F} \\
\text { sujeito a } & M^{T} M=I,
\end{aligned}
$$

onde $\|\cdot\|_{F}$ representa a norma de Frobenius e as matrizes $A$ e $B$ são dadas por:

$$
A=\left[\begin{array}{c}
\sqrt{\alpha_{1}} \hat{\mathbf{x}}_{1}^{T} \\
\sqrt{\alpha_{2}} \hat{\mathbf{x}}_{2}^{T} \\
\vdots \\
\sqrt{\alpha_{c}} \hat{\mathbf{x}}_{c}^{T}
\end{array}\right], \quad B=\left[\begin{array}{c}
\sqrt{\alpha_{1}} \hat{\mathbf{y}}_{1}^{T} \\
\sqrt{\alpha_{2}} \hat{\mathbf{y}}_{2}^{T} \\
\vdots \\
\sqrt{\alpha_{c}} \hat{\mathbf{y}}_{c}^{T}
\end{array}\right] .
$$

Como mencionado anteriormente, a Equação (2.15) possui solução conhecida. Fazendo $A^{T} B=$ $U D V^{T}$, na qual $U D V^{T}$ corresponde à decomposição em valores singulares (SVD, do inglês Singular Value Decomposition) de $A^{T} B$, temos que $M=U V^{T}$. Agora é possível calcular $f_{\mathbf{x}_{i}}$, a partir da qual obtém-se $\mathbf{y}_{i}$,

$$
f_{\mathbf{x}_{i}}(\mathbf{x})=\left(\mathbf{x}-\overline{\mathbf{x}}^{\prime}\right) M+\overline{\mathbf{y}}^{\prime}
$$

Os mapeamentos locais para cada instância tornam a LAMP uma técnica eficiente e eficaz. Respostas mais rápidas e a possibilidade de modificações locais de mapeamento permitem que a técnica seja utilizada em várias aplicações (JOIA et al., 2011).

\subsubsection{0 t-Distributed Stochastic Neighbor Embedding (t-SNE)}

Diferente das técnicas anteriores, Maaten e Hinton (2008) apresentam um método que utiliza modelos probabilísticos para encontrar o mapeamento das instâncias do espaço multidimensional em um espaço de baixa dimensionalidade, chamado de $t$-Distributed Stochastic Neighbor Embedding ( $\mathrm{t}-\mathrm{SNE}$ ). A técnica t-SNE é capaz de capturar estruturas locais presentes nos dados e também revelar estruturas globais, tais como a presença de grupos de instâncias similares.

A abordagem da t-SNE acontece em dois passos principais: no primeiro, uma distribuição probabilística é construída sobre pares de instâncias no espaço multidimensional de forma que 
instâncias similares possuam alta probabilidade de serem vizinhas, enquanto que instâncias dissimilares possuam probabilidade baixa. Essa probabilidade é dada por:

$$
p_{i j}=\frac{\left(p_{i \mid j}+p_{j \mid i}\right)}{2 n},
$$

na qual,

$$
p_{j \mid i}=\frac{\exp \left(-\frac{\delta\left(\mathbf{x}_{i}, \mathbf{x}_{j}\right)^{2}}{2 \sigma_{i}^{2}}\right)}{\sum_{k \neq i} \exp \left(-\frac{\delta\left(\mathbf{x}_{i}, \mathbf{x}_{k}\right)^{2}}{2 \sigma_{i}^{2}}\right)},
$$

onde os valores $\sigma_{i}$ controlam indiretamente o tamanho das vizinhanças em $\mathbf{X}$.

No segundo, uma distribuição probabilística também é determinada para os pontos no espaço transformado, sendo definida como

$$
q_{i j}=\frac{\left(1+\left\|\mathbf{y}_{i}-\mathbf{y}_{j}\right\|^{2}\right)^{-1}}{\sum_{k \neq l}\left(1+\left\|\mathbf{y}_{k}-\mathbf{y}_{l}\right\|\right)^{-1}} .
$$

O posicionamento dos pontos no espaço visual é alcançado pela minimização da divergência de Kullback-Leibler (KULLBACK; LEIBLER, 1951), dada por

$$
K L(P \| Q)=\sum_{j \neq i} p_{i j} \log \frac{p_{i j}}{q_{i j}} .
$$

Embora a t-SNE apresente bons resultados em termos de preservação de distâncias, principalmente quando aplicada sobre conjuntos de dados reais, para conjuntos de dados que apresentam elevada dimensionalidade esses resultados podem não ser tão bons.

\subsection{Técnicas incrementais}

Nos casos em que os conjuntos de dados são volumosos e não podem ser inteiramente armazenados em memória principal ou são produzidos de forma constante e infinita, abordagens capazes de processá-los conforme parte desses dados são apresentadas ao processo de projeção se fazem necessárias. Essas abordagens são geralmente chamadas de incrementais e buscam atualizar o modelo de projeção à medida que novas instâncias são apresentadas. A maioria das técnicas incrementais são adaptações de técnicas tradicionais para tratar os fluxos de dados. Entre elas estão as técnicas apresentadas na sequência.

\subsubsection{Incremental PCA (I-PCA)}

Em sua versão não-incremental, a técnica PCA necessita que o conjunto de dados esteja disponível na memória para poder computar a matriz de projeção PCA. Caso novas instâncias sejam incorporadas ao conjunto, é necessário re-calcular a matriz e, novamente, o conjunto inteiro se faz necessário. 
A abordagem conhecida como Incremental PCA (I-PCA) (ARTAC; JOGAN; LEONARDIS, 2002) é um exemplo de algoritmo incremental. Muitos tipos de IPCA foram propostos, sendo a principal diferença entre eles a representação incremental da matriz de covariância.

Na versão incremental proposta por Artac, Jogan e Leonardis (2002), é preciso atualizar os elementos previamente calculados: matriz de autovetores $U$, matriz diagonal dos autovalores $\Lambda$ e média $\overline{\mathbf{x}}$ (ver Seção 2.2.1).

Primeiro, a média é atualizada por

$$
\overline{\mathbf{x}}^{\prime}=\frac{1}{n+1}\left(n \overline{\mathbf{x}}+\mathbf{x}_{\mathbf{n}+\mathbf{1}}\right)
$$

Para atualizar os autovetores, computa-se o vetor ortogonal residual $\mathbf{h}_{n+1}=\left(U \mathbf{y}_{n+1}+\right.$ $\overline{\mathbf{x}})-\mathbf{x}+n+1$ e normaliza-o obtendo $\hat{\mathbf{h}}_{n+1}=\frac{\mathbf{h}_{n+1}}{\left\|\mathbf{h}_{n+1}\right\| 2}$ para $\left\|\mathbf{h}_{n+1}\right\| 2>0$ e $\hat{\mathbf{h}}_{n+1}=\mathbf{0}$ caso contrário. A matriz $U^{\prime} \in \mathbb{R}^{m \times(p+1)}$ é então calculada como

$$
U^{\prime}=\left[U \hat{\mathbf{h}}_{n+1}\right] R,
$$

na qual $R \in \mathbb{R}^{(p+1) \times(p+1)}$ é uma matriz de rotação e solução do problema

$$
D R=R \Lambda^{\prime}
$$

Sendo $D \in \mathbb{R}^{(p+1) \times(p+1)}$ dada por

$$
D=\frac{n}{n+1}\left[\begin{array}{cc}
\Lambda & 0 \\
0^{T} & 0
\end{array}\right]+\frac{n}{(n+1)^{2}}\left[\begin{array}{cc}
\mathbf{a a}^{T} & \gamma \mathbf{a} \\
\gamma \mathbf{a}^{T} & \gamma^{2}
\end{array}\right]
$$

onde $\gamma=\hat{\mathbf{h}}_{n+1}^{T}\left(\mathbf{x}_{n+1}-\overline{\mathbf{x}}\right)$ e $\mathbf{a}=U^{T}\left(\mathbf{x}_{n+1}-\overline{\mathbf{x}}\right)$.

No final desse processo, tem-se a nova média calculada por meio da Equação (2.22), a matriz intermediária $D$ dada pela Equação (2.25) e a resolução do problema da Equação 2.24, o que produz um novo subespaço de autovetores $U^{\prime}$. Esse procedimento gera um espaço $p+$ 1-dimensional, e para manter a $p$-dimensionalidade basta preservar apenas os $p$ primeiros autovetores.

Para o reposicionamento das instâncias nesse novo subespaço é preciso primeiro calcular um vetor auxiliar $\eta$

$$
\eta=\left[U \hat{\mathbf{h}}_{n+1}\right]^{T}\left(\overline{\mathbf{x}}-\overline{\mathbf{x}}^{\prime}\right),
$$

e, em seguida, encontra-se o novo mapeamento

$$
\mathbf{y}_{i(n+1)}=\left(R^{\prime}\right)^{T}\left[\begin{array}{c}
\mathbf{y}_{i(n)} \\
0
\end{array}\right]+\eta, i=1 \ldots n+1 .
$$

Um problema dessa abordagem está no fato de que, ao descartar a $C P$ menos significativa a cada atualização, uma certa quantidade de informação é descartada, podendo levar a um aumento no erro propagado. 


\subsubsection{Incremental ISOMAP (I-ISOMAP)}

Law e Jain (2006) apresentam uma modificação no algoritmo ISOMAP, chamado de Incremental ISOMAP (I-ISOMAP), para que ele possa atualizar de forma gradual a representação das instâncias no espaço de baixa dimensionalidade, à medida que mais e mais instâncias são apresentadas.

Os principais cálculos na ISOMAP não incremental são: a resolução do problema de encontrar o caminho mais curto entre todos os pares de instâncias e um problema de decomposição matricial. Um novo vértice no grafo, muitas vezes, muda os caminhos mais curtos apenas entre um subconjunto dos vértices, e os autovetores e autovalores de uma matriz real simétrica ficam próximos de seus valores originais. Isto justifica a reutilização da distância geodésica atual e das estimativas de coordenadas para a atualização. Na versão incremental, a vizinhança utilizada é dada pelo $k-\mathrm{NN}$.

O problema da I-ISOMAP é definido como: sejam $\mathbf{y}_{i}$ as coordenadas no espaço transformado de $\mathbf{x}_{i}$ para as primeiras $n$ instâncias que chegam. A nova instância observada é $\mathbf{x}_{n+1}$. Para atualizar o conjunto de $\mathbf{y}_{i}$ existente e encontrar $\mathbf{y}_{i+1}$, a solução consiste em três etapas.

As distâncias geodésicas $g_{i j}$ são atualizadas tendo em conta a mudança do grafo de vizinhança devido à inserção de $v_{n+1}$. Isso é feito pela equação

$$
g_{n+1, i}=g_{i, n+1}=\min _{j \text { tal que } e(n+1, j) \in A}\left(g_{i j}+w_{j, n+1}\right) \quad \forall i
$$

na qual $A$ é o conjunto de arestas que serão inseridas no grafo de vizinhança. As distâncias geodésicas da instância nova para as instâncias existentes são utilizadas para estimar $\mathbf{y}_{n+1}$. A equação que realiza essa aproximação é:

$$
\mathbf{y}_{n+1}=\left(\frac{1}{\sqrt{\lambda_{1}}} v_{1}^{T} \mathbf{f}, \ldots, \frac{1}{\sqrt{\lambda_{p}}} v_{p}^{T} \mathbf{f}\right)^{T}
$$

sendo $\mathbf{f}=\left(f_{1}, \ldots, f_{2}\right)^{T}$ e $f_{i}$ o produto interno entre $\mathbf{y}_{n+1}$ e $\mathbf{y}_{i}$, estimado por

$$
2 f_{i} \approx \frac{\sum_{j} g_{i j}^{2}}{n}-\frac{\sum_{l j} g_{l j}^{2}}{n^{2}}+\frac{\sum_{l} g_{l, n+1}^{2}}{n}-g_{i, n+1}^{2}
$$

Por fim, todos os $y_{i}$ são atualizados em vista das mudanças em $g_{i j}$.

Em resumo, a ideia desse algoritmo é atualizar as distâncias geodésicas, por meio da inserção de vértices no grafo e re-estimar os autovetores utilizando computações prévias. $\mathrm{O}$ algoritmo se aproxima bastante, em termos de preservação de distâncias, quando comparado com a versão não incremental, quando as novas instâncias são apresentadas uma a uma, porém o tempo de processamento se torna elevado. 


\subsection{Avaliação de projeções}

Ao realizar uma redução de dimensionalidade, mapeando instâncias de um espaço de alta dimensão para um de mais baixa dimensão, uma grande perda de informação pode ocorrer. Como resultado, os mapeamentos gerados podem não refletir as características reais presentes nos dados (LESPINATS; AUPETIT, 2011). Algumas medidas podem ser utilizadas para avaliar se a projeção preserva essas características.

Uma dessas medidas é o conjunto de funções de stress. Tais medidas buscam quantificar a preservação das distâncias calculadas no espaço original após o processo de projeção, ou seja, quanto essas distâncias são mantidas no espaço projetado. Nesse trabalho a função de stress utilizada foi apresentada por Kruskal (KRUSKAL, 1964) dada por

$$
S_{1}=\sqrt{\frac{\sum_{i<j}\left(\boldsymbol{\delta}\left(\mathbf{x}_{\mathbf{i}}, \mathbf{x}_{\mathbf{j}}\right)-d\left(\mathbf{y}_{\mathbf{i}}, \mathbf{y}_{\mathbf{j}}\right)\right)^{2}}{\sum_{i<j} \boldsymbol{\delta}\left(\mathbf{x}_{\mathbf{i}}, \mathbf{x}_{\mathbf{j}}\right)^{2}}} .
$$

Essa função varia entre $[0,1]$, sendo que, quanto mais próximo de 0 maior é a preservação de distâncias indicando uma melhor projeção nesse sentido.

Quando a característica que se deseja preservar, após o mapeamento dos dados, está relacionada com a vizinhança, uma métrica que pode ser utilizada para avaliação é a Neighborhood Preservation (NP) (FADEL et al., 2014). Essa métrica avalia quantos vizinhos mais próximos, estabelecidos no espaço original, continuam como vizinhos mais próximos no espaço projetado, dada por

$$
N P_{k}=\frac{1}{n} \sum_{i}^{n} \frac{\left|N_{k_{i}}^{m} \cap N_{k_{i}}^{p}\right|}{k},
$$

onde $N_{k_{i}}^{m}$ corresponde aos $k$ vizinhos mais próximos de $\mathbf{x}_{i}$ no espaço $m$-dimensional e $N_{k_{i}}^{p}$ aos $k$ vizinhos mais próximos de $\mathbf{x}_{i}$ no espaço $p$-dimensional. $N P_{k}$ também varia entre $[0,1]$, com valores mais próximos de 1 representando uma melhor preservação de vizinhança.

\subsection{Considerações finais}

Foram apresentados nesse capítulo definições gerais sobre projeção multidimensional e detalhamentos sobre as técnicas atuais mais relevantes. De forma geral, as técnicas de projeção multidimensional são uma importante ferramenta analítica devido à sua capacidade de revelar estruturas de similaridade e vizinhança em espaços multidimensionais.

As técnicas apresentadas foram divididas em técnicas não-incrementais, as quais necessitam que os dados estejam inteiramente armazenados em memória principal ou realizam mais de um acesso a eles para obter a projeção final, e técnicas incrementais, que realizam a projeção dos dados à medida que são apresentados para projeção sem a necessidade de que todos os dados anteriormente processados estejam a disposição na memória principal. Essas técnicas 
serviram de base, ou de inspiração, para as abordagens desenvolvidas nesse trabalho, além de serem usadas nos testes comparativos que foram executados. 



\section{3}

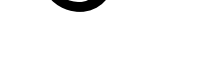

\section{VISUALIZAÇÃO DE INFORMAÇÃO DE DISTÂNCIA POR MEIO DE PROJEÇÕES MULTIDIMENSIONAIS ASSISTIDAS}

\subsection{Considerações iniciais}

As técnicas de projeção multidimensionais buscam mapear instâncias de dados originalmente encontradas em um espaço com múltiplas dimensões para um espaço visual, com duas ou três dimensões. Durante o processo de mapeamento, busca-se preservar no espaço projetado as relações de distância ou de vizinhança estabelecidas no espaço original.

Apesar dos avanços dos métodos de projeção, com técnicas cada vez mais precisas e rápidas (PAULOVICH; SILVA; NONATO, 2010), algumas deficiências ainda impedem a sua utilização como ferramentas de exploração visual completamente interativa. Um bom exemplo do problema citado é a falta de mecanismos apropriados que permitam ao usuário uma intervenção durante o processo de projeção com liberdade. A grande maioria das técnicas funcionam como "caixas-pretas", recebendo os dados como entrada e produzindo os mapas visuais. Isto limita a utilização do conhecimento do usuário a apenas definir parâmetros. Somente algumas técnicas vão além disso.

Neste sentido, é possível classificar as técnicas de projeção em duas categorias diferentes: métodos assistidos por usuários e os métodos não-assistidos. Nos métodos não-assistidos, a entrada é formada pelos dados que serão projetados e os parâmetros necessários para a execução de cada técnica. Por outro lado, os métodos assistidos por usuários utilizam-se de uma solução parcial inicial baseada em um subconjunto de instâncias de dados que podem ser livremente manipuladas pelo usuário e que controla a criação do mapa visual final.

Embora algumas técnicas já permitam algum tipo de intervenção do usuário durante 
o processo de criação do mapa visual, o domínio que elas abrangem ainda é limitado. As técnicas existentes utilizam a representação dos dados na forma de vetores de características. Assim, cenários nos quais apenas informação de distância está disponível não podem usufruir da manipulação do usuário para guiar o processo de criação do mapa visual.

Este capítulo apresenta uma nova técnica de projeção multidimensional, chamada de User-assisted Projection Technique for Distance Information (UPDis), que permite a intervenção do usuário em casos nos quais apenas a informação de dissimilaridade é encontrada. A UPDis permite a utilização de uma técnica de projeção multidimensional assistida pelo usuário em aplicações que estão em um domínio até então sem cobertura.

A seguir, a UPDis é detalhada, os resultados obtidos são apresentados e a avaliação comparativa desses resultados é descrita.

\subsection{Descrição da técnica}

Considerando que as coordenadas das instâncias $m$-dimensionais não são fornecidas, apenas as informações de dissimilaridade estão disponíveis, a UPDis realiza um mapeamento preservando no espaço reduzido os relacionamentos de dissimilaridade presentes no espaço $m$-dimensional tanto quanto possível.

Esse processo é dividido em duas fases. Na primeira fase, amostras representativas $\overline{\mathbf{X}} \subset$ $\mathbf{X}, \overline{\mathbf{X}}=\left\{\overline{\mathbf{x}}_{1}, \ldots, \overline{\mathbf{x}}_{k}\right\}$ são recuperadas do conjunto original e projetadas no espaço bidimensional por meio de uma técnica de alta precisão, obtendo $\overline{\mathbf{Y}}=\left\{\overline{\mathbf{y}}_{1}, \ldots, \overline{\mathbf{y}}_{k}\right\}$. Na segunda fase, as amostras $\overline{\mathbf{X}}$ são mapeadas em um espaço $m$-dimensional recuperando as coordenadas das distâncias $\delta\left(\mathbf{x}_{i}, \mathbf{x}_{j}\right)$. Baseando-se no mapeamento inicial, cada uma das instâncias restantes é mapeada no espaço $m$-dimensional, recuperando suas coordenadas, e é criada uma transformação afim que realiza o mapeamento de tal instância para o espaço visual como uma interpolação das posições $\overline{\mathbf{Y}}$. A Figura 2 apresenta uma visão geral do processo.

\subsubsection{Mapeando a informação de distância}

A abordagem começa por selecionar amostras representativas $\overline{\mathbf{X}}$ a partir do conjunto de dados (que será discutido mais a seguir) e recuperar suas coordenadas cartesianas. Essa última atividade é realizada utilizando a técnica Classical Multidimensional Scaling (CMDS) (COX; COX, 2000). Uma propriedade interessante da CMDS é que, se uma quantidade suficiente de instâncias for considerada, as coordenadas em um espaço Euclidiano podem ser encontradas de forma que o posicionamento das instâncias $m$-dimensionais representam exatamente as distâncias $\delta\left(\mathbf{x}_{i}, \mathbf{x}_{j}\right)$.

Para compor essa transformação, primeiramente a matriz do produto interno $B_{k}$ entre as amostras é construída e dela são calculadas as coordenadas. $B_{k}$ é uma matriz do produto 
Figura 2 - Visão geral da técnica UPDis. Inicialmente uma amostra é recuperada e projetada para o espaço bidimensional. Em seguida, utilizando essa informação, as instâncias restantes são mapeadas para o espaço bidimensional por meio de uma abordagem de interpolação.

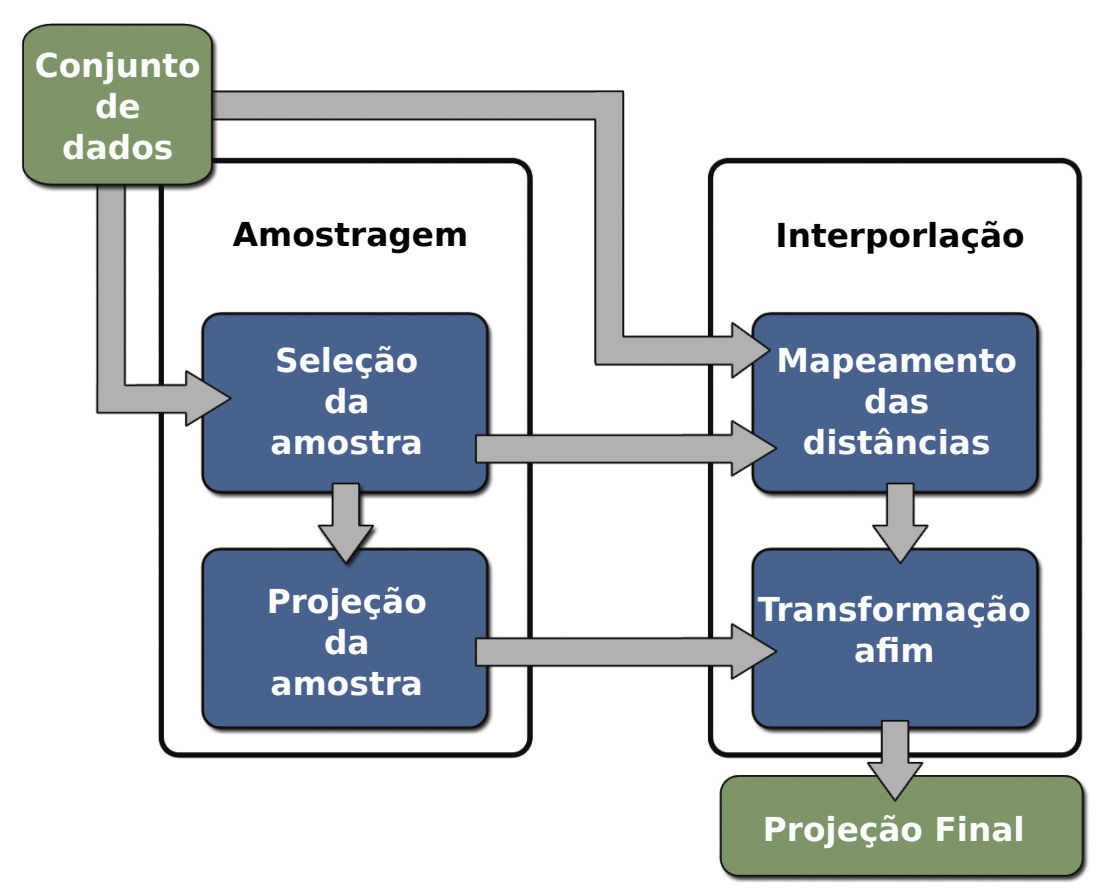

Fonte: Elaborada pelo autor.

interno duplamente centrada, calculada por $B_{k}=-\frac{1}{2} H_{k} D_{k} H_{k}$, onde $H_{k}$ é a matriz de centragem com entradas $h_{i j}=\delta\left(\overline{\mathbf{x}}_{i}, \overline{\mathbf{x}}_{j}\right)-\frac{1}{k}$ e $D_{k}$ é a matriz contendo o quadrado das distâncias entre as $k$ amostras representativas com entradas $d_{i j}=\delta\left(\overline{\mathbf{x}}_{i}, \overline{\mathbf{x}}_{j}\right)^{2}$. Uma decomposição de valores singulares (SVD, sigla em inglês para Singular Value Decomposition) é então aplicada sobre $B_{k}$, calculando os autovalores $\lambda_{i}$ e os autovetores $\vec{v}_{i}$, e as coordenadas mapeadas são determinadas utilizando as colunas da seguinte matriz

$$
\overline{\mathbf{X}}=\left[\begin{array}{c}
\sqrt{\lambda_{1}} \times \vec{v}_{1}^{T} \\
\sqrt{\lambda_{2}} \times \vec{v}_{2}^{T} \\
\vdots \\
\sqrt{\lambda_{r}} \times \vec{v}_{r}^{T}
\end{array}\right]_{r \times k}
$$

na qual $\lambda_{1} \geq \lambda_{2} \geq \ldots \geq \lambda_{r}>0$ e $r \leq k$

Uma vez que as amostras representativas estão mapeadas no espaço Euclidiano, as coordenadas cartesianas de cada instância $\mathbf{x}_{i} \in \mathbf{X}$ são computadas utilizando um método de triangulação definido em (SILVA; TENENBAUM, 2004). Para mapear uma instância $\mathbf{x}_{i}$, primeiro calcula-se a matriz $D_{\mathbf{x}_{i}}$, contendo as diferenças dos quadrados das distâncias entre $\mathbf{x}_{i}$ e todas as amostras representativas e a média quadrática das distâncias entre as amostras, por meio da 
equação

$$
D_{x_{i}}=\left[\begin{array}{c}
\delta\left(\mathbf{x}_{i}, \overline{\mathbf{x}}_{1}\right)^{2}-\left(\boldsymbol{\delta}\left(\overline{\mathbf{x}}_{1}, \overline{\mathbf{x}}_{1}\right)^{2}+\ldots+\delta\left(\overline{\mathbf{x}}_{1}, \overline{\mathbf{x}}_{k}\right)^{2}\right) / k \\
\delta\left(\mathbf{x}_{i}, \overline{\mathbf{x}}_{2}\right)^{2}-\left(\delta\left(\overline{\mathbf{x}}_{2}, \overline{\mathbf{x}}_{1}\right)^{2}+\ldots+\delta\left(\overline{\mathbf{x}}_{2}, \overline{\mathbf{x}}_{k}\right)^{2}\right) / k \\
\vdots \\
\delta\left(\mathbf{x}_{i}, \overline{\mathbf{x}}_{k}\right)^{2}-\left(\delta\left(\overline{\mathbf{x}}_{k}, \overline{\mathbf{x}}_{1}\right)^{2}+\ldots+\delta\left(\overline{\mathbf{x}}_{k}, \overline{\mathbf{x}}_{k}\right)^{2}\right) / k
\end{array}\right]_{k \times 1}
$$

Então, o mapeamento final é computado tomando a pseudo-inversa transposta de $\overline{\mathbf{X}}$ (Equação (3.1)), multiplicando por $D_{\mathbf{x}_{i}}$ e dividindo por dois, como mostra a equação

$$
\mathbf{x}_{i}=\frac{1}{2}\left[\begin{array}{c}
\vec{v}_{1}^{T} / \sqrt{\lambda_{1}} \\
\vec{v}_{2}^{T} / \sqrt{\lambda_{2}} \\
\vdots \\
\vec{v}_{k}^{T} / \sqrt{\lambda_{k}}
\end{array}\right] D_{\mathbf{x}_{i}}
$$

A dimensionalidade desse mapeamento depende do número de autovetores considerados para criar a matriz da Equação (3.1), com o limite superior sendo o número $k$ de amostras representativas. Entretanto, na prática, o número de dimensões desse mapeamento pode ser muito menor. Jackson (1993) apresenta critérios diferentes para definir a dimensionalidade alvo. Aqui, foi utilizada uma heurística simples baseada na quantidade de variância capturada pelos autovetores. É possível provar que os autovalores $\lambda_{i}$ são proporcionais à quantidade de variância nos dados, capturada pelos autovetores $\vec{v}_{i}$. Assim, a dimensionalidade do mapeamento pode ser limitada pela determinação de um limiar do percentual da variância total que pretendese preservar. Ou seja, o número de autovetores é definido considerando-se o menor valor de $r \in\{1, \ldots, k\}$ que satisfaz

$$
\frac{\sum_{i=1}^{r} \lambda_{i}}{\sum_{i=1}^{k} \lambda_{i}} \geq \Lambda
$$

na qual $\Lambda$ é o percentual mínimo da variância total que se pretende capturar. Para este trabalho, o valor utilizado foi de $\Lambda=0.95$ visto que esse é considerado um bom limiar (JACKSON, 1993; JOLLIFFE, 2005). No entanto, esse é um parâmetro e, como tal, pode variar de acordo com a necessidade do usuário. Observe que os próximos passos do algoritmo (transformação afim) só irão funcionar se o número de autovetores for pelo menos igual a dimensionalidade da representação visual desejada. Como nesse trabalho o foco são representações visuais bidimensionais, sempre serão utilizados pelo menos 2 autovetores na criação da matriz da Equação (3.1), mesmo se $\Lambda=0.99$ definir menos que isso.

\subsubsection{Criando a transformação afim}

Uma vez recuperadas as coordenadas de uma instância $\mathbf{x}_{i}$ no espaço $m$-dimensional (neste capítulo, uma instância e suas coordenadas são ambas identificadas por $\mathbf{x}_{i}$ ), uma transformação 
$T_{\mathbf{x}_{i}}: \mathbb{R}^{m} \rightarrow \mathbb{R}^{2}$, que preserva tanto quanto possível a informação de distância do espaço $m$ dimensional no espaço reduzido, é computada. Para isso, primeiro as amostras representativas são projetadas para o espaço 2-dimensional por meio de uma técnica de alta precisão (que será discuta mais adiante no texto), obtendo $\overline{\mathbf{Y}}=\left\{\overline{\mathbf{y}}_{1}, \ldots, \overline{\mathbf{y}}_{k}\right\}$. Esse mapa inicial bidimensional e seu respectivo mapeamento no espaço $m$-dimensional $\overline{\mathbf{X}}=\left\{\overline{\mathbf{x}}_{1}, \ldots, \overline{\mathbf{x}}_{k}\right\}$, dado pela Equação (3.1), são então utilizados para criar uma transformação afim $T_{\mathbf{x}_{i}}\left(\overline{\mathbf{x}}_{j}\right)=\overline{\mathbf{x}}_{j} M+\mathbf{t}$ associada com $\mathbf{x}_{i}$ que minimiza

$$
\sum_{j=1}^{k} \alpha_{j}\left\|T_{\mathbf{x}_{i}}\left(\overline{\mathbf{x}}_{j}\right)-\overline{\mathbf{y}}_{j}\right\|^{2}, \quad \text { com } \alpha_{j}=\frac{1}{\delta\left(\mathbf{x}_{i}, \overline{\mathbf{x}}_{j}\right)}
$$

Com alguma manipulação algébrica, a Equação (3.5) pode ser escrita na forma matricial

$$
\|A M-B\|_{F}
$$

na qual $\|\cdot\|_{F}$ significa a norma de Frobenius e $A$ e $B$ são as matrizes com a $i$-ézima linha dada por

$$
\sqrt{\alpha_{i}}\left(\overline{\mathbf{x}}_{i}-\frac{\sum_{j} \alpha_{j} \overline{\mathbf{x}}_{j}}{\sum_{j} \alpha_{j}}\right) \text { e } \sqrt{\alpha_{i}}\left(\overline{\mathbf{y}}_{i}-\frac{\sum_{j} \alpha_{j} \overline{\mathbf{y}}_{j}}{\sum_{j} \alpha_{j}}\right)
$$

respectivamente.

A Equação (3.7) pode ser resolvida pela decomposição de $A^{T} B=U D V$ e calculando-se $M=U V$, na qual $U D V$ é a decomposição de valores singulares (SVD) de $A^{T} B$. Após computar $M$, a projeção $\mathbf{y}_{i}$ de $\mathbf{x}_{i}$ é calculada por

$$
\mathbf{y}_{i}=\left(\mathbf{x}_{i}-\frac{\sum_{j} \alpha_{j} \overline{\mathbf{x}}_{j}}{\sum_{j} \alpha_{j}}\right) M+\frac{\sum_{j} \alpha_{j} \overline{\mathbf{y}}_{j}}{\sum_{j} \alpha_{j}} .
$$

Esta formulação é, estritamente, a formulação da LAMP. Entretanto, quando combinada com o passo anterior (mapeamento de distâncias), permite que a LAMP opere sobre informação de distância. Assim, todas as vantagens da LAMP ficam disponíveis para aplicações nas quais apenas a informação de distância está disponível.

\subsubsection{Amostrando e projetando}

O primeiro passo da UPDis é recuperar as amostras representativas. Existem várias formas de se conseguir isso, como por exemplo, por meio da utilização de uma abordagem de agrupamento, como a técnica $k$-means (MACQUEEN, 1967), ou simplesmente por meio de uma escolha aleatória. A Figura 3 apresenta o resultado, em termos de preservação de distâncias, dessas duas abordagens. Para esse experimento foram utilizadas as bases descritas na Tabela 1 e o coeficiente de stress (veja Seção 2.4). Para cada base foram geradas 30 projeções por abordagem de amostragem, aleatória e agrupamento. Neste trabalho foi utilizada a abordagem de 
Figura 3 - Comparação de stress entre a abordagem aleatória e utilizando agrupamento. É possível observar que não há diferença significativa entre as abordagens.

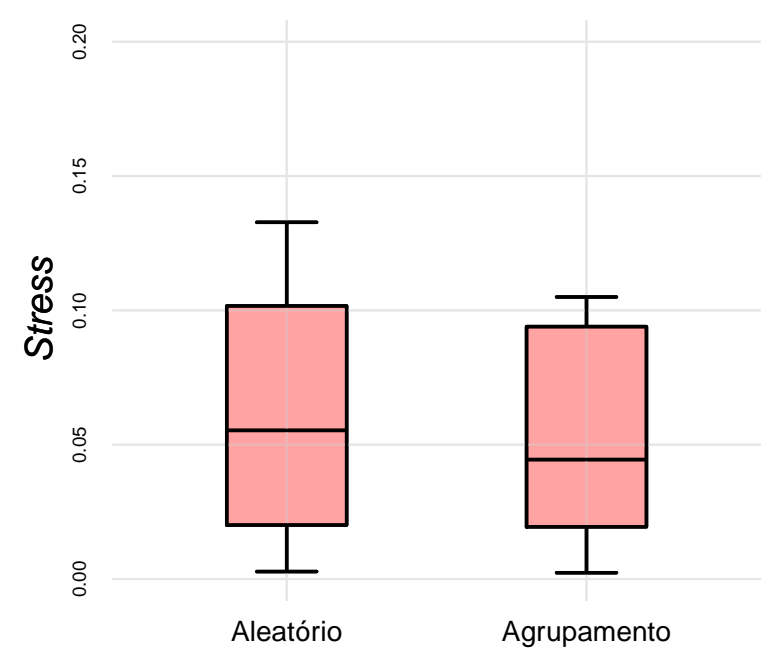

Fonte: Elaborada pelo autor.

escolha aleatória, tendo em vista que a outra abordagem não produz resultados significativamente melhores e é mais cara computacionalmente.

Outro aspecto importante do passo de amostragem está relacionado com o número de amostras que são recuperadas, pois isso afeta a complexidade computacional e o tempo de processamento da técnica. Segundo Joia et al. (2011), $\sqrt{n}$ é uma quantidade suficiente de amostras, com $n$ sendo o tamanho do conjunto de dados. Uma vez que este valor corresponde a uma boa combinação entre qualidade e complexidade computacional, esta é a heurística adotada neste trabalho.

Um fator que também exerce grande influência na qualidade da projeção final obtida é a projeção das amostras representativas. Diferentes técnicas podem ser empregadas para realizar essa tarefa, como por exemplo: Classical Scaling (COX; COX, 2000) ou Sammon's Mapping (SAMMON, 1969). A única restrição é que a informação de distância estabelecida no espaço original seja preservada o máximo possível. Neste caso, como a projeção é realizada em uma pequena amostra do conjunto original, técnicas computacionalmente mais caras podem ser usadas como forma de obter um aumento na precisão observada na projeção final.

O Algoritmo 1 sumariza o funcionamento da UPDis. As linhas de 5 a 8 correspondem ao passo de mapeamento das amostras para o espaço $m$-dimensional. A criação da transformação afim e o mapeamento do restante das instâncias é descrito pelas linhas 10 a 15 . 


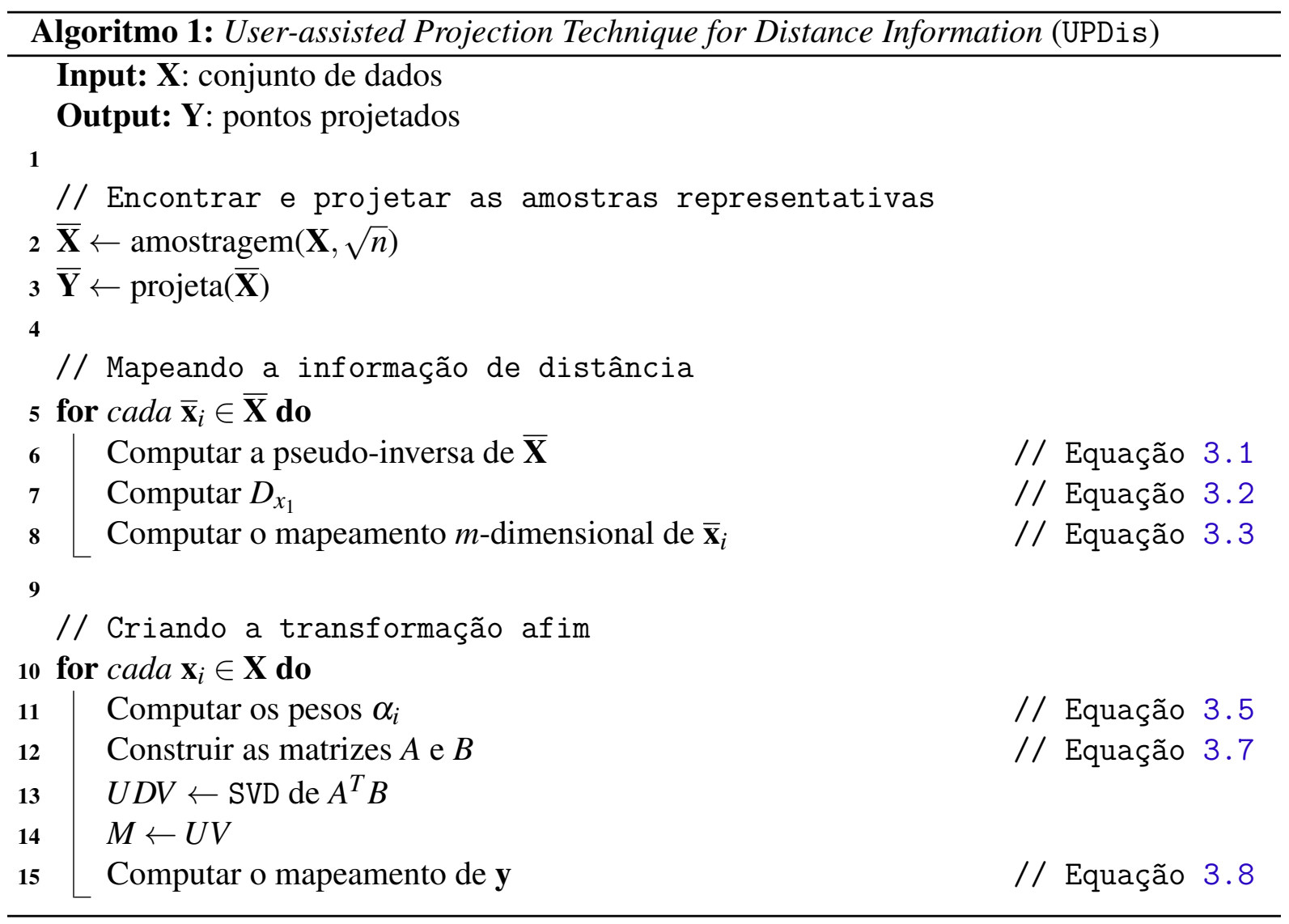

\subsection{Resultados e avaliação}

A seguir, são apresentadas as avaliações e comparações da UPDis em relação a outras técnicas de projeção multidimensional existentes. A escolha das técnicas para comparação baseou-se no critério de que essas são técnicas do estado-da-arte ou apresentam um bom desempenho em termos de tempo computacional e qualidade na preservação de relacionamentos de distância. De forma mais específica, as técnicas escolhidas foram: LAMP (JOIA et al., 2011), PLMP (PAULOVICH; SILVA; NONATO, 2010), PLP (PAULOVICH et al., 2011), Hybrid (MORRISON; ROSS; CHALMERS, 2002), L-MDS (SILVA; TENENBAUM, 2004), L-ISOMAP (SILVA; TENENBAUM, 2002), Fastmap (FALOUTSOS; LIN, 1995), LSP (PAULOVICH et al., 2008), e a abordagem Pekalska (PEKALSKA et al., 1999) (ver Capítulo 2).

Com relação aos conjuntos de dados foram escolhidos conjuntos de diferentes tamanhos e dimensionalidade, possibilitando a análise de diferentes cenários. Todos os conjuntos, com exceção do viscontest e do us-counties, foram obtidos a partir do repositório de aprendizado de máquina da UCI (BACHE; LICHMAN, 2013). O conjunto fibers é formado por instâncias que representam feixos de fibras obtidas a partir do 2009 Pittsburgh Brain Competition (PBC) - Brain Connectivity Challenge. A Tabela 1 apresenta a quantidade de instâncias e a dimensionalidade de cada conjunto.

Todos os resultados apresentados nesta seção foram produzidos por um Intel ${ }^{\circledR}$ Cor $e^{\mathrm{TM}}$ 
Tabela 1 - Conjuntos de dados utilizados nas comparações. Da esquerda para a direita a coluna corresponde ao nome, tamanho (número de instâncias de dados) e dimensionalidade (número de atributos).

\begin{tabular}{|l|r|r|}
\hline \multicolumn{1}{|c|}{ Nome } & Tamanho & Dimensionalidade \\
\hline \hline wdbc & 569 & 30 \\
\hline diabetes & 768 & 8 \\
\hline segmentation & 2,100 & 19 \\
\hline us-counties & 3,028 & 14 \\
\hline isolet & 6,238 & 617 \\
\hline letter rcn & 20,000 & 16 \\
\hline mammals & 50,000 & 72 \\
\hline fibers & 250,000 & 30 \\
\hline
\end{tabular}

i7 CPU 3.40GHz, com uma placa de vídeo NVIDIA ${ }^{\circledR}$ GeForce GT 640 e $24 \mathrm{~GB}$ de memória RAM. A fim de garantir uma comparação justa entre as técnicas, todas foram implementadas em Java, incluindo a UPDis.

\subsubsection{Análise do parâmetro lambda $(\Lambda)$}

A primeira análise realizada tem o objetivo de verificar a influência do parâmetro $\Lambda$ (ver Equação (3.4)), o qual controla a quantidade de variância capturada pela fase de mapeamento, sobre a qualidade, em termos de preservação de distância, das projeções obtidas. Para isso, é utilizada a função de stress de Kruskal (ver Seção 2.4). Essa função varia entre [0,1], com valores pequenos representando os melhores resultados.

A Figura 4 ilustra o gráfico que apresenta o resultado em termos de stress de acordo com a variação de $\Lambda$ para os conjuntos descritos na Tabela 1 . É possível observar que a qualidade não sofre uma melhora significativa com o aumento de $\Lambda$ acima de 0.9 , indicando que esta é uma boa heurística para a técnica (como mencionado na Seção 3.2.1). Algumas curvas no gráfico começam com $\Lambda=0.4$, entretanto, outras começam $\operatorname{com} \Lambda=0.6$ ou $\Lambda=0.9$. Como explicado na Seção 3.2.1, para esse trabalho serão criadas representações visuais bidimensionais sendo necessário pelo menos 2 autovetores na criação da matriz da Equação 3.1. Assim, valores de $\Lambda$ que resultam em menos de 2 autovetores são desconsiderados.

\subsubsection{Análise de tempo e stress}

A Figura 5 apresenta os boxplots com os resultados, em termos de stress e tempos de execução, produzidos pela UPDis e por outras técnicas executadas sobre os conjuntos descritos na Tabela 1. É possível observar na Figura 5a, que a UPDis é uma das técnicas mais precisas, obtendo resultados similares a outros métodos bastante precisos como Pekalska e L-MDS. Comparada com a abordagem original da técnica LAMP, a UPDis apresenta resultados bem parecidos, obtendo quase que a mesma média de stress. 
Figura 4 - Stress vs. $\Lambda$. Para a maioria dos conjuntos de dados, valores de $\Lambda$ acima de 0.95 não causam melhora significativa na qualidade das projeções produzidas, o que indica uma boa heurística para a técnica.

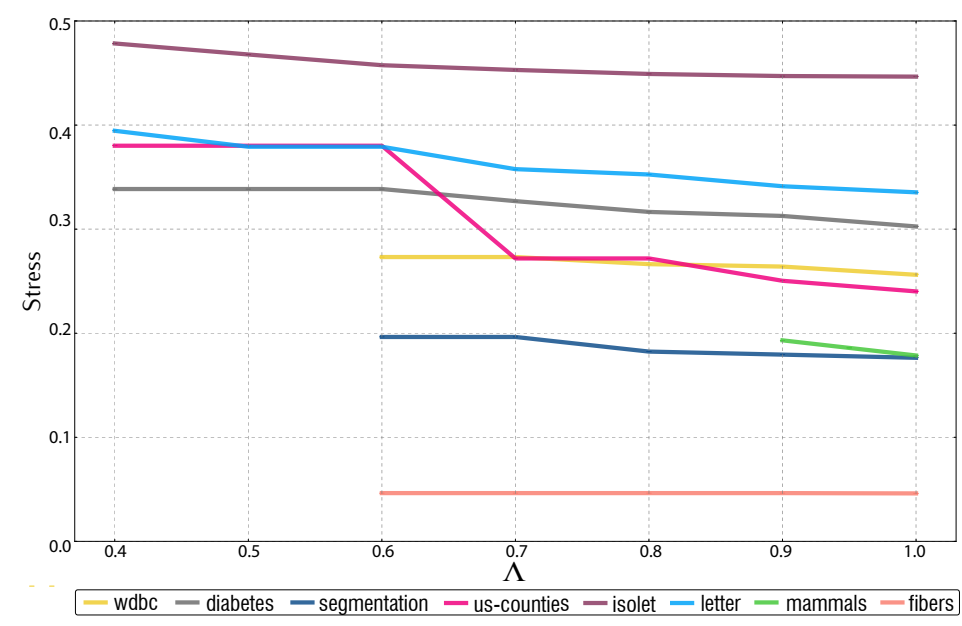

Fonte: Elaborada pelo autor.

Em termos de tempo de execução, cujos resultados podem ser observados na Figura 5b, a UPDis é também bastante competitiva. Os resultados são comparáveis aos dos métodos mais rápidos, tais como Fastmap e PLMP. Novamente comparando com a abordagem original da técnica LAMP, os resultados são bem próximos daqueles produzidos pela UPDis, indicando que a fase de mapeamento não afeta, de forma significativa, os tempos de execução. Adicionalmente, os resultados sugerem que as propriedades interessantes apresentadas pela LAMP são preservadas na UPDis, agora com a possibilidade de utilização da informação de distância para criar as projeções, característica não suportada pela abordagem original da LAMP.

A fim de permitir uma análise detalhada da distorção induzida no processo de projeção por cada técnica, foi produzido um gráfico de dispersão entre a distância no espaço original e a distância no espaço projetado para ilustrar o resultado de cada técnica sobre cada conjunto de dados. Este gráfico de dispersão é apresentado na Figura 6. Neste tipo de gráfico, as projeções que apresentam menor distorção, ou seja, aquelas que melhor preservam os relacionamentos de distância, são representadas pelos gráficos de dispersão com pontos posicionados próximos da diagonal. Números nos cantos superiores esquerdos em cada gráfico de dispersão correspondem ao stress e ao tempo computacional (em segundos).

É possível observar que a técnica UPDis consegue obter resultados próximos a diagonal na maioria dos casos de teste. Resultados similares são apresentados pela LAMP, PLMP, Fastmap e L-MDS, dando evidências que permitem posicionar a técnica UPDis entre as técnicas do estadoda-arte, não apenas por produzir projeções com baixa distorção, mas também por apresentar bom tempo computacional. 
Figura 5 - Boxplots dos resultados de stress e tempo de execução. A UPDis consegue resultados similares aos de outras técnicas bastante precisas em termos de stress e de tempo de execução.

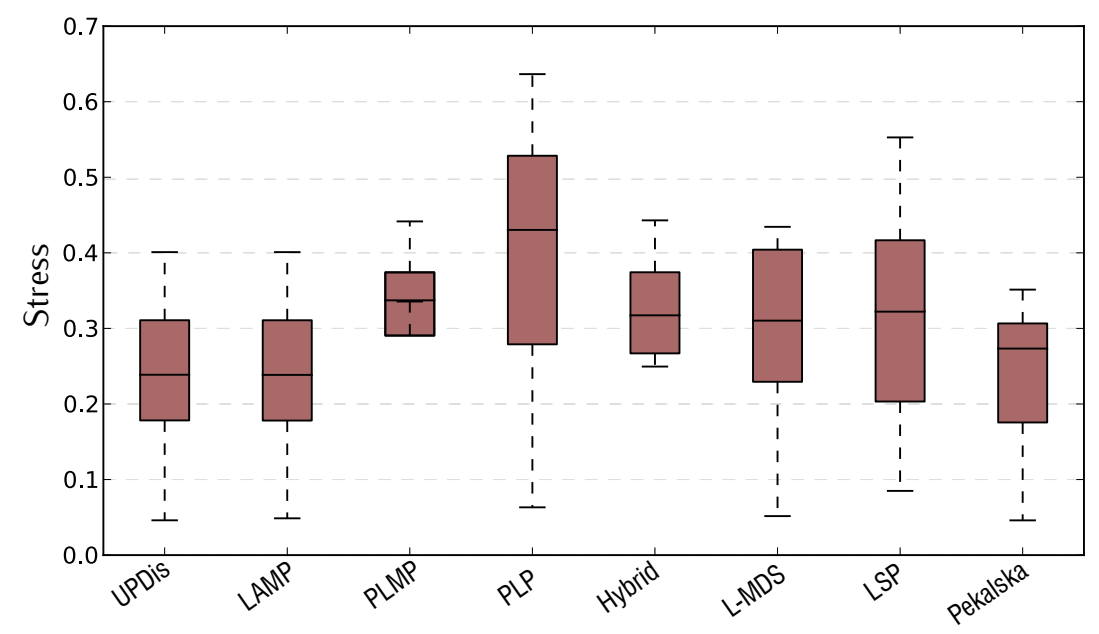

(a) Stress.

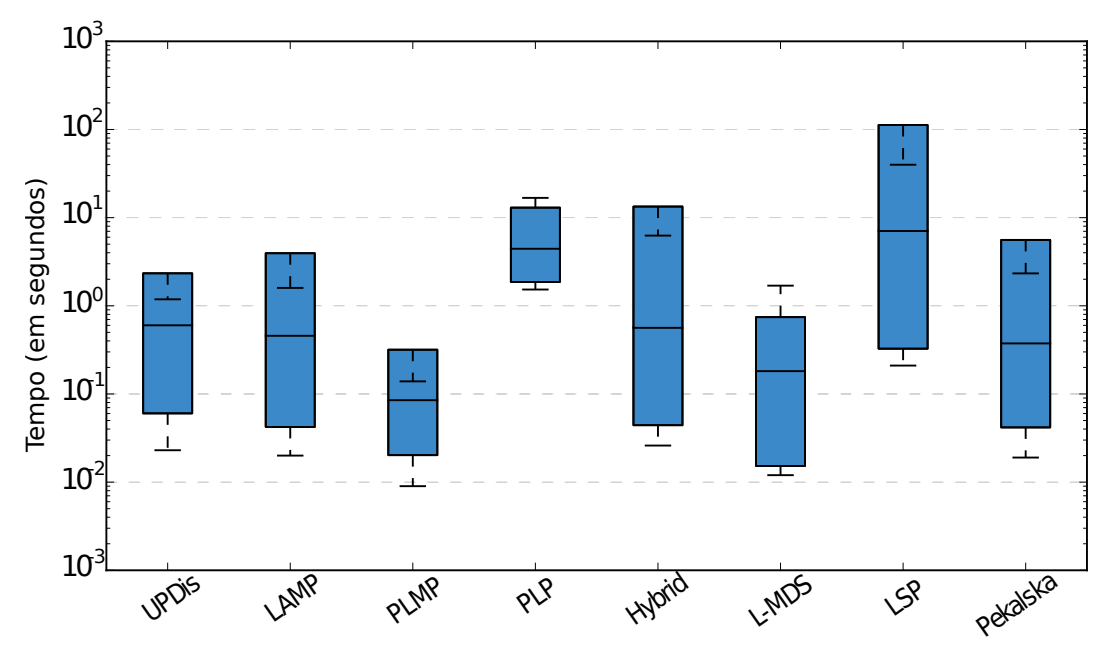

(b) Tempo de execução.

Fonte: Elaborada pelo autor.

\subsubsection{Manipulação realizada pelo usuário}

Como já foi discutido, a técnica UPDis, inicialmente, projeta para o espaço visual algumas amostras representativas. Então, baseada nessa geometria inicial, mapeia o restante das instâncias de dados para o espaço 2-dimensional utilizando uma estratégia de interpolação (como ilustrado na Figura 2). Assim, o posicionamento das amostras representativas pode ser utilizado para controlar a geometria da projeção final. Uma aplicação interessante é permitir a um usuário adicionar conhecimento ao processo de projeção por meio da manipulação do posicionamento das amostras, alterando os relacionamentos de distância de acordo com o seu ponto de vista.

Nos próximos testes, busca-se demonstrar a efetividade da manipulação realizada pelo usuário para controlar o layout da projeção final. A ideia é compor ou melhorar grupos de 
Figura 6 - Gráfico de dispersão entre as distâncias no espaço original e as distâncias no espaço projetado. Números nos cantos superiores esquerdos em cada gráfico de dispersão correspondem ao stress e ao tempo computacional (em segundos).

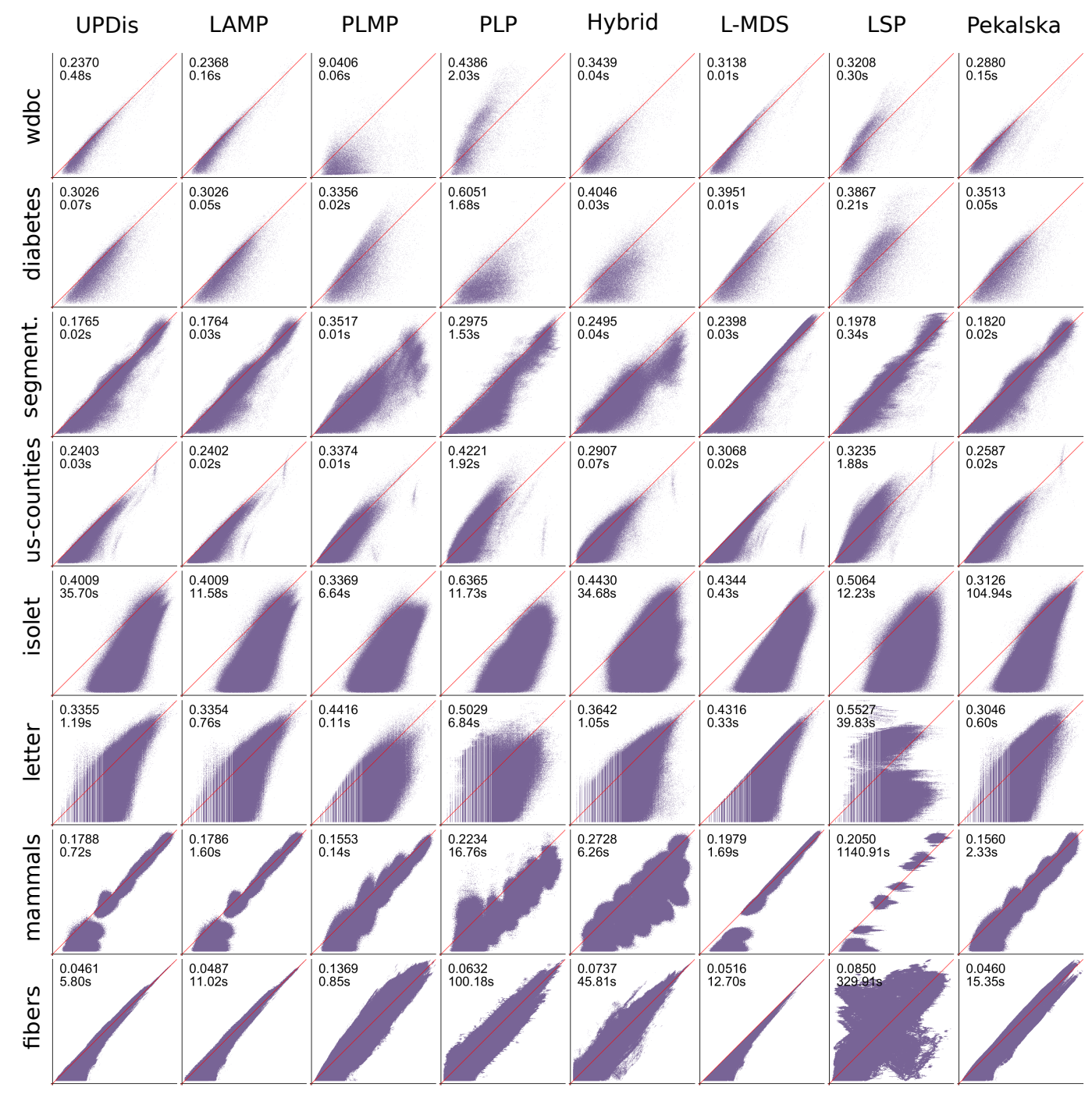

Fonte: Elaborada pelo autor.

instâncias no layout inicial das amostras representativas e medir o grau de preservação desses grupos no layout final. Para realizar essa medida, o coeficiente de silhueta (TAN; STEINBACH; KUMAR, 2005) foi utilizado. O coeficiente de silhueta mede a coesão e a separação entre instâncias agrupadas. Matematicamente, a coesão $a_{\mathbf{x}}$ de $\mathbf{x}$ é calculada como a média das distâncias entre $\mathbf{x}$ e todas as outras instâncias que pertencem ao mesmo grupo de $\mathbf{x}$. A separação $b_{\mathbf{x}}$ é a distância mínima entre $\mathbf{x}$ e todas as outras instâncias pertencentes a outros grupos. $\mathrm{O}$ coeficiente de silhueta é dado por

$$
\frac{1}{n} \sum_{\mathbf{x} \in \mathbf{X}} \frac{\left(b_{\mathbf{x}}-a_{\mathbf{x}}\right)}{\max \left(a_{\mathbf{x}}, b_{\mathbf{x}}\right)}
$$

na qual $n$ é o número de instâncias. O resultado fica no intervalo $[-1,1]$ e valores altos significam melhor coesão e separação. 
A Figura 7 apresenta um exemplo da manipulação do usuário. Essas imagens são projeções do conjunto de dados segmentation. A Figura 7a ilustra a projeção das amostras representativas obtida por meio de uma abordagem baseada em forças sem intervenção do usuário. A Figura $7 \mathrm{c}$ ilustra a projeção final produzida considerando esse posicionamento inicial. $\mathrm{O}$ posicionamento final obedece a geometria inicial, sem uma boa separação entre grupos de instâncias (as cores indicam os grupos). O usuário é livre para manipular o layout inicial, agrupando as instâncias para melhor refletir seu ponto de vista. Uma possível manipulação da projeção inicial das amostras (Figura 7a) é apresentada na Figura 7b. Neste novo layout, as instâncias são melhor agrupadas de acordo com o grupo ao qual pertencem. A projeção final baseada nessa geometria é ilustrada na Figura 7d. Na projeção final alcançada há uma melhor separação entre os grupos, indicando a efetividade da manipulação realizada pelo usuário. Isso é confirmado pelo coeficiente de silhueta. Considerando o posicionamento inicial, produzido pela abordagem baseada em forças, o coeficiente de silhueta obteve um valor de 0.1426 , o qual foi elevado para 0.4434 quando o posicionamento foi alterado pelo usuário, definindo melhor os grupos. Para fins de comparação, os mapeamentos iniciais foram utilizados como entradas para duas outras técnicas assistidas, LSP e PLMP. Quando comparada com a PLMP, a UPDis alcança uma maior elevação no coeficiente de silhueta, indicando uma superioridade na efeutividade da manipulação realizada pelo usuário. A LSP alcança bons resultados, assim como a UPDis, entretanto, necessita de um poder computacional muito maior devido a sua complexidade, o que impede o seu uso em cenários envolvendo conjuntos de dados volumosos.

Como observado por Joia et al. (2011), a efetividade da manipulação pode ser melhorada restringindo a transformação afim (ver Seção 3.2.2) a pequenas partes do espaço original. Isso é alcançado considerando-se apenas as amostras representativas mais próximas da instância que está sendo projetada na construção de tais transformações na fase de interpolação (utilizando $\delta(\cdot, \cdot)$ como função de dissimilaridade). Como o número de amostras representativas consideradas diminui, a transformação afim torna-se mais local e a manipulação da projeção inicial torna-se mais efetiva, melhorando o resultado do coeficiente de silhueta. A Figura 8 apresenta o resultado da utilização de 75\%,50\%,25\%, e 10\% das amostra representativas mais próximas para construir a transformação afim. A coluna da esquerda contém as projeções produzidas pela técnica UPDis e a coluna da direita contém as projeções obtidas por meio da abordagem original da LAMP. Nestes exemplos, a projeção inicial das amostras representativas é a mesma apresentada pela Figura 7b. A separação entre os grupos melhora bastante quando o número de amostras representativas diminui, o que pode ser confirmado pelos valores do coeficiente de silhueta. Adicionalmente, os resultados produzidos pela técnica UPDis são muito similares àqueles produzidos pela LAMP, indicando que a UPDis é uma boa aproximação da técnica original.

Em termos de preservação de vizinhança, isto é, a porcentagem de vizinhos mais próximos no espaço original que permanecem como vizinhos mais próximos no espaço visual (ver Seção 2.4), a possibilidade de tornar a UPDis mais local não afeta de forma negativa os resultados obtidos. A Figura 9 apresenta a preservação de vizinhança (considerando os 5 vizinhos 
mais próximos) obtidos variando-se o percentual de amostras representativas que são utilizadas para computar a transformação afim. Para a maioria dos conjuntos de dados, $20 \%$ das amostras representativas é suficiente para definir o valor máximo possível da preservação de vizinhança. Portanto, as pequenas vizinhanças são preservadas mesmo que poucas amostras representativas sejam consideradas. Isso indica que a manipulação realizada pelo usuário pode melhorar a separação dos grupos sem distorcer ou prejudicar as estruturas locais de vizinhança.

Essa análise indica que a manipulação do posicionamento das amostras representativas é efetiva, permitindo ao usuário incorporar o seu conhecimento ao processo de projeção sem afetar de forma negativa os layouts produzidos. Além disso, a possibilidade de utilizar a informação de distância como entrada, uma propriedade que não está presente na técnica original, possibilita a exploração de novos domínios que podem se beneficiar de técnicas de projeção centradas no usuário baseadas em distância.

\subsection{Considerações finais}

Neste capítulo uma nova técnica chamada de User-assisted Projection Technique for Distance Information (UPDis) foi apresentada, a qual mostrou-se bastante efetiva para a produção de layouts utilizando informação de dissimilaridade. A UPDis é uma adaptação de uma técnica existente (LAMP) que mantém as propriedades interessantes dessa técnica, como a sólida fundamentação matemática e a possibilidade de intervenção do usuário no processo de projeção, mas que pode operar utilizando apenas informação de dissimilaridade, o que não era realizado pela técnica original. As comparações fornecidas mostram que a UPDis está no mesmo nível das técnicas estado-da-arte, mas pode lidar com domínios de aplicação até então não cobertos pelos métodos assistidos pelo usuário. 
Figura 7 - Efetividade da manipulação realizada pelo usuário. Os posicionamentos iniciais ((a) e (b)) guiam a geometria final das projeções produzidas por dierentes técnicas ((b), (c), (d), (f), (g) e (h)). A efetividade da intervenção do usuário transmitida pela técnica UPDis é confirmada pelos coeficientes de silhueta obtidos, resultando em grupos mais compactos que seguem os grupos compostos pela manipulação.

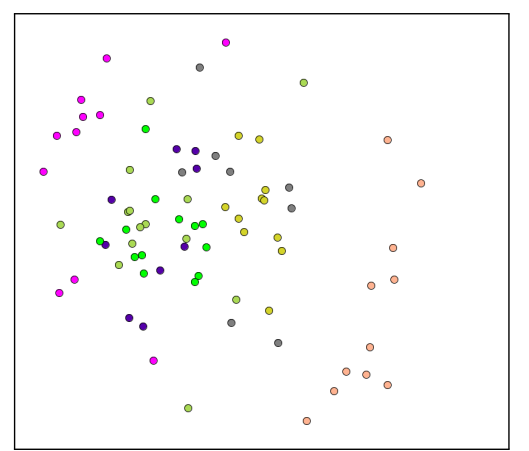

(a) Posicionamento inicial por abordagem baseada em forças.

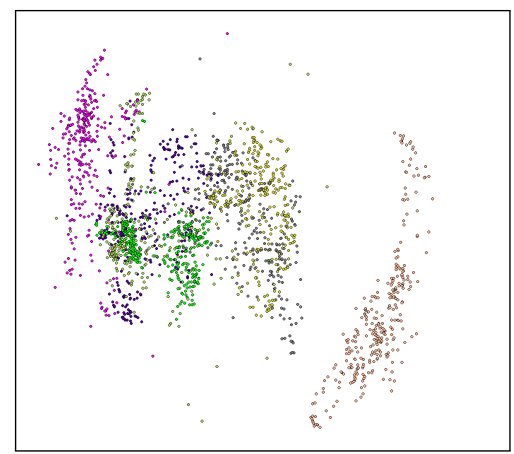

(c) Projeção final de (a) pela UPDis (silh. $=0.1426)$

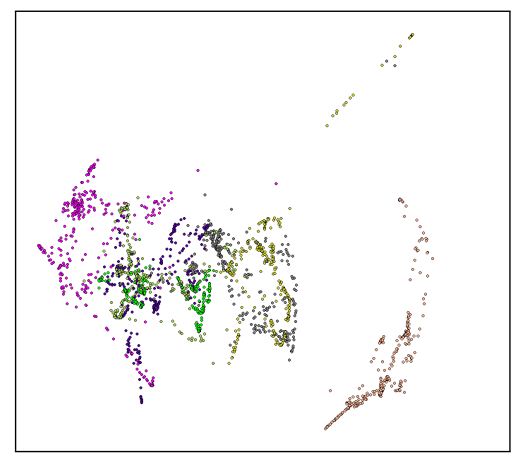

(e) Projeção final de (a) pela LSP $($ silh. $=0.1253)$

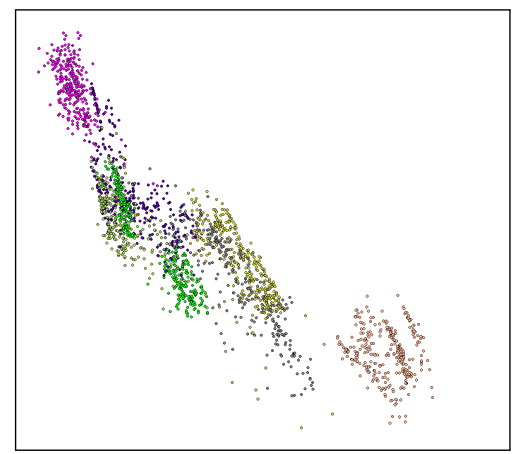

(g) Projeção final de (a) pela PLMP $($ silh.$=0.2073)$

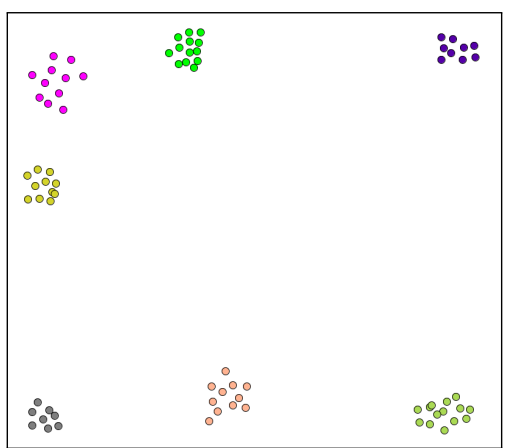

(b) Posicionamento inicial fornecido pelo usuário.

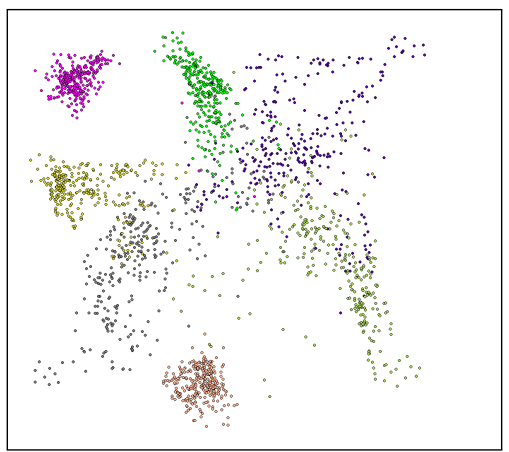

(d) Projeção final de (b) pela UPDis (silh. $=0.4434$ ).

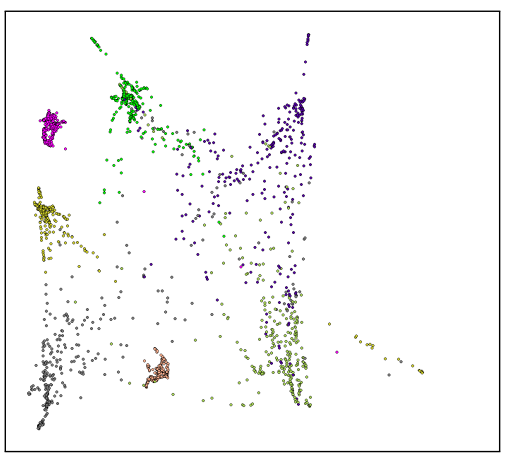

(f) Projeção final de (b) pela LSP $($ silh.$=0.4410)$.

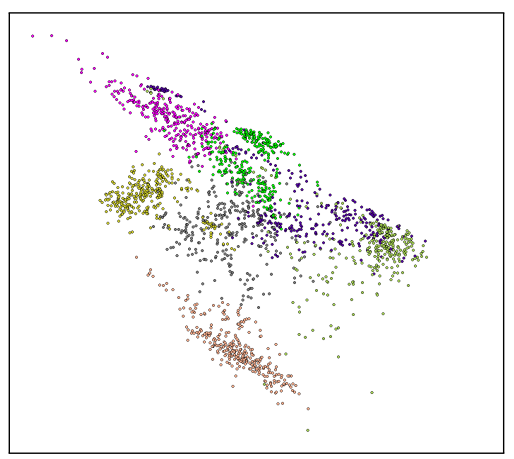

(h) Projeção final de (b) pela PLMP (silh. $=0.2730)$.

Fonte: Elaborada pelo autor. 
Figura 8 - Projeções produzidas pela UPDis e pela LAMP variando a porcentagem de amostras representativas mais próximas utilizadas para construir o mapeamento. A medida que o número de amostras diminui, a transformação se torna mais local e a efetividade da manipulação realizada pelo usuário se torna mais evidente.

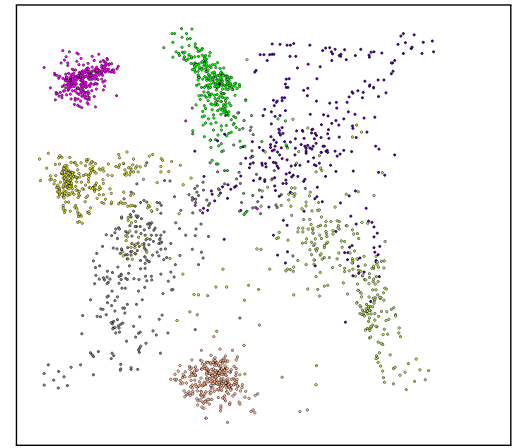

(a) UPDis $75 \%($ silh. $=0.4468)$

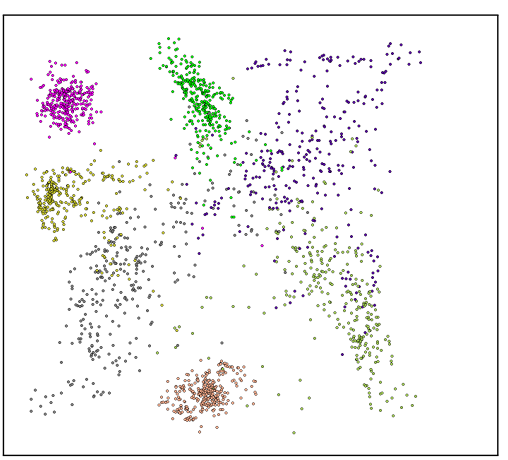

(c) UPDis $50 \%($ silh. $=0.4370)$

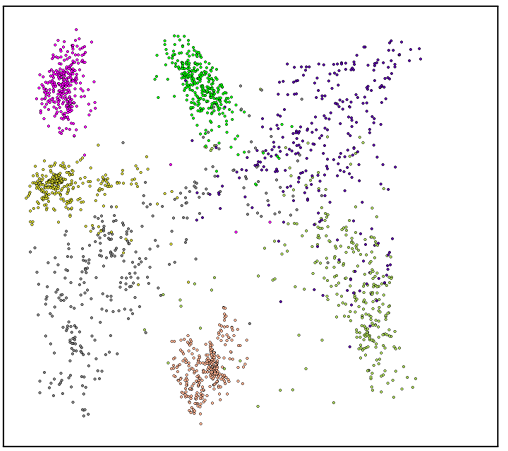

(e) UPDis $25 \%($ silh. $=0.4554)$

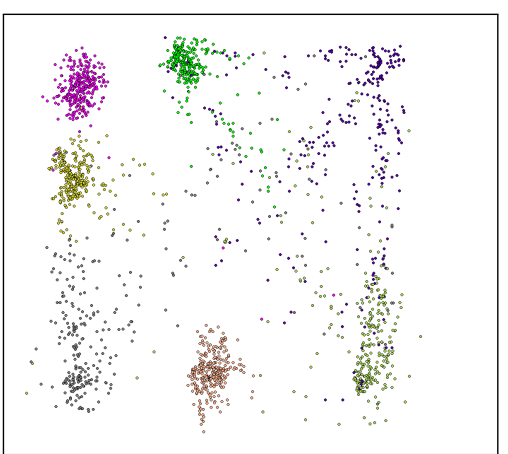

(g) UPDis 5\% (silh. $=0.4896)$

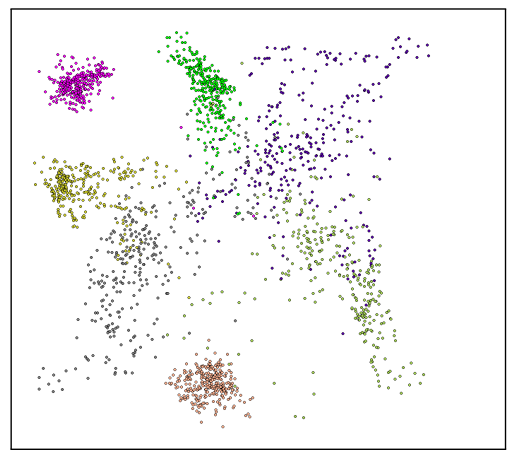

(b) LAMP $75 \%($ silh. $=0.4485)$

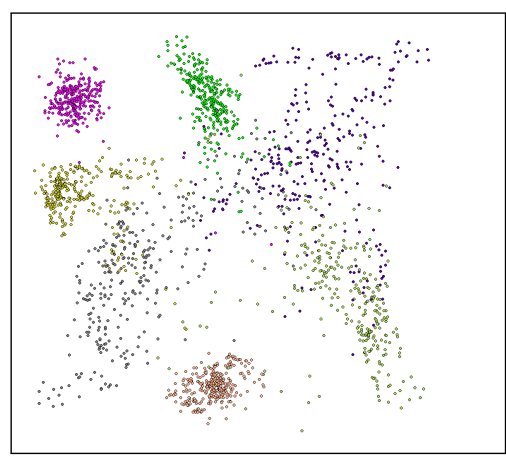

(d) LAMP 50\% (silh. $=0.4382)$

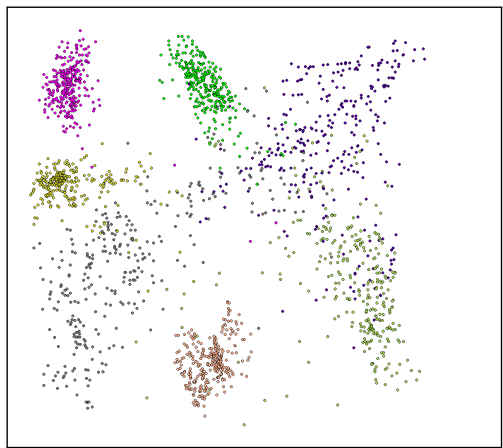

(f) LAMP $25 \%($ silh. $=0.4556)$

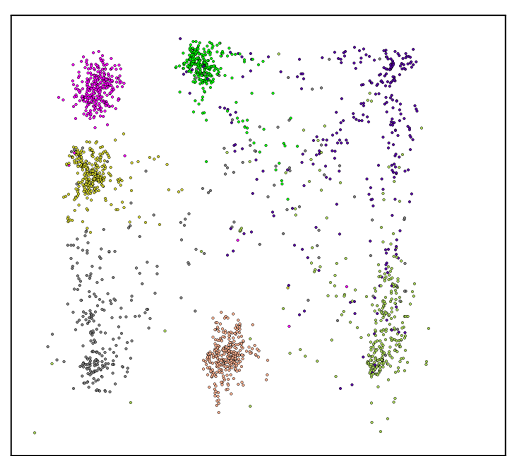

(h) LAMP 5\% $($ silh. $=0.4904)$

Fonte: Elaborada pelo autor. 
Figura 9 - Preservação de vizinhança vs. porcentagem de vizinhos mais próximos utilizados para construir os mapeamentos afins. Poucas amostras representativas alcançam uma boa preservação, indicando que a melhora trazida pela manipulação realizada pelo usuário não afeta negativamente a estrutura local de vizinhança.

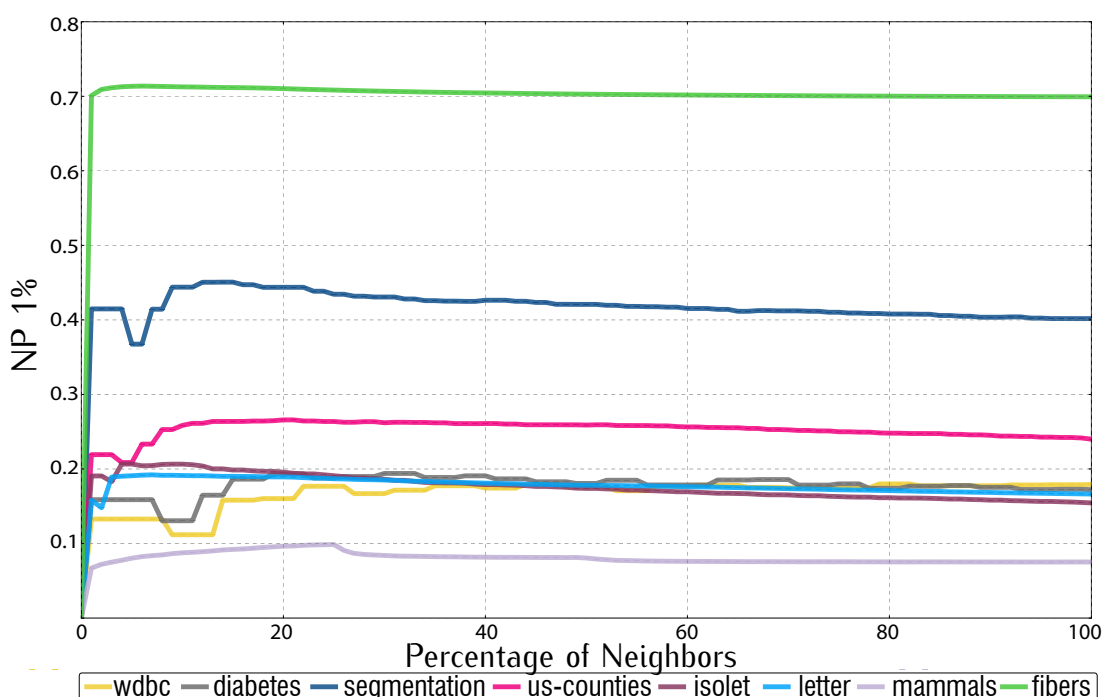

Fonte: Elaborada pelo autor. 
CAPÍTULO

\section{4}

\section{VISUALIZAÇÃO DE FLUXOS DE DADOS POR MEIO DE PROJEÇÕES MULTIDIMENSIONAIS}

\subsection{Considerações iniciais}

Fluxos de dados diferem de outros tipos de dados tradicionalmente considerados no processo de análise exploratória. Nos métodos tradicionais, o conjunto completo de dados está disponível para os algoritmos de análise. Porém, um desafio atual é o desenvolvimento de algoritmos que atuem em ambientes dinâmicos, nos quais os dados são coletados de forma contínua (GUHA et al., 2003; GAMA et al., 2010).

Soluções para os novos desafios impostos por esse tipo de conjuntos de dados requerem novas técnicas, como novas abordagens de amostragem ou algoritmos de mapeamento que sejam incrementais. Segundo Gama et al. (2010), a descoberta de conhecimento a partir de fluxos de dados deve levar em consideração alguns fatores como:

- Os algoritmos terão recursos computacionais limitados, em termos de poder computacional, memória e tempo de processamento;

- Os algoritmos terão acesso direto limitado aos dados;

- As respostas devem ser produzidas em tempo real;

- A aquisição dos dados e seu processamento devem ser distribuídos.

Existem dois tipos de fenômenos cuja representação por fluxos de dados é mais adequada (GUHA et al., 2003). Em um deles, a principal característica é o grande volume de dados, 
os quais são armazenados em memórias secundárias, caracterizadas por baixa taxa de transferência. Bases de dados médicos (DAURA et al., 1998) e socioeconômicas (AGGARWAL et al., 2003) são exemplos desse primeiro tipo. No outro tipo, os dados são coletados em altas taxas e quantidades, o que impossibilita seu armazenamento e exige seu descarte após processamento. Como exemplos desse segundo caso, pode-se citar aplicações de detecção de intrusão em redes de computadores (AGGARWAL et al., 2003) e registros de chamadas telefônicas (CORTES; PREGIBON, 2001).

Esses dois tipos diferentes de fluxo de dados caracterizam um cenário de processamento chamado de cenário streaming, que exige um processamento incremental, no qual os dados devem ser processados à medida que são produzidos ou recebidos, diferente das aplicações estáticas tradicionais, nas quais os dados são armazenados primeiro em tabelas para depois serem processados. Isto traz novos desafios para o desenvolvimento de tecnologias e ferramentas a fim de permitir a análise e interpretação das informações contidas na quantidade de dados que é capturada ou produzida (GAMA, 2012).

Atualmente, a maioria das técnicas e aplicações de visualização são baseadas no processamento de dados armazenados em tabelas e não podem ser diretamente aplicadas sobre fluxos de dados. Entre elas estão as técnicas de projeção multidimensional (ver Capítulo 2). Projeções multidimensionais têm recebido atenção especial nos últimos anos e estão se tornando uma ferramenta fundamental na maioria dos sistemas de visualização devido à sua capacidade de lidar com grandes conjuntos de dados de elevada dimensionalidade (JOIA et al., 2011), produzindo layouts nos quais as distâncias e os padrões de vizinhança são "visíveis". O problema de tais técnicas reside na necessidade que essas tem dos dados estarem disponíveis em memória principal ou, caso isso não seja possível, precisarem de múltiplos acessos em memória secundária, o que é computacionalmente caro ou mesmo inviável em cenários de fluxo de dados.

Nesse capítulo é apresentada mais do que apenas uma técnica de projeção, é apresentado um novo modelo de projeção voltado a fluxos de dados, chamado de Xtreaming. A principal contribuição é o desenvolvimento de estratégias diferentes as quais permitem a projeção dos dados à medida que esses são recebidos, adaptando o layout visual para refletir as novas estruturas que surgem ao longo do tempo.

\subsection{Descrição da técnica}

Considerando que o conjunto de dados $\mathbf{X}$ é dividido em $k$ partições não sobrepostas, i.e., $\mathbf{X}=\mathbf{X}_{1} \cup \mathbf{X}_{2} \cup \ldots \cup \mathbf{X}_{k}$ com $\mathbf{X}_{i} \cap \mathbf{X}_{j}=\emptyset, \forall \mathbf{X}_{i}, \mathbf{X}_{j} \subset \mathbf{X}$, a abordagem Xtreaming busca criar funções de projeção que são capazes de mapear de forma subsequente as partições fazendo com que a união de todas as projeções se aproxime da projeção do conjunto inteiro de dados. Ou seja, $f^{1}\left(\mathbf{X}_{1}\right) \cup f^{2}\left(\mathbf{X}_{2}\right) \cup \ldots \cup f^{k}\left(\mathbf{X}_{k}\right) \approx f\left(\mathbf{X}_{1} \cup \mathbf{X}_{1} \cup \ldots \cup \mathbf{X}_{k}\right)$, onde $f^{i}$ representa a função empregada para projetar $\mathbf{X}_{i}$. 
Isso é realizado criando-se uma nova função de projeção $f^{r}$ para mapear $\mathbf{X}_{r}$, adaptando-se a projeção $\mathbf{Y}_{[1 \ldots r-1]}=\mathbf{Y}_{1} \cup \mathbf{Y}_{2} \cup \ldots \cup \mathbf{Y}_{r-1}$ das partições anteriores para $f^{r}$. Em outras palavras, quando $\mathbf{X}_{r}$ é processado, a projeção alcançada é obtida por meio de

$$
\mathbf{Y}_{[1 \ldots r]}=f^{r}\left(\mathbf{X}_{1} \cup \mathbf{X}_{2} \cup \ldots \cup \mathbf{X}_{r-1}\right) \cup f^{r}\left(\mathbf{X}_{r}\right)
$$

Em um cenário de fluxo de dados, no qual armazenar todos os dados em memória principal é inviável, as partições $\mathbf{X}_{1}, \mathbf{X}_{2}, \ldots, \mathbf{X}_{r-1}$ não estão disponíveis no momento da projeção de $\mathbf{X}_{r}$, apenas as projeções $\mathbf{Y}_{[1 \ldots r]}$ estão. Assim, $f^{k}\left(\mathbf{X}_{1} \cup \mathbf{X}_{2} \cup \ldots \cup \mathbf{X}_{k-1}\right)$ não pode ser realizada e alguma estratégia precisa ser utilizada para realizar a projeção. A Figura 10 ilustra a visão geral do modelo de projeção desenvolvido para lidar com fluxos de dados. Quando uma nova partição de dados $\mathbf{X}_{r}$ é recebida, primeiro uma verificação é realizada para identificar se a nova partição é diferente das partições anteriores em termos de distribuição dos dados. Se nenhuma mudança é detectada, a nova partição é simplesmente projetada utilizando a função de projeção atual $\left(f^{r}=f^{r-1}\right)$. Por outro lado, se houver uma detecção de mudança, a função de projeção é reconstruída, a nova partição é projetada utilizando a nova função de projeção e as partições anteriores são re-projetadas de forma a considerar essa nova função. A seguir são descritos cada um desses passos de forma mais detalhada.

Figura 10 - Visão geral da técnica Xtreaming.

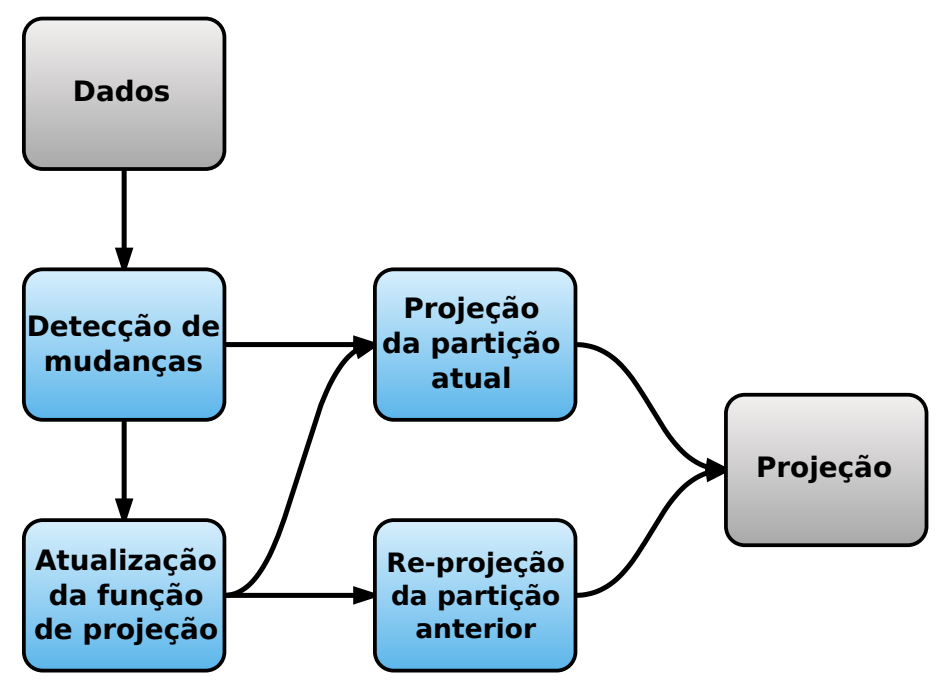

Fonte: Elaborada pelo autor.

\subsubsection{Construindo a função de projeção}

Para obter a projeção $Y^{r}=f^{r}\left(X_{r}\right)$, a função $f^{r}$ precisa atender a alguns requisitos. Deve ser rápida e precisa, de modo que o tempo de execução e a qualidade dos mapeamentos produzidos não sejam prejudicadas. Além disso, ela precisa ser baseada em uma estratégia conhecida como out-of-sample (ver Seção 2.1). Técnicas out-of-sample basicamente constroem 
a função de projeção considerando apenas uma pequena amostra dos dados e seu mapeamento para o espaço visual, em vez de usar todo o conjunto de dados. Esta estratégia pode ser vista como um processo de amostragem e interpolação, no qual a projeção da amostra conduz a geometria da projeção final. Na abordagem da Xtreaming, uma técnica out-of-sample é obrigatória uma vez que para a re-projeção das partições anteriormente projetadas, ou seja, para executar $f^{r}\left(\mathbf{X}_{1} \cup \mathbf{X}_{2} \cup \ldots \cup \mathbf{X}_{r-1}\right)$, informações sobre essas partições são necessárias e num cenário streaming apenas pequenas partes dos dados podem ser armazenadas.

Como consequência, a fim de manter a coerência entre as diferentes partições durante o processo de projeção, a amostra deve conter informações sobre todas as partições já projetadas e também sobre a partição atual, tentando representar o máximo possível da distribuição dos dados conhecidos até o momento. Deste modo, se $\overline{\mathbf{X}}_{j}=\left\{\overline{\mathbf{x}}_{j_{1}}, \overline{\mathbf{x}}_{j_{2}}, \ldots \overline{\mathbf{x}}_{j_{w_{j}}}\right\}$ representa $w_{j}$ amostras selecionadas da partição $\mathbf{X}_{j}$, ao criar $f^{r}$, a amostra será formada por $\overline{\mathbf{X}}_{[1 \ldots r]}=\overline{\mathbf{X}}_{1} \cup \overline{\mathbf{X}}_{2} \cup \ldots \cup$ $\overline{\mathbf{X}}_{r-1} \cup \overline{\mathbf{X}}_{r}$.

Finalmente, como último requisito, a função de projeção deve receber como entrada apenas informações de dissimilaridade, ou seja, quando estiver projetando $\mathbf{x}_{i}$ a única informação necessária é a distância entre $\mathbf{x}_{i}$ e as amostras, uma vez que as coordenadas das instâncias em $\mathbb{R}^{m}$ não estão mais disponíveis para as partições já projetadas. Esta última restrição é imposta pela fase de re-projeção, a qual será discutida na próxima seção.

Atualmente, algumas técnicas podem cumprir tais requisitos, como, por exemplo, a aproximação Pekalska (PEKALSKA et al., 1999) e a técnica UPDis (ver Capítulo 3). A Figura 11 apresenta o resultado comparando essas aboradgens em termos de preservação de distância. Esse experimento foi realizado utilizando as bases descritas na Tabela 2 e o coeficiente de stress (ver Seção 2.4). Novamente, para cada base foram geradas 30 projeções por abordagem, Pekalska e UPDis. Neste trabalho foi utilizada a técnica UPDis, já que os resultados em termos de precisão foram bastante satisfatórios, mas qualquer outra técnica que obedecer a essas restrições pode ser utilizada.

\subsubsection{Re-projeção}

Toda vez que uma nova partição $\mathbf{X}_{r}$ é projetada, a projeção das partições anteriores $\mathbf{X}_{1}, \mathbf{X}_{2}, \ldots, \mathbf{X}_{r-1}$ precisa ser atualizada conforme a nova função de projeção $f^{r}$. Portanto, de acordo com o requisito acima mencionado, para projetar uma instância $\mathbf{x}_{i} \in \mathbf{X}_{r}$ é necessário calcular o conjunto de distâncias $\delta_{\mathbf{x}_{i}}=\left\{\boldsymbol{\delta}\left(\mathbf{x}_{i}, \overline{\mathbf{x}}_{1}\right), \boldsymbol{\delta}\left(\mathbf{x}_{i}, \overline{\mathbf{x}}_{2}\right), \ldots, \boldsymbol{\delta}\left(\mathbf{x}_{i}, \overline{\mathbf{x}}_{w}\right)\right\}, w=\sum w_{j}$, entre $\mathbf{x}_{i}$ e

as amostras $\overline{\mathbf{x}}_{j} \in \overline{\mathbf{X}}_{[1 \ldots k]}$. O problema é que, uma vez que apenas os dados das amostras podem ser armazenados, este conjunto de distâncias não pode ser completamente calculado, pois as distâncias entre as instâncias já projetadas e as instâncias da amostra não podem ser diretamente calculadas.

Uma estratégia simples, porém muito eficiente, foi adotada para lidar com esse desafio. 
Figura 11 - Comparação de stress alterando a técnica de mapeamento que constrói a função de projeção: Pekalska e UPDis.

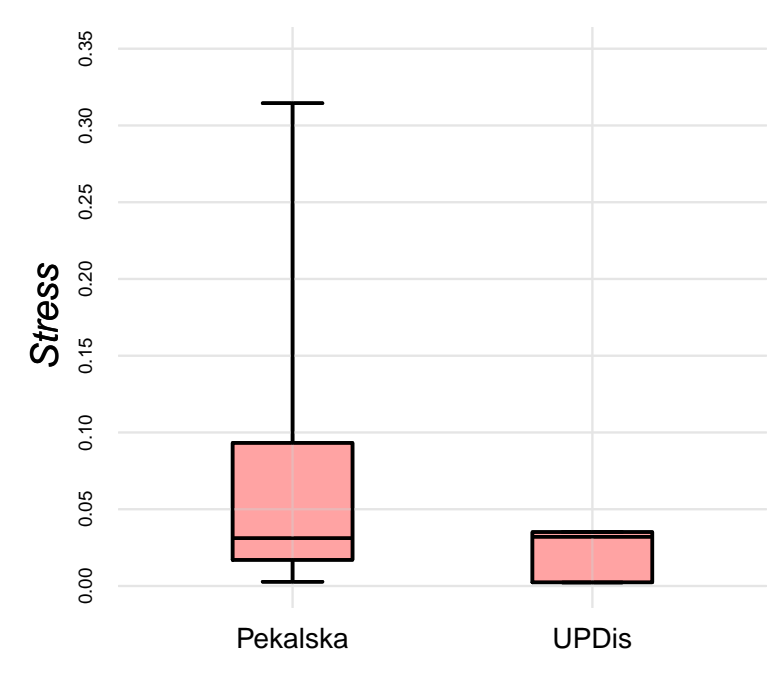

Fonte: Elaborada pelo autor.

Considerando que a função de projeção é precisa em termos de preservação distância (primeiro requisito), as distâncias entre as instâncias $\mathbf{X}_{1}, \mathbf{X}_{2}, \ldots, \mathbf{X}_{r-1}$ e as amostras $\overline{\mathbf{X}}_{[1 \ldots r-1]}$ podem ser aproximadas por meio da substituição de $\delta\left(\mathbf{x}_{i}, \mathbf{x}_{j}\right)$ por $d\left(\mathbf{y}_{i}, \mathbf{y}_{j}\right), \forall \mathbf{x}_{i}, \mathbf{x}_{j} \in \mathbf{X}_{[1 \ldots r-1]}$, e essa informação pode ser completamente recuperada da projeção $\mathbf{Y}_{[1 \ldots r-1]}$. Assim, a única informação que está faltando é a distância entre as amostras $\overline{\mathbf{X}}_{r}$ selecionadas a partir da nova partição $\mathbf{X}_{r}$ e as instâncias já projetadas.

A fim de calcular tais distâncias, as amostras $\overline{\mathbf{X}}_{r}$ são projetadas utilizando a função de projeção anterior $f^{r-1}$ e essa projeção é utilizada para calcular as distâncias. Uma vez que $\overline{\mathbf{X}}_{r}$ é muito menor do que a partição $\mathbf{X}_{r}$, isso não afeta o tempo de execução da abordagem Xtreaming de forma significativa. Com base nisso, o conjunto $\delta_{\mathbf{x}_{i}}$ é, então, substituído por $d_{\mathbf{y}_{i}}=\left\{d\left(\mathbf{y}_{i}, \overline{\mathbf{y}}_{1}\right), d\left(\mathbf{y}_{i}, \overline{\mathbf{y}}_{2}\right), \ldots, d\left(\mathbf{y}_{i}, \overline{\mathbf{y}}_{w}\right)\right\}$ ao re-projetar as instâncias das partições anteriores $\mathbf{X}_{1}, \mathbf{X}_{2}, \ldots, \mathbf{X}_{r-1}$ usando $f^{r}$ (segundo e terceiro requisitos). A Figura 12 ilustra esse processo de re-projeção das instâncias antigas para corresponder a nova função de projeção $f^{r}$.

Um problema que pode surgir nesse modelo de re-projeção é a incoerência temporal, que é caracterizada pela mudança no posicionamento dos pontos entre projeções subsequentes. Como solução para este problema, sempre que a projeção das amostras é atualizada utiliza-se a técnica de Procrustes (GOWER; DIJKSTERHUIS, 2004) para aproximar a nova projeção da antiga, tanto quanto possível. Essa técnica busca a obtenção de um posicionamento semelhante entre as projeções por meio da minimização de uma medida de diferença de forma, chamada de distância de Procustes. O resultado é uma matriz de transformação que pode ser aplicada sobre os pontos da nova projeção, realizando a aproximação com a anterior. 
Figura 12 - Ilustração do processo de re-projeção da Xtreaming. Em (a) a amostra $\overline{\mathbf{X}}_{r}$ pela função de projeção anterior $f^{r-1}$. Em seguida, em (b), a projeção $f^{r-1}\left(\overline{\mathbf{X}}_{r}\right)$ é concatenada com a projeção das instâncias do conjunto de amostras passadas e as distâncias dessas amostras para as intâncias passadas pode ser calculada, formando $d_{y_{i}}$. Por fim, utilizando $d_{y_{i}}$ são projetadas as instâncias antigas segundo a nova função de projeção $f^{r}$ assim como são projetadas as instâncias da partição $\mathbf{X}_{r}$ para formar a projeção atual $\mathbf{Y}_{r}$.

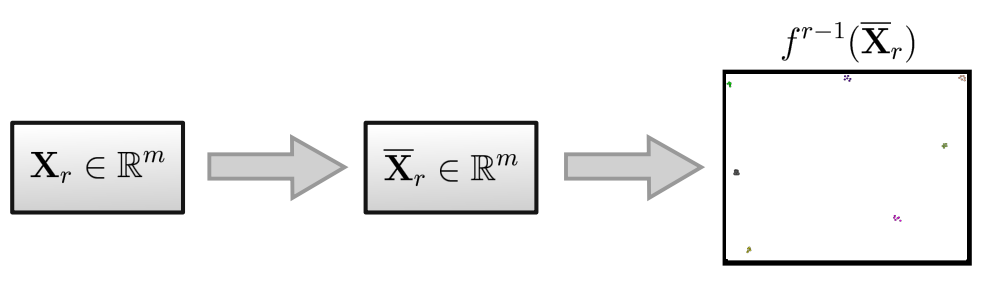

(a) Projeção da amostra $\overline{\mathbf{X}}_{r}$ pela função $f^{r-1}$.

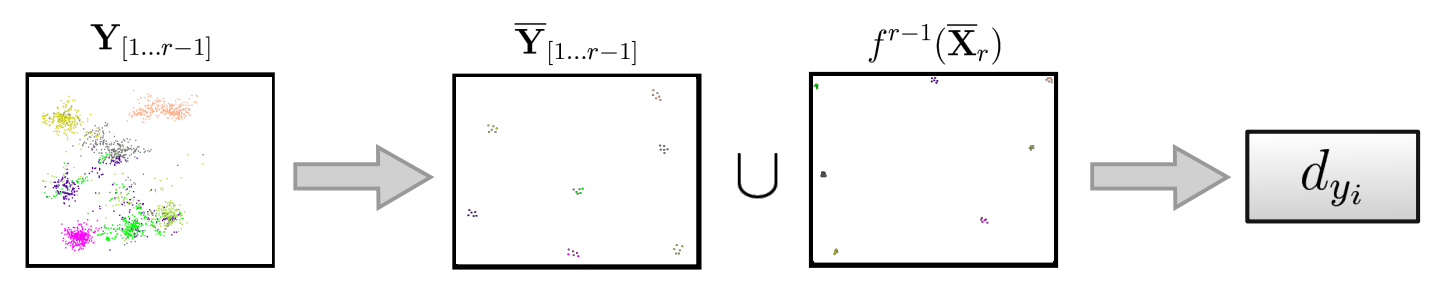

(b) Cálculo das distâncias $d_{\mathbf{y}_{i}}$.

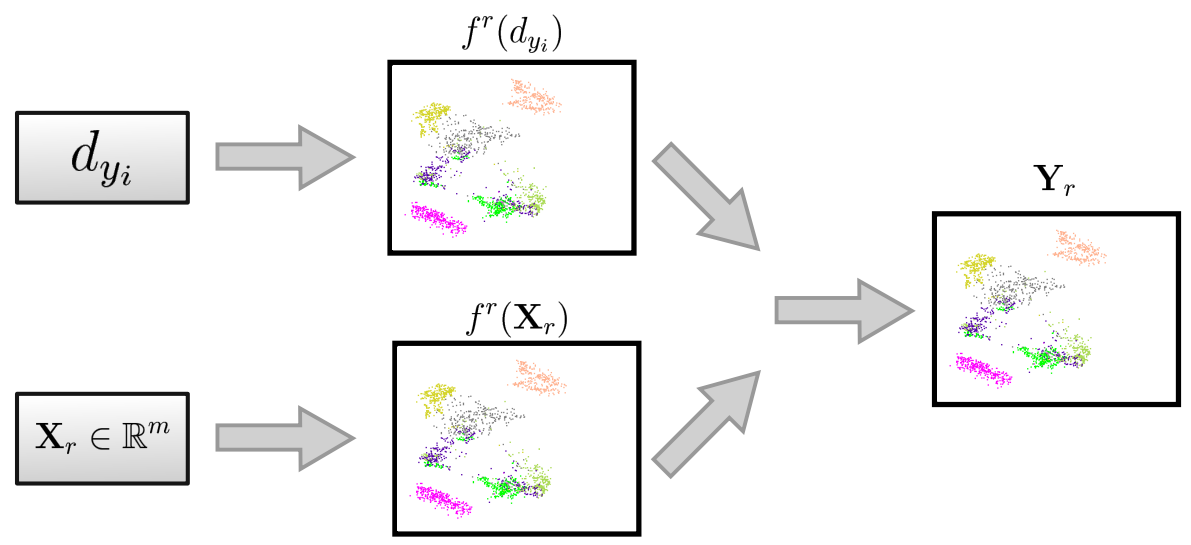

(c) Projeção das instâncias antigas e das instâncias de $\mathbf{X}_{r}$ formando $\mathbf{Y}_{r}$.

Fonte: Elaborada pelo autor. 


\subsubsection{Detecção de mudanças}

Sem perda de generalidade, a abordagem descrita na seção anterior é apresentada como se a função de projeção fosse atualizada sempre que uma nova partição é recebida. Na verdade, ela é atualizada somente se a nova partição contém novas informações, em termos de distribuição dos dados, quando comparada com as partições já processadas. Atualmente, a detecção de mudanças é uma área de pesquisa muito ativa, com diferentes abordagens disponíveis (BASSEVILLE; NIKIFOROV et al., 1993; GUSTAFSSON; GUSTAFSSON, 2000; FARIA; GAMA; CARVALHO, 2013; SÁEZ et al., 2014; BIFET et al., 2011). No modelo de projeção apresentado, entre as diferentes abordagens que foram testadas, o melhor equilíbrio entre tempo de execução e qualidade foi atingido por uma simples estratégia baseada em agrupamento.

Nesta estratégia, quando uma partição $\mathbf{X}_{r}$ é recebida, inicialmente algumas amostras representativas são recuperadas a fim de capturar a sua distribuição. Para fazer isso, uma técnica de agrupamento baseada em distância, chamada de bisecting k-means (STEINBACH; KARYPIS; KUMAR, 2000), é aplicada dividindo $\mathbf{X}_{r}$ em $q$ grupos disjuntos de instâncias similares $\mathbf{X}_{r}=$ $\overline{\mathbf{C}}_{1} \cup \ldots \cup \overline{\mathbf{C}}_{q}$. Então, para cada cluster $\overline{\mathbf{C}}_{i}$ seu medoide $\overline{\mathbf{x}}_{i}^{m}$, que é a instância mais próximo de seu centróide, é selecionado como um representante. Com base em uma heurística comum, empregada pelas técnicas de projeção out-of-sample, o número de grupos é definido por $q=\sqrt{w_{r}}$, na qual $w_{r}$ representa o tamanho de $\mathbf{X}_{r}$, uma vez que esse valor define um bom limite superior para o número de grupos (PAULOVICH et al., 2011; PAULOVICH; SILVA; NONATO, 2010; JOIA et al., 2011).

Após esse processo inicial, cada medoide é testado para verificar se ele deve ser adicionado ao conjunto de amostras $\overline{\mathbf{X}}_{r}$ ou não. A razão é evitar que as instâncias já representadas na amostra atual $\overline{\mathbf{X}}_{[1 \ldots r-1]}$ sejam adicionados ao conjunto de amostras. Sendo cada medoide candidato a ser inserido no conjunto de amostras, esse teste verifica se a instância mais próxima no conjunto de amostras estaria dentro do raio de atuação dessa instância candidata. Se estiver, o medoide já possui uma instância que o representa, caso contrário, o medoide é inserido no conjunto de amostras. Com esse teste, um medoide $\overline{\mathbf{x}}_{i}^{m}$ é adicionado a $\overline{\mathbf{X}}_{r}$ se a seguinte equação for respeitada

$$
\max _{\mathbf{x}_{j} \in \overline{\mathbf{C}}_{i}}\left(\boldsymbol{\delta}\left(\overline{\mathbf{x}}_{i}^{m}, \mathbf{x}_{j}\right)\right)<\min _{\overline{\mathbf{x}}_{k} \in \overline{\mathbf{X}}}\left(\boldsymbol{\delta}\left(\overline{\mathbf{x}}_{i}^{m}, \mathbf{x}_{k}\right)\right)
$$

O lado esquerdo da inequação correspondente ao raio de atuação do medoide candidato e o lado direito correspondente a distância entre esse medoide e a instância mais próxima no conjunto de amostras.

A Figura 13 ilustra o teste de detecção de mudanças da Xtreaming. Após a definição dos medoides da nova partição por meio do algoritmo bisecting $k$-means, sendo representados pelos círculos da cor amarela, encontra-se a instância mais próxima no conjunto de amostras, representados pelos círculos da cor marrom. Na Figura 13a e na Figura 13c ilustra-se a definição da instância do conjunto de amostras mais próxima ao medoide. Na Figura 13b essa instância 
está no raio do grupo do medoide e esse medoide não será inserido no conjunto de amostras. Já na Figura 13d essa instância não está no raio do grupo do medoide e o medoide deve ser inserido no conjunto de amostras.

Figura 13 - Ilustração do teste de detecção de mudanças da Xtreaming. Após a definição dos medoides da nova partição encontra-se a instância mais próxima no conjunto de amostras. Em (b) essa instância está no raio do grupo do medoide e ele não será inserido no conjunto de amostras. Já (d) essa instância não está no raio do grupo do medoide ele deve ser inserido no conjunto de amostras.

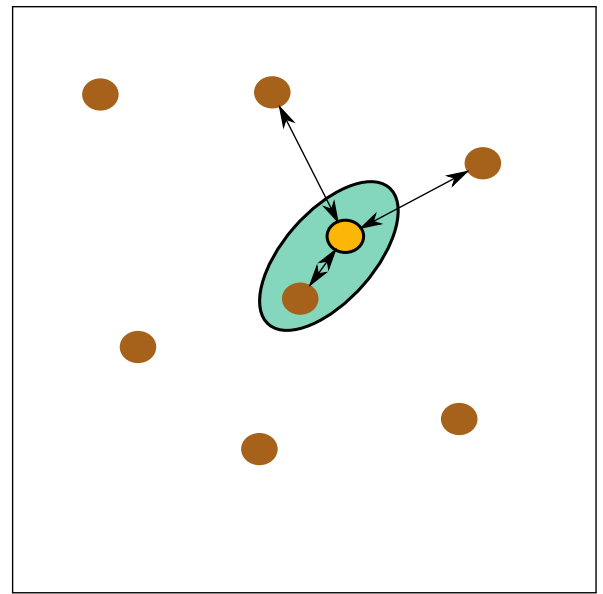

(a) Busca a amostra mais próxima.

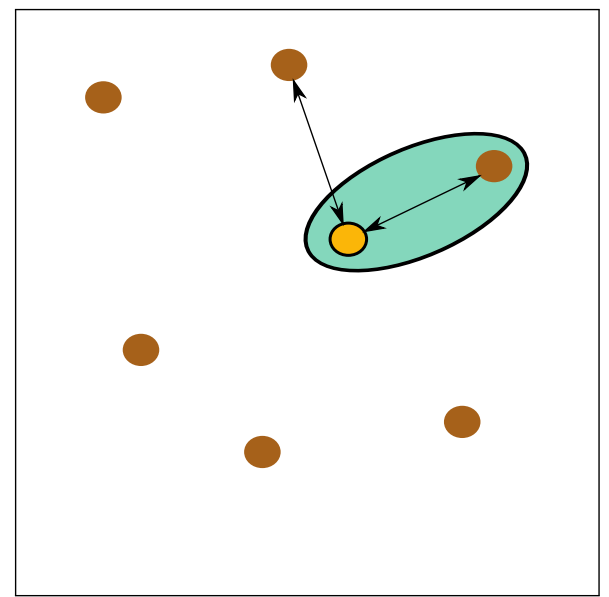

(c) Novamente busca a amostra mais próxima.

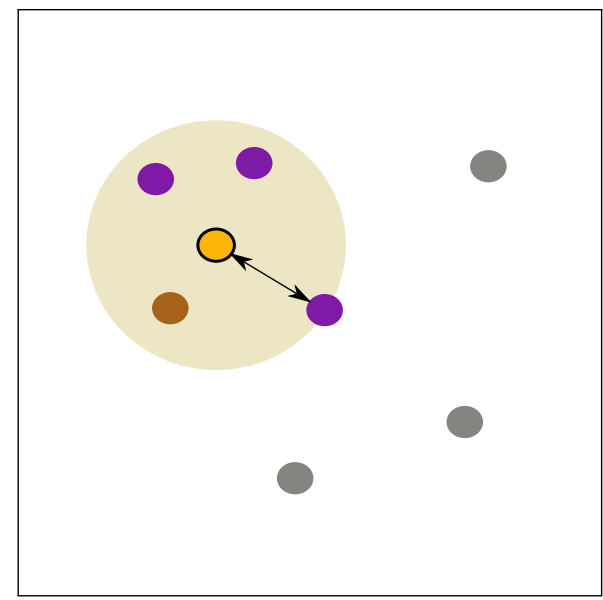

(b) Instância dentro do raio do medoide.

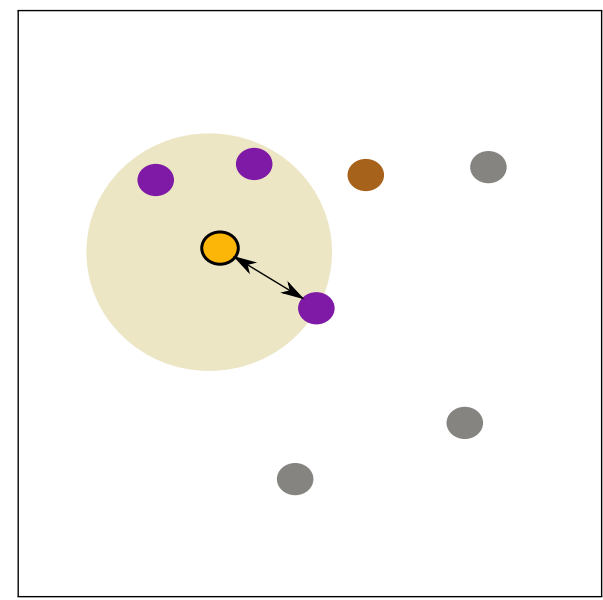

(d) Instância fora do raio do medoide.

Fonte: Elaborada pelo autor.

De acordo com esta equação, $\overline{\mathbf{x}}_{i}^{m}$ é adicionado ao conjunto $\overline{\mathbf{X}}_{r}$ somente se não houver nenhuma instância no conjunto de amostras atual $\overline{\mathbf{X}}$ que esteja dentro do raio do grupo $\overline{\mathbf{C}}_{i}$. Em outras palavras, nenhuma instância do atual conjunto de amostras $\overline{\mathbf{X}}$ seria atribuída ao grupo $\overline{\mathbf{C}}_{i}$ se a técnica de agrupamento fosse aplicada a $\overline{\mathbf{X}}$ considerando os medoides computados e $\overline{\mathbf{x}}_{i}^{m}$ representa uma novidade. Se nenhum medoide for adicionado a $\overline{\mathbf{X}}_{r}$, nenhuma alteração é detectada na nova partição e a função de projeção não é modificada, e $f^{r}=f^{r-1}$.

Todos os passos do modelo de projeção incremental apresentado formam o Algoritmo 2. O primeiro bloco do algoritmo corresponde a detecção de mudanças na distribuição dos dados, 
linhas 6 a 12. Se houver mudança a função de projeção é atualizada, isso corresponde a atualizar a projeção do conjunto de amostras $\overline{\mathbf{X}}$, os pontos antigos são re-projetados e as novas instâncias são projetadas. Caso contrário, apenas as novas instâncias são projetadas.

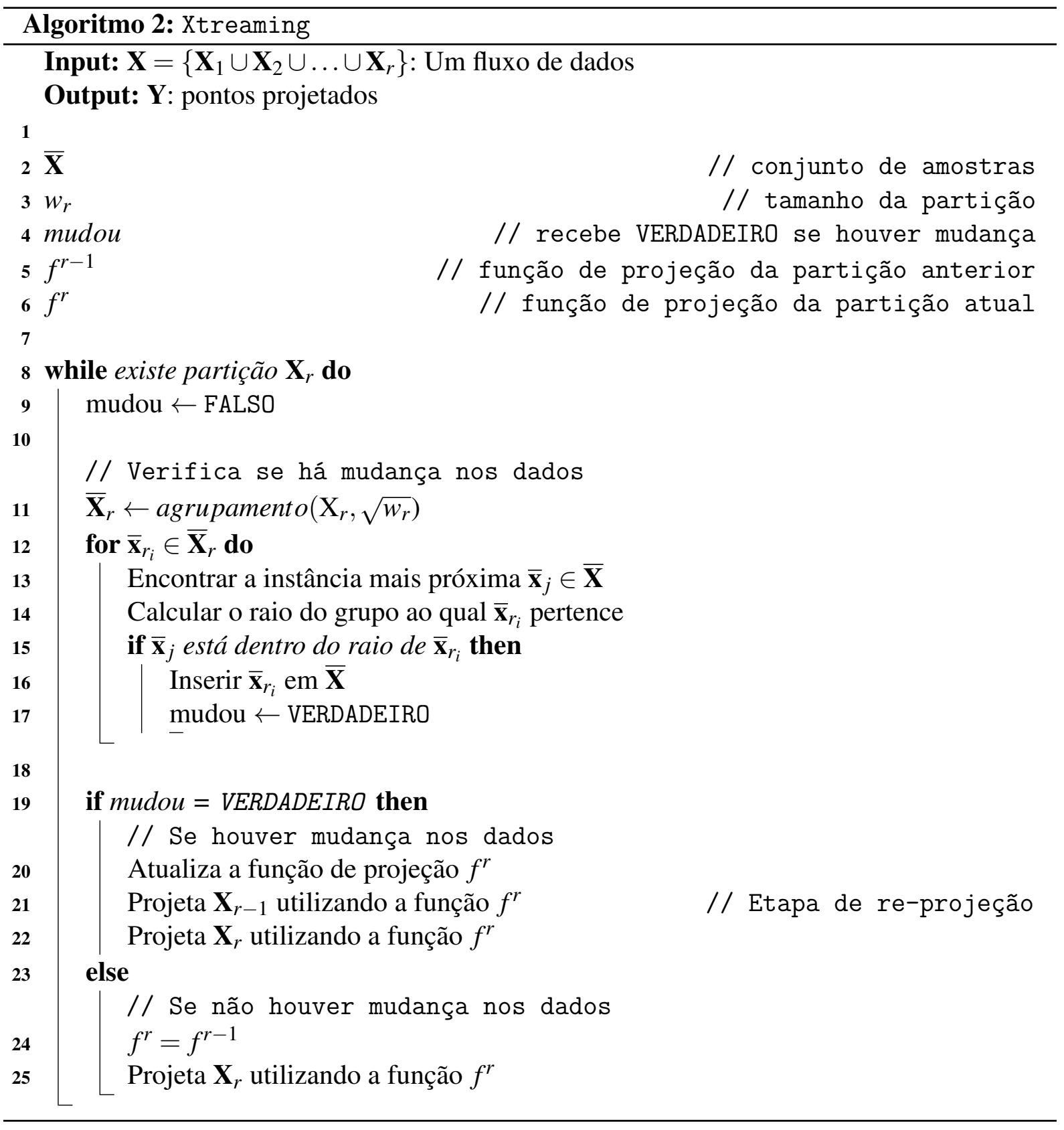

\subsection{Resultados e avaliação}

Nessa seção, a abordagem Xtreaming é testada e comparada com algumas técnicas de projeção estado-da-arte. Para essas comparações foram utilizados diferentes conjuntos de dados com diferentes tamanhos e dimensionalidades permitindo a análise de diferentes cenários. $\mathrm{O}$ primeiro conjunto de dados, shuttle, é composto por instâncias que representam informações de log. A base mammals é um conjunto de dados gerados artificialmente, representando diferentes 
características de mamíferos de quatro classes distintas (cães, gatos, cavalos e girafas). A corel é um conjunto de dados formado por imagens, da coleção de imagens do Corel, representadas por histogramas de cor. O conjunto de dados viscontest corresponde a uma amostra de um intervalo de tempo de uma simulação obtida a partir do IEEE Visualization 2008 Contest data set. A base quantum é um conjunto de dados de partículas físicas obtidos a partir do KDD-Cup 2004. Por fim, o conjunto fibers é formado por instâncias que representam feixos de fibras obtidas a partir do 2009 Pittsburgh Brain Competition (PBC) - Brain Connectivity Challenge. A Tabela 2 apresenta o tamanho, a dimensionalidade e as fontes desses conjuntos de dados.

Tabela 2 - Conjuntos de dados utilizados nas comparações, da esquerda para a direita as colunas correspondem ao nome do conjunto de dados, ao tamanho, a dimensionalidade (número de atributos) e fonte.

\begin{tabular}{|l|r|r|l|}
\hline \multicolumn{1}{|c|}{ Nome } & Tamanho & Dimensionalidade & \multicolumn{1}{c|}{ Fonte } \\
\hline \hline shuttle & 43,500 & 9 & (BACHE; LICHMAN, 2013) \\
\hline mammals & 50,000 & 72 & (BACHE; LICHMAN, 2013) \\
\hline corel & 68,040 & 32 & (BACHE; LICHMAN, 2013) \\
\hline viscontest & 100,000 & 10 & (WHALEN; NORMAN, 2008) \\
\hline quantum & 150,000 & 78 & (CARUANA; JOACHIMS, 2004) \\
\hline fibers & 250,000 & 30 & (PAULOVICH et al., 2011) \\
\hline
\end{tabular}

Foram realizados testes comparativos com técnicas estáticas como forma de se obter um ground truth. A ideia é de que uma técnica estática tradicional consegue gerar mapas visuais com as menores distorções possíveis. Se a abordagem incremental consegue se aproximar da precisão de uma técnica estática ela pode ser considerada boa. Assim, a fim de confirmar a qualidade do modelo desenvolvido, a primeira análise realizada buscou avaliar sua estabilidade e sensibilidade. Em seguida, diferentes comparações com outras técnicas foram realizadas. As técnicas empregadas nas comparações foram escolhidos com base em dois critérios: eles devem ser abordagens out-of-sample e devem apresentar bom desempenho em termos de tempo de execução. Isso permite a comparação da Xtreaming em relação as técnicas aptas a lidar com grandes conjuntos de dados. Mais especificamente, a comparação se deu com as técnicas LAMP (JOIA et al., 2011), PLMP (PAULOVICH; SILVA; NONATO, 2010), L-MDS (TENENBAUM; SILVA; LANGFORD, 2000), Pekalska (PEKALSKA et al., 1999), L-ISOMAP (SILVA; TENENBAUM, 2002), e o Hybrid spring model (JOURDAN; MELANCON, 2004).

Todos os resultados apresentados nessa seção foram produzidos em um computador com processador Intel ${ }^{\circledR}$ Core $^{\mathrm{TM}}$ i7 CPU $2.40 \mathrm{GHz}$, com uma placa de vídeo NVIDIA ${ }^{\circledR}$ GeForce GTX 765M e 16GB de memória RAM. A fim de proporcionar uma comparação justa entre as técnicas, todas elas foram implementadas em Java, incluindo a Xtreaming.

O primeiro teste apresentado tem como objetivo verificar se o mecanismo de detecção de mudanças produz um conjunto de amostras de tamanho razoável e se esse conjunto estabiliza à medida que as partições são recebidas. A Figura 14 apresenta os resultados para os conjuntos 
de dados da Tabela 2. Nesse teste, cada conjunto de dados é dividido em 10 partições que são apresentadas de forma sequencial à técnica Xtreaming, como forma de caracterizar um fluxos de dados. A linha tracejada representa o limite superior $(\sqrt{n})$ para o tamanho do conjunto de amostras definido por algumas técnicas de projeção out-of-sample estado-da-arte (JOIA et al., 2011; PAULOVICH; SILVA; NONATO, 2010). É possível observar que os tamanhos dos conjuntos de amostras não ultrapassam esse limite superior para os conjuntos de dados testados. $\mathrm{Na}$ verdade, para a maioria deles, o tamanho permanece bem abaixo do limite e estabiliza depois de receber algumas partições, mostrando que o mecanismo de detecção de mudanças, embora muito simples, é capaz de distinguir e capturar novas informações à medida que o processo de projeção é realizado.

Figura 14 - Tamanho da amostra vs . partições recebidas. Para os conjuntos de dados testados, o mecanismo de detecção de mudança baseado em agrupamento constrói um conjunto de amostras que não é maior do que o limite superior, e normalmente estabiliza-se depois de receber as primeiros partições.

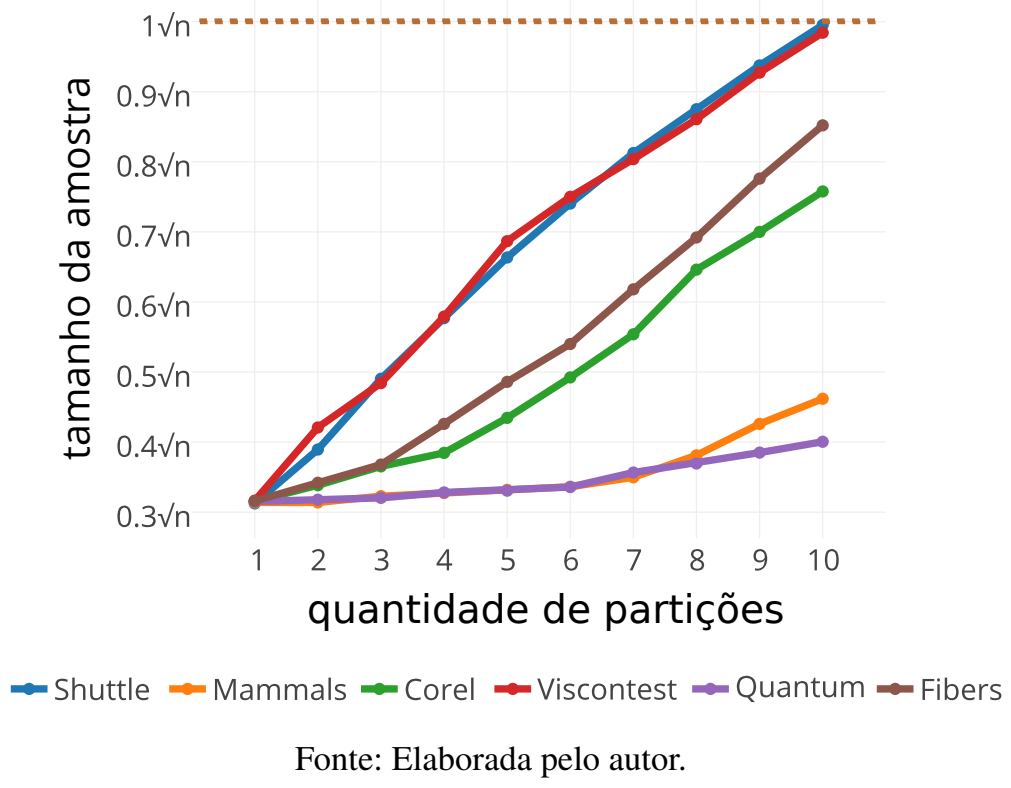

Outra análise realizada busca verificar se o mecanismo de re-projeção (ver Seção 4.2.2) prejudica a qualidade do layout produzido em termos de preservação distância, à medida que as partições são processadas. Conforme detalhado anteriormente, cada vez que uma nova partição é recebida, as partições anteriores são ajustadas para considerar as novas informações. No entanto, uma vez que os dados processados não são armazenados, as distâncias multidimensionais são aproximadas, substituindo-as pelas distâncias bidimensionais para re-projetar as instâncias já projetadas. Nesse teste, cada conjunto de dados é dividido em 10 partições que são apresentadas sequencialmente para a técnica Xtreaming, como se fossem fluxos de dados, medindo a qualidade das projeções produzidas ao longo do tempo. Para medir a qualidade, a função stress de Kruskal (KRUSKAL, 1964) apresentada na Seção 2.4 foi utilizada. A Figura 15 apresenta os resultados para os conjuntos de dados da Tabela 2. Para a maioria dos conjuntos de dados, o stress apresenta valores semelhantes do começo ao fim do processo ou estabiliza com o passar 
do tempo. Apenas o conjunto de dados corel apresenta variação. Na verdade, esse é um conjunto de dados difícil de lidar, e, como será apresentado mais adiante (ver Figura 19), todas as técnicas comparadas apresentam problemas para produzir uma projeção precisa. Esse teste evidencia que a estratégia de re-projeção desenvolvida é uma boa aproximação e não afeta negativamente a qualidade da projeção final produzida. Para os próximos testes a quantidade de partições apresentadas será igual a 10.

Figura 15 - Stress vs . partições recebidas. Para a maioria dos conjuntos de dados, o stress não aumenta ao longo do tempo, por isso a estratégia de re-projeção pode ser considerada uma boa aproximação e não afeta negativamente a qualidade da projeção produzida.

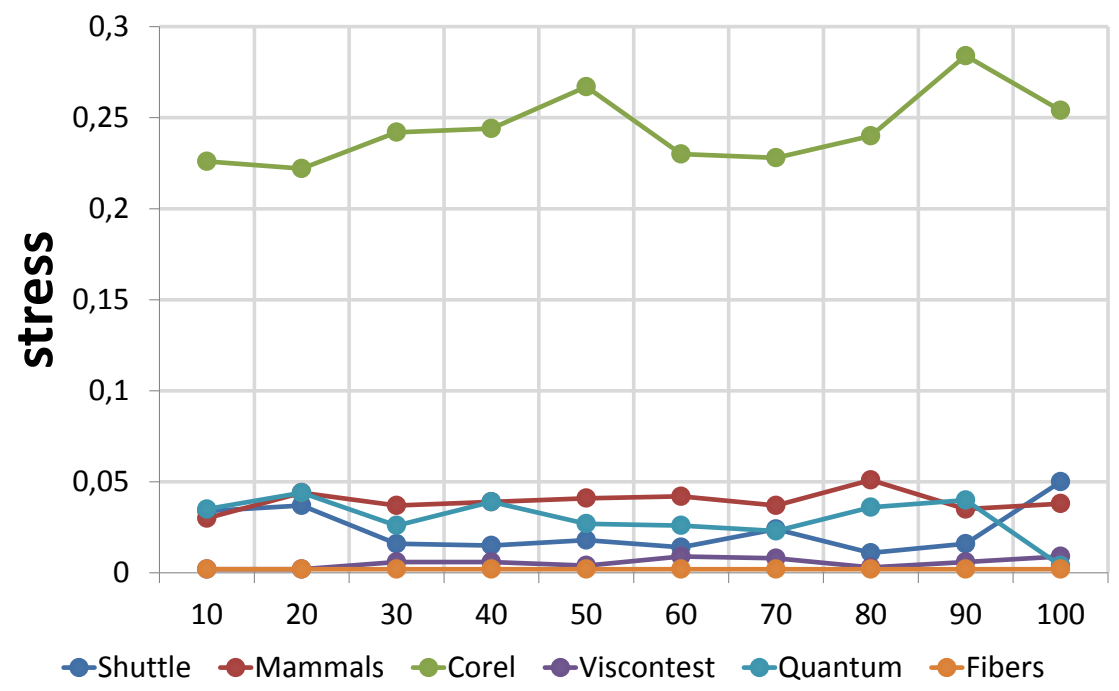

Fonte: Elaborada pelo autor.

Por fim, uma análise foi realizada para verificar se a técnica é sensível à ordenação dos dados. Nesse teste, a Xtreaming foi executada 30 vezes para cada conjunto de dados, alterando aleatoriamente a ordem na qual as instâncias de dados são apresentadas para a técnica - as instâncias de dados são embaralhadas antes dos dados serem processados e esse processo é repetido em cada uma das 30 execuções. Novamente, cada conjunto de dados é dividido em 10 partições que são apresentadas, sequencialmente, para a Xtreaming, simulando fluxos de dados. A Figura 16 apresenta boxplots resumindo os resultados obtidos em termos de preservação distância. Observa-se que a variação do stress para cada conjunto de dados é pequena, o que indica que a qualidade global dos layouts produzidos é independente da ordem na qual os dados são processados. Essa é uma característica muito importante para uma técnica de fluxo contínuo de dados, uma vez que os resultados são consistentes em diferentes cenários de execução, assegurando um bom grau de reprodutibilidade.

Em termos de comparação entre a Xtreaming e outras técnicas de projeção out-of- 
Figura 16 - Boxplots dos resultados de stress da técnica Xtreaming considerando diferentes ordenações de dados. A pequena variação de stress para cada conjunto de dados indica que a Xtreaming produz resultados consistentes em diferentes cenários de execução, garantindo um bom grau de reprodutibilidade.

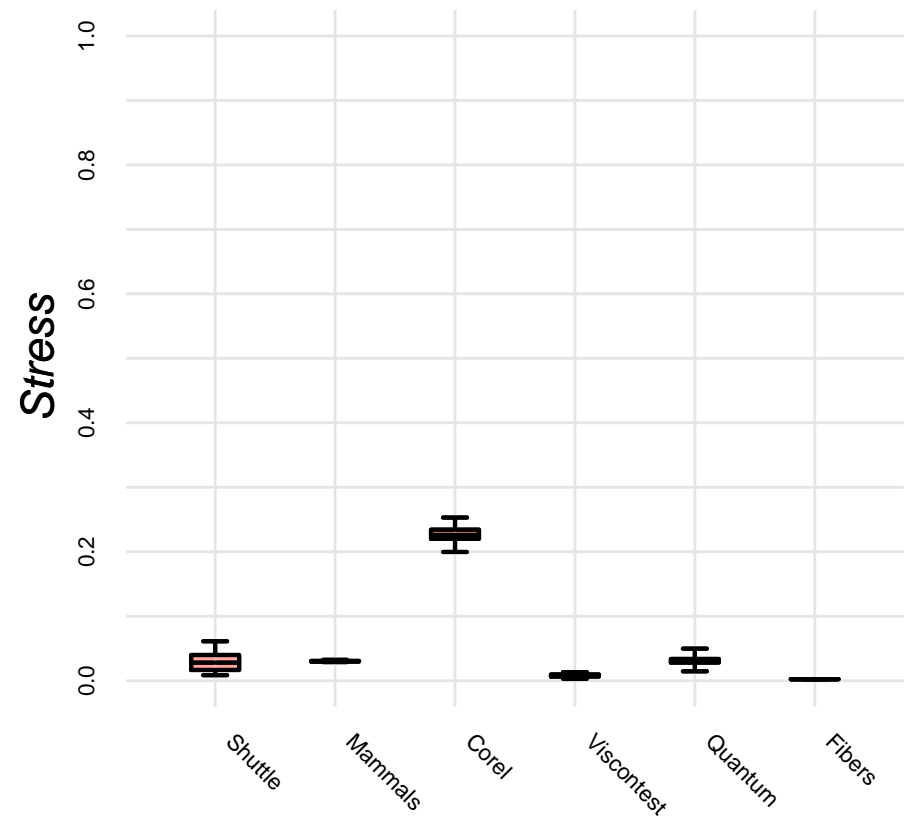

Fonte: Elaborada pelo autor.

sample, basicamente foram realizadas duas análises diferentes: preservação de distância e tempos de execução. A Figura 17 apresenta os boxplots resumindo os resultados em termos de stress. A Xtreaming produz consideravelmente melhores resultados quando comparada com a L-ISOMAP, a Hybrid, e a PLMP. Isso é esperado, uma vez que a L-ISOMAP procura preservar distâncias geodésicas, a estratégia de interpolação empregada pela Hybrid é conhecida por obter aproximações pobres, e a PLMP troca precisão por alto desempenho.

Quando comparada com as técnicas mais precisas, ou seja, Pekalska, L-MDS e LAMP, a Xtreaming produz resultados muito semelhantes. Esse é um resultado inesperado, uma vez que a Xtreaming tem um passo adicional, a re-projeção, o qual aproxima as distâncias multidimensionais substituindo-as pelas distâncias bidimensionais (ver Seção 4.2.2). Além da re-projeção, uma outra diferença entre a Xtreaming e estas técnicas é o mecanismo utilizado para selecionar as instâncias de amostra. Para estas técnicas, uma técnica de agrupamento é utilizada para produzir $\sqrt{n}$ grupos, tomando seus medoides como amostras. Na Xtreaming, a amostra é construída à medida em que os dados são recebidos sem fixar o número de amostras, embora o tamanho do conjunto de amostras nunca fica maior do que $\sqrt{n}$ (ver Figura 14). Assim, a fim de ignorar a influência do processo de amostragem nessa análise, utilizou-se o conjunto de amostras produzido pela Xtreaming e repetiu-se o teste. As técnicas L-ISOMAP e Hybrid foram removidas desse teste por apresentarem resultados, em média, de má qualidade. Os resultados são apresentados pela 
Figura 17 - Boxplots de stress. Comparando com técnicas não-incrementais, a Xtreaming apresenta resultados semelhantes ou melhores, resultando em um processo confiável para projetar fluxo de dados.

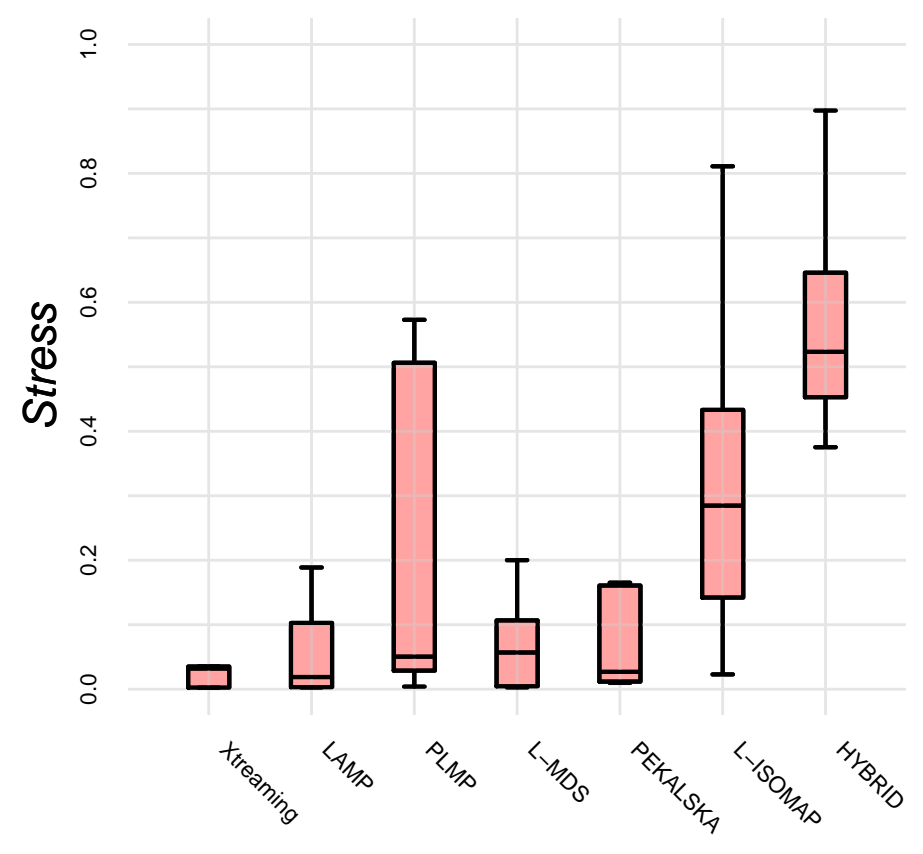

Fonte: Elaborada pelo autor.

Figura 18. Como esperado, LAMP e Pekalska produziram resultados ligeiramente melhores, em média, dando evidências de que a fase de re-projeção é realmente eficaz. No entanto, nenhuma dessas técnicas pode ser usada em cenários streaming, o que indica que a Xtreaming fornece resultados confiáveis para projetar fluxos de dados.

Uma análise comparativa mais detalhada entre os resultados produzidos pelas diferentes técnicas é apresentado pela Figura 19. A figura apresenta uma matriz de gráfico de dispersão distância original vs . distância projetada, que permite uma análise da distorção induzida no processo de projeção por cada técnica. Nesse tipo de gráfico as projeções que melhor preservam as relações de distância são representados por gráficos de dispersão com pontos próximos a diagonal $45^{\circ}$. Como esperado, PLMP, S-PLMP, Hybrid e L-ISOMAP induzem as maiores distorções nas projeções. A abordagem Xtreaming apresenta resultados semelhantes, se comparada com a LAMP, a L-MDS e a Pekalska, confirmando a boa qualidade e confiabilidade do layout produzido.

Em termos de tempos de execução, a Xtreaming não é tão rápida como as técnicas out-of-sample mais rápidas. A Figura 20 resume os resultados produzidos. LAMP, PLMP, L-MDS e Pekalska são uma ordem de magnitude mais rápidas para os conjuntos de dados da Tabela 2. Isto é esperado, principalmente devido à estratégia de detecção de mudança e a da fase de re-projeção da Xtreaming, que não estão presentes nas demais técnicas. No entanto, como discutido antes, elas não podem ser utilizadas para aplicações streaming. 
Figura 18 - Boxplots de stress. Todas as projeções utilizam o conjunto de amostras produzido pela Xtreaming, indicando que a fase de re-projeção é muito eficaz.

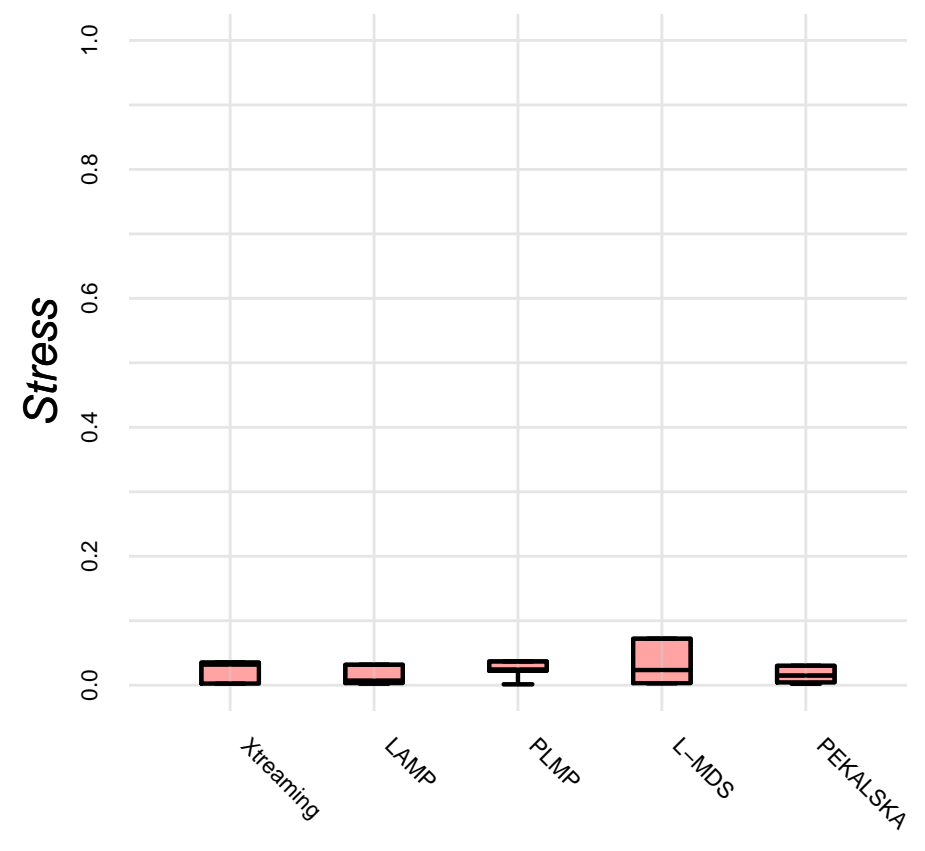

Fonte: Elaborada pelo autor.

A fim de verificar o tempo de execução para conjuntos de dados maiores, um teste adicional foi executado. Foram criados 8 conjuntos de dados mammals (que é um conjunto de dados gerado de forma artificial) com tamanhos diferentes, variando de 1.000 .000 a 8.000 .000 de instâncias, com partições que contendo 100.000 instâncias de dados cada uma. Os resultados comparando a Xtreaming com a LAMP são apresentados na Figura 21. A comparação se deu apenas contra esta técnica pois a LAMP apresenta o melhor equilíbrio entre a preservação de distância e tempos de execução entre as técnicas out-of-sample. De forma assintótica, a Xtreaming é muito mais rápida do que a LAMP. Isso acontece porque na Xtreaming a amostra estabiliza após as partições iniciais, assim a função de projeção também estabiliza ao longo do tempo e a re-projeção não é executada. Na LAMP o conjunto de amostras aumenta de acordo com o aumento do conjunto de dados e seu tamanho tem uma grande influência sobre o tempo de execução. Desse modo, a Xtreaming apresenta um melhor equilíbrio entre qualidade e tempo de execução não só para cenários streaming, mas também quando os conjuntos de dados não cabem na memória principal, uma característica importante para o atual cenário de Big Data.

Um último teste foi realizado para comparar a Xtreaming com a técnica incremental I-PCA e com a versão streaming da PLMP, chamada de S-PLMP, em relação à preservação de distâncias. A Figura 22 apresenta o resultado dessa comparação. A Xtreaming apresenta resultados melhores, mostrando que a atualização do modelo de projeção é importante quando se trata de fluxos de dados. 
Figura 19 - Gráfico de dispersão distância original vs . distância projetada. Números no canto superior esquerdo de cada gráfico de dispersão correspondem ao stress e ao tempo de execução (em segundos). Xtreaming alcança resultados semelhantes ao de outras técnicas precisas, mas é uma técnica capaz de lidar com fluxos de dados.

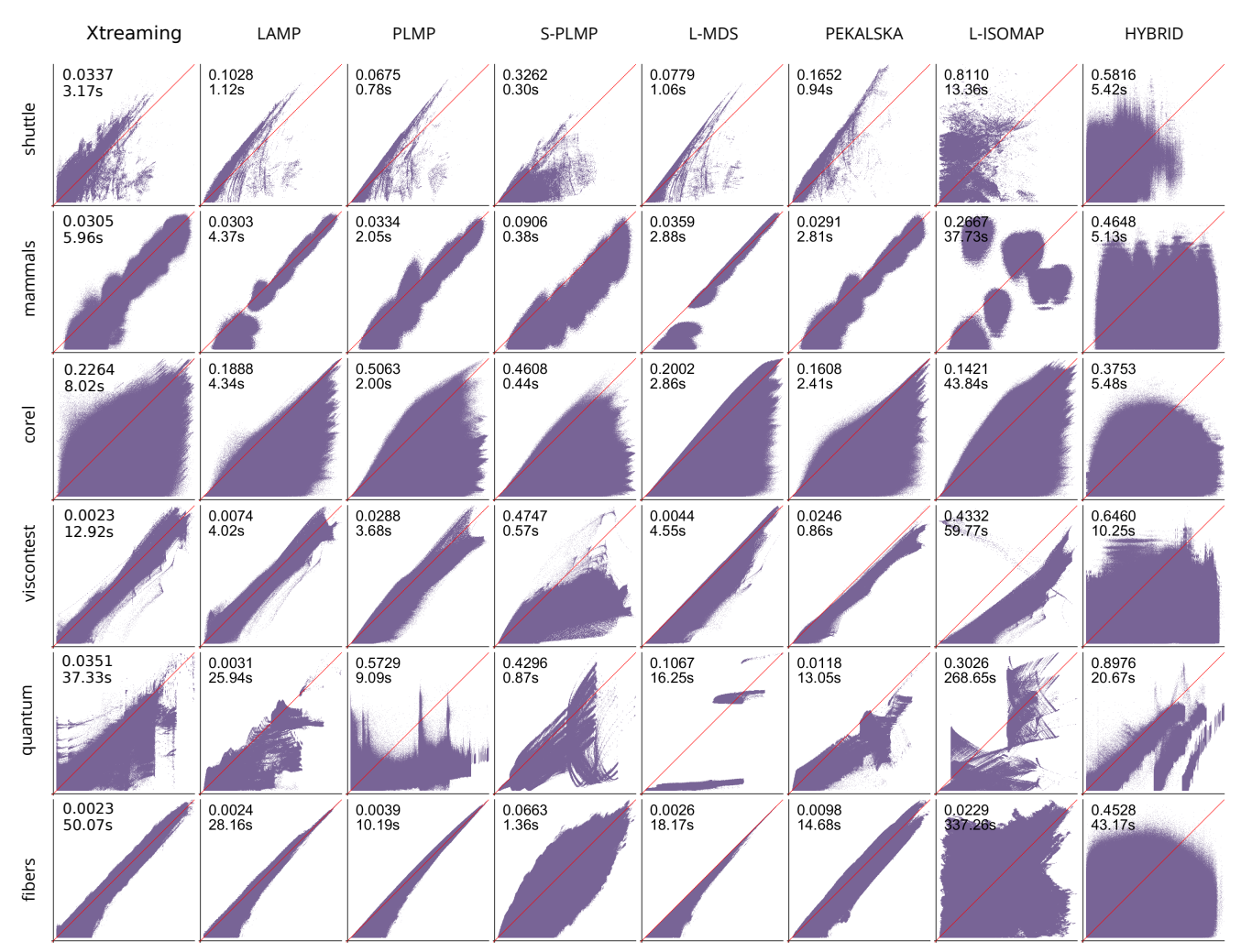

Fonte: Elaborada pelo autor.

\subsection{Discussão e limitações}

Uma limitação, que é uma consequência direta da robustez da Xtreaming, é que a técnica não é indicada para problemas de pequeno porte. Devido às aproximações e às estratégias utilizadas para permitir um único acesso aos dados, em geral, para conjuntos de dados pequenos, a Xtreaming é mais lenta do que a maioria das técnicas out-of-sample e não é tão precisa como a maioria das técnicas in-sample. No entanto, essa queda na precisão é o preço a pagar para a manipulação de dados streaming e soluções aproximadas são aceitáveis, a fim de permitir aplicativos streaming (GAMA, 2012).

Um outro problema que pode ocorrer está relacionado com a taxa na qual os dados são capturados ou produzidos em aplicações streaming dependentes de tempo. Nessas aplicações, é importante produzir o layout da projeção em tempo real, conforme os dados são recebidos. No entanto, se a taxa de produção dos dados for maior do que o tempo de processamento imposto pela Xtreaming, será necessário descartar alguns dados. Uma possível solução é a utilização de uma estratégia conhecida como double-buffer, na qual parte dos dados podem ser armazenadas, enquanto outra parte é processada. Para isso, dividi-se o espaço de memória principal reservado para o processamento em duas regiões chamadas de buffers. Os dados que são coletados ou 
Figura 20 - Boxplots de tempo de execução. A Xtreaming não é tão rápida como as técnicas mais rápidas, mas é uma técnica que pode ser usada de forma confiável em cenários streaming.

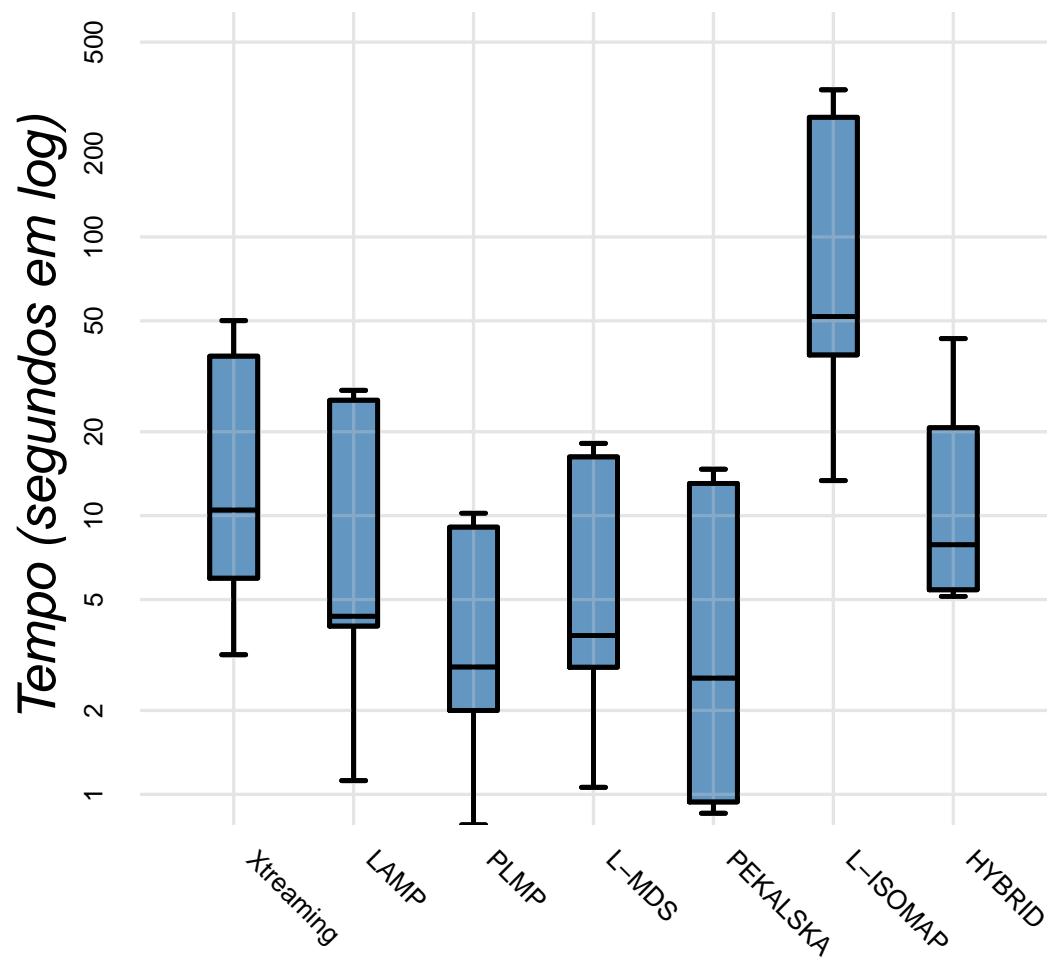

Fonte: Elaborada pelo autor.

Figura 21 - Tempo de execução para grandes conjuntos de dados. Assintoticamente, a Xtreaming apresenta melhores resultados do que a LAMP, uma característica importante para o atual cenário de Big Data.

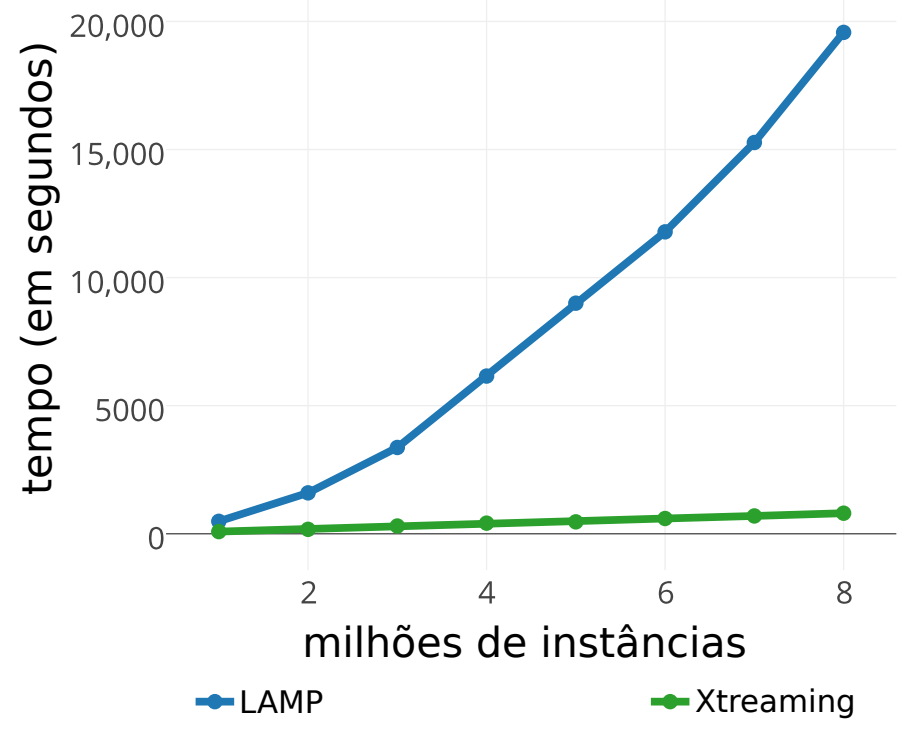

Fonte: Elaborada pelo autor. 
Figura 22 - Boxplots de stress comparado a Xtreaming com a I-PCA e a S-PLMP. É possível observar que a Xtreaming apresenta um melhor resultado em relação as outras técnicas.

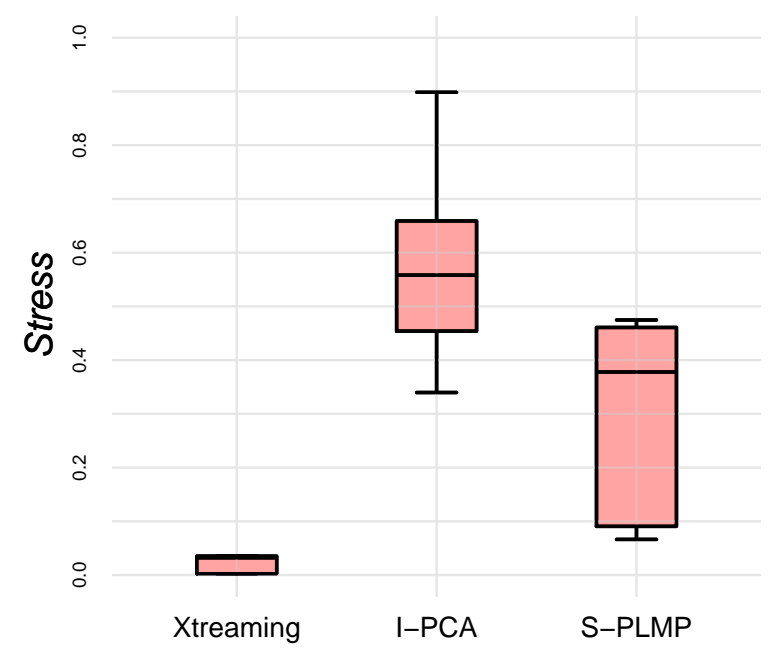

Fonte: Elaborada pelo autor.

produzidos primeiro são armazenado em uma dessas duas regiões, aqui chamada de buffer de coleta. Quando o buffer de coleta estiver cheio, se o buffer de processamento estiver vazio, os dados são transferidos para ele e começam a ser processados pela a abordagem Xtreaming. Assim, o buffer de coleta fica livre para continuar recebendo os dados que chegam.

\subsection{Considerações finais}

Neste capítulo foi apresentada a Xtreaming, um novo modelo de projeção multidimensional que é capaz de lidar com fluxos de dados de forma confiável. A Xtreaming apresenta diferentes estratégias inovadoras, permitindo projetar os dados à medida que são recebidos, adaptando o layout visual para novas estruturas sem a necessidade de percorrer os dados mais de uma vez.

O conjunto de comparações apresentado mostra que a Xtreaming é comparável às técnicas out-of-sample existentes em termos de preservação de distância, enquanto apresenta bons tempos de execução, especialmente para conjuntos de dados realmente grandes. A criação do mapa visual de forma incremental possibilita a aplicação da Xtreaming em cenários streaming. Com isso, novas metáforas visuais capazes de representar projeções streaming, no sentido de prover percepções visuais sobre mudanças estruturais e tendências que surgem ao longo do tempo, se tornam um desafio para os próximos anos. 


\subsection{Considerações iniciais}

O objetivo deste capítulo é descrever aplicações para cada uma das abordagens propostas nessa tese de doutorado. A primeira delas foi a User-assisted Projection Technique for Distance Information (UPDis), apresentada no Capítulo 3. A User-assisted Projection Technique for Distance Information permite a intervenção do usuário no processo de projeção e é adequada para os casos nos quais a informação disponível são as distâncias entre as instâncias de dados. A aplicação ilustra a utilização dessa técnica é apresentada na Seção 5.2.

Outra abordagem apresentada nesse documento foi a técnica Xtreaming. Essa técnica permite a criação de mapas visuais a partir de fluxos de dados. Ela consegue projetar uma grande quantidade de instâncias realizando um processo de projeção incremental, o qual consegue adaptar o modelo de projeção ao perceber uma mudança na distribuição dos dados, mantendo o máximo possível a coerência espacial entre layouts subsequentes. Também como forma de ilustrar a utilização para essa técnica, uma aplicação será descrita na Seção 5.3.

\subsection{Organização de coleções de livros}

A criação de mapas visuais interativos guiadas pelo conhecimento do usuário a partir de informações de distância é uma funcionalidade útil para muitas aplicações de visualização. Como exemplo de aplicação, está a organização de coleções de livros e sugestões de leitura. A ideia é primeiro pedir ao usuário para fornecer uma lista de livros conhecidos (já lidos). Então, um mapa visual inicial é fornecido para que ele possa organizar essa lista em diferentes grupos de interesse e, com base nessa organização inicial (o conhecimento do usuário), novas leituras presentes na base são sugeridas por meio do mapa visual gerado. Para essa aplicação, foi utilizada como base 
de dados o conjunto rede de co-compras de produtos da Amazon ${ }^{1}$. Este conjunto de dados é composto por 548.552 produtos diferentes (livros, CDs de música, DVDs e fitas de vídeo VHS) coletados do site da Amazon, contendo metadados, avaliações e informações de co-compra dos produtos, isto é, grupos de produtos que foram comprados pelo mesmo usuário. O conjunto foi filtrado para conter apenas as informações sobre livros, resultando em 393.561 livros.

A Figura 23 ilustra o processo geral da aplicação de recomendação de leituras. O usuário começa escolhendo os livros lidos por ele em uma lista. Em seguida uma projeção inicial é apresentada contendo os livros escolhidos e outros selecionados na base de dados de acordo com a informação de co-compra, ou seja, os livros que costumam ser vendidos em conjunto com os livros escolhidos pelo usuário. Após o usuário organizar a projeção inicial de acordo com suas necessidades, uma projeção final é gerada. Os livros mais próximos daqueles selecionados pelo usuário são as sugestões de leitura.

Figura 23 - Ilustração do processo de recomendação de leituras. O usuário começa escolhendo os livros lidos por ele em uma lista. Em seguida uma projeção inicial é apresentada contendo os livros escolhidos e outros selecionados na base de dados. Após o usuário organizar a projeção inicial de acordo com suas necessidades, uma projeção final é gerada. Os livros mais próximos daqueles selecionados pelo usuário são as sugestões de leitura.

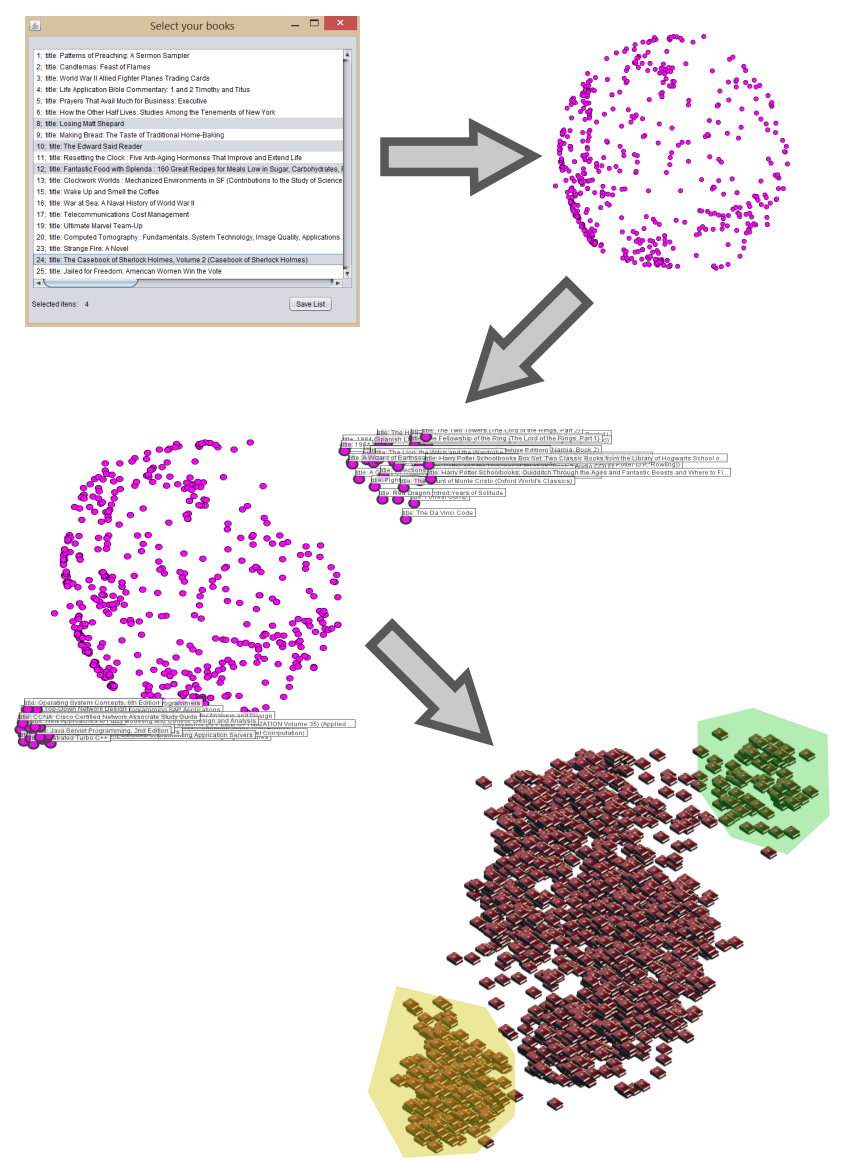

Fonte: Elaborada pelo autor. 
Um aspecto que desempenha papel importante nessa aplicação é o cálculo da distância $\left(\delta\left(\mathbf{x}_{i}, \mathbf{x}_{j}\right)\right)$ entre dois livros, uma vez que a organização final irá refletir isso. Para isso, foram utilizados os metadados associados a cada livro. Mais especificamente, as informações de classe e sub-classe, considerando-se como mais semelhantes os livros que pertencem a sub-classes mais específicas. Partindo do pressuposto de que estas classes e sub-classes compõem uma árvore, da classe mais genéria a mais específica, a similaridade entre dois livros foi definida como o quadrado do valor que identifica o nível das classes comuns mais específicas entre eles, sendo o primeiro nível correspondente à classe mais genérica. Quando dois livros são classificados por mais de uma classe, a similaridade final é a média das semelhanças entre todas as combinações de classes. A distância final é então calculado invertendo a similaridade por

$$
\delta\left(\mathbf{x}_{i}, \mathbf{x}_{j}\right)=e^{-s\left(\mathbf{x}_{i}, \mathbf{x}_{j}\right)}
$$

onde $s\left(\mathbf{x}_{i}, \mathbf{x}_{j}\right)$ representa a similaridade entre $\mathbf{x}_{i}$ e $\mathbf{x}_{j}$. A Figura 24 ilustra o calculo da distância entre dois livros. Primeiro encontra-se o nível no qual os livros possuem a classe específica em comum. Em seguida a similaridade é computada e transformada em distância.

Figura 24 - Ilustração do cálculo da distância entre dois livros. Primeiro encontra-se o nível no qual os livros possuem a classe específica em comum. Em seguida a similaridade é computada e transformada em distância.

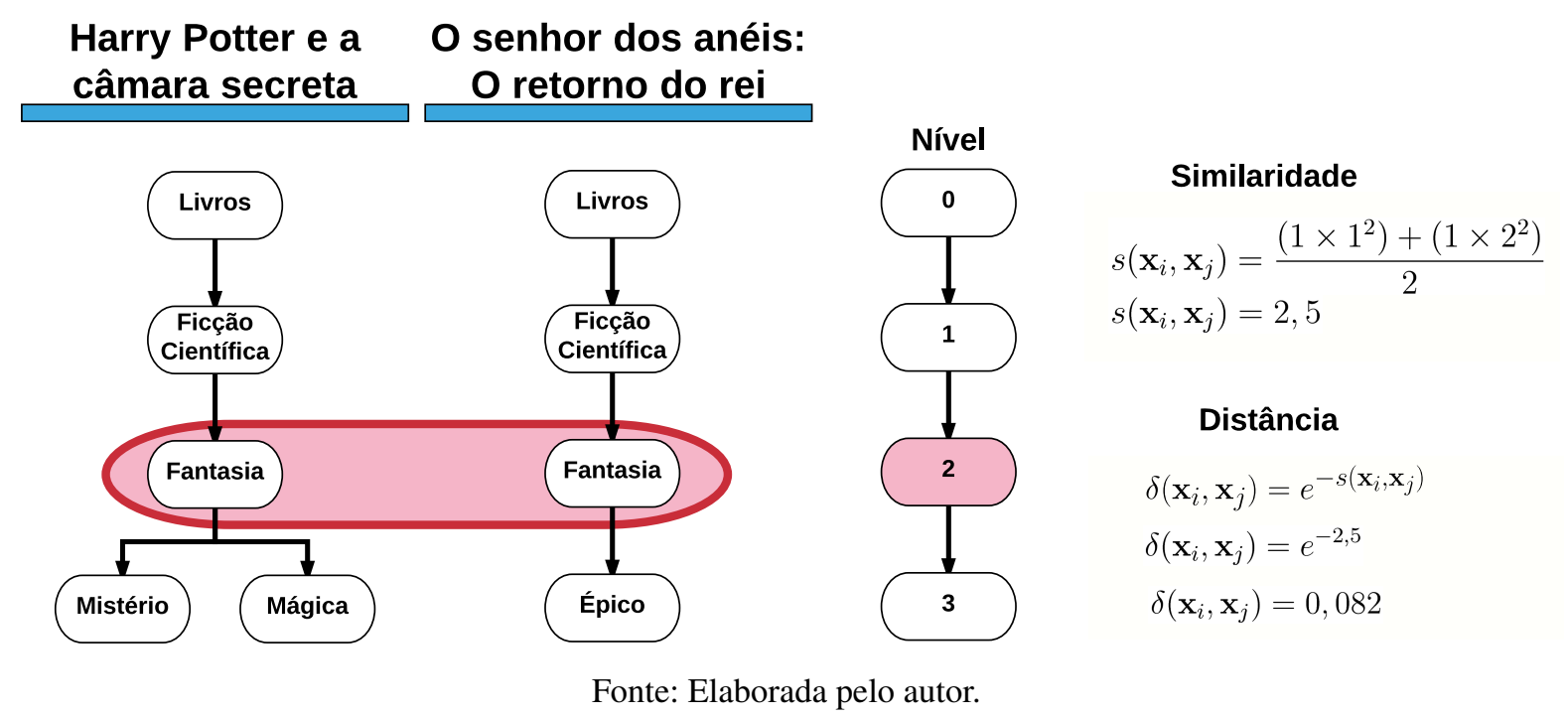

A Figura 25a apresenta o resultado da projeção de uma lista inicial de livros usando esse cálculo de distância. A projeção é formada por 50 livros fornecidos pelo usuário (todos eles devem existir no conjunto de dados da Amazon), representando livros que ele é capaz de classificar. Nessa figura os círculos representam os livros e as legendas são os títulos dos livros. O usuário pode então manipular tal representação, criando os grupos de interesse. A Figura 25b apresenta os grupos formados pelo usuário. Dois grupos principais são criados na parte inferior, um contendo "livros de romance", e outro contendo "livros técnicos". Os livros 
restantes são colocadas em conjunto na parte superior do layout, formando uma classe de livros que não são de interesse do usuário. É possível observar que esses grupos não precisam refletir as classes e sub-classes definidas no conjunto de dados da Amazon, uma nova classificação pode ser totalmente imposta pelo usuário.

Uma vez que os grupos de livros de interesse são formados, um conjunto de livros relacionados é recuperado a partir do conjunto de dados da Amazon. Esse conjunto contém os $k$ livros mais semelhantes de cada livro na lista dada pelo usuário. Nesse exemplo, foi definido $k=200$. Como são 50 os livros iniciais o resultado é uma projeção contendo 10.000 livros. Esse parâmetro pode ser alterado de acordo com as necessidades ou expectativas do usuário. Depois disso, esse novo conjunto de livros é projetado considerando a projeção inicial manipulada. A representação visual obtida pode então ser usada como um guia para sugerir novas leituras. A ideia é procurar visualmente na vizinhança de cada livro da lista inicial, verificando cuidadosamente os livros mais próximo a eles, uma vez que são potenciais candidatos de interesse. A Figura 26a apresenta a projeção final considerando a projeção inicial da Figura 25b. Os livros representados por círculos amarelos são os que constam na lista inicial fornecida pelo usuário, e os livros representados por círculos azuis são livros relacionados, recuperados do conjunto de dados da Amazon. A Figura 26b mostra uma aproximação visual de uma região da Figura 26a. Os livros perto daqueles representados por cículos amarelos são boas indicações para leitura.

Uma vantagem dessa sugestão de aplicação é que vários grupos de livros pode ser formados simultaneamente. Isso permite a sugestão de livros de diferentes assuntos, incluindo livros pertencentes à intersecção de diferentes classes, uma característica difícil de implementar usando metáforas baseadas em listas comuns, utilizados pela maioria dos sistemas de recomendação atuais. Apesar de outras técnicas de visualização permitirem a manipulação do usuário no processo de projeção, como a LAMP por exemplo, essas técnicas não recebem informação de distância como entrada. Isso impede que elas realizem uma tarefa como a da aplicação demonstrada nessa seção.

\subsection{Análise de tweets}

Benevenuto et al. (2012) afirmam que as redes sociais ultrapassaram o uso de e-mails tornando-se a atividade mais popular online. Entre essas redes sociais encontra-se o Twitter ${ }^{\circledR}$, que é uma rede social que permite aos usuários o envio de mensagens com no máximo 140 caracteres. As mensagens são exibidas na página do usuário cadastrado e usuários cadastrados e não cadastrados podem ler essas mensagens.

Estudos sobre a repercussão das mensagens publicadas em redes sociais tornaram-se uma área de pesquisa bastante explorada. Um exemplo desses estudos é o caso da análise da eleição do presidente Barack Obama em 2008. Williams e Gulati (2008) mostraram que o uso das redes sociais fez com que Obama atingisse um recorde em doações. 
Figura 25 - Projeções dos livros escolhidos pelo usuário. Em (a) a projeção original é apresentada e, em (b), essa projeção é manipulada pelo usuário definindo dois grupos de interesse, um contendo "livros de romance" e outro "livros técnicos".

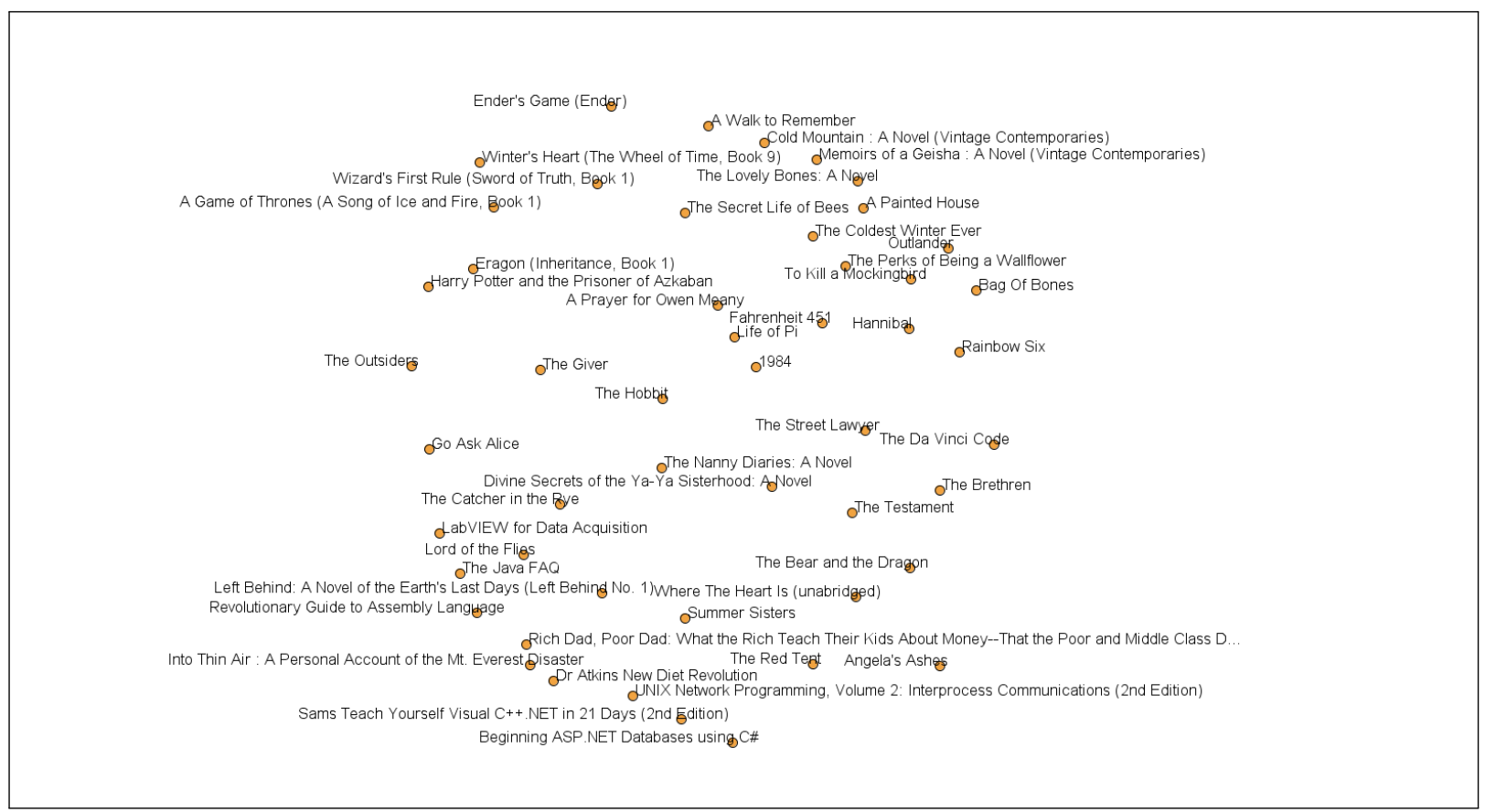

(a) Projeções dos livros escolhidos pelo usuário.

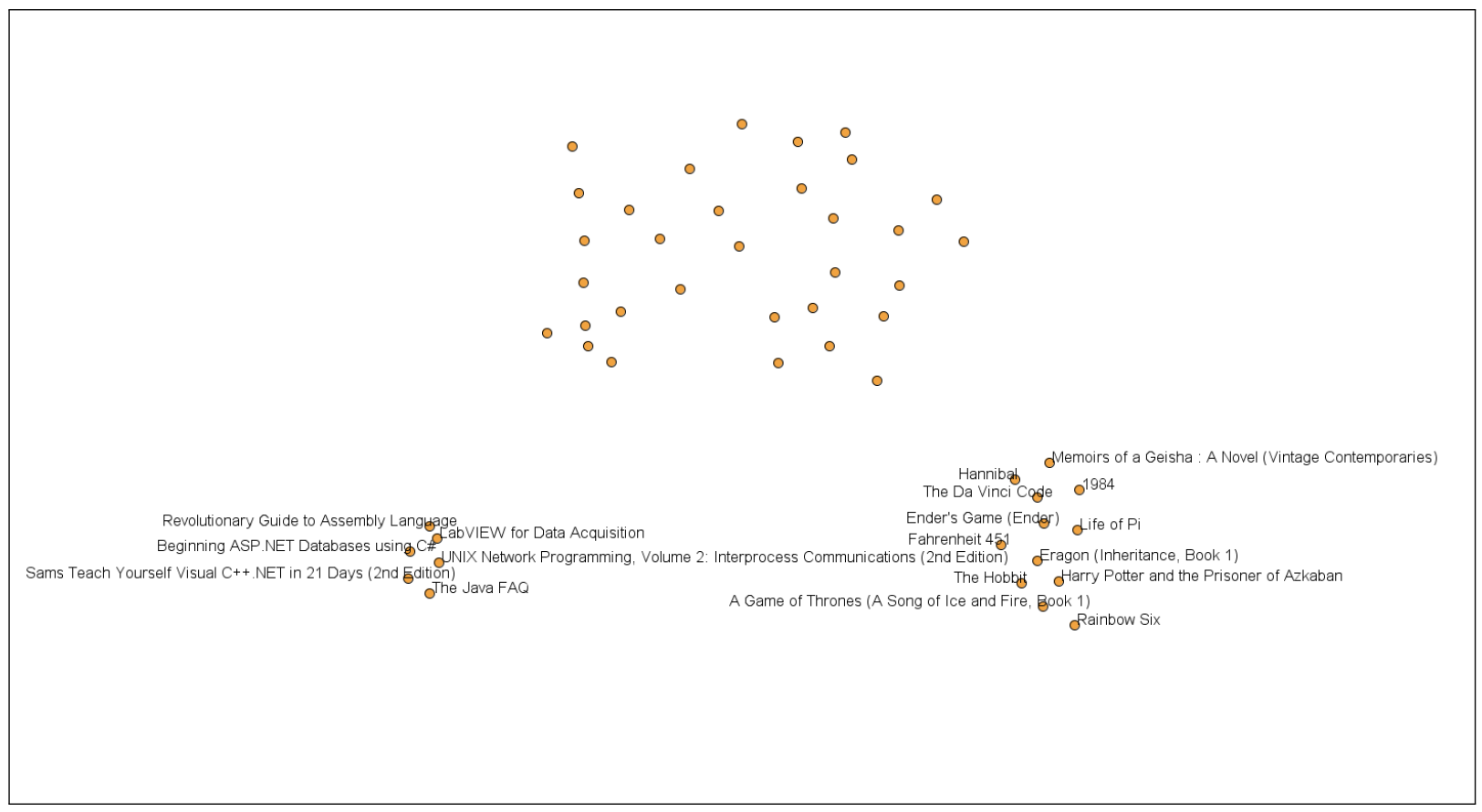

(b) Projeção manipulada refletindo os grupos de interesse.

Fonte: Elaborada pelo autor. 
Figura 26 - Projeção final de todos os livros relacionados. Sugestões de leitura podem ser encontradas pela observação dos vizinhos dos livros fornecidos pelo usuário (círculos amarelos).

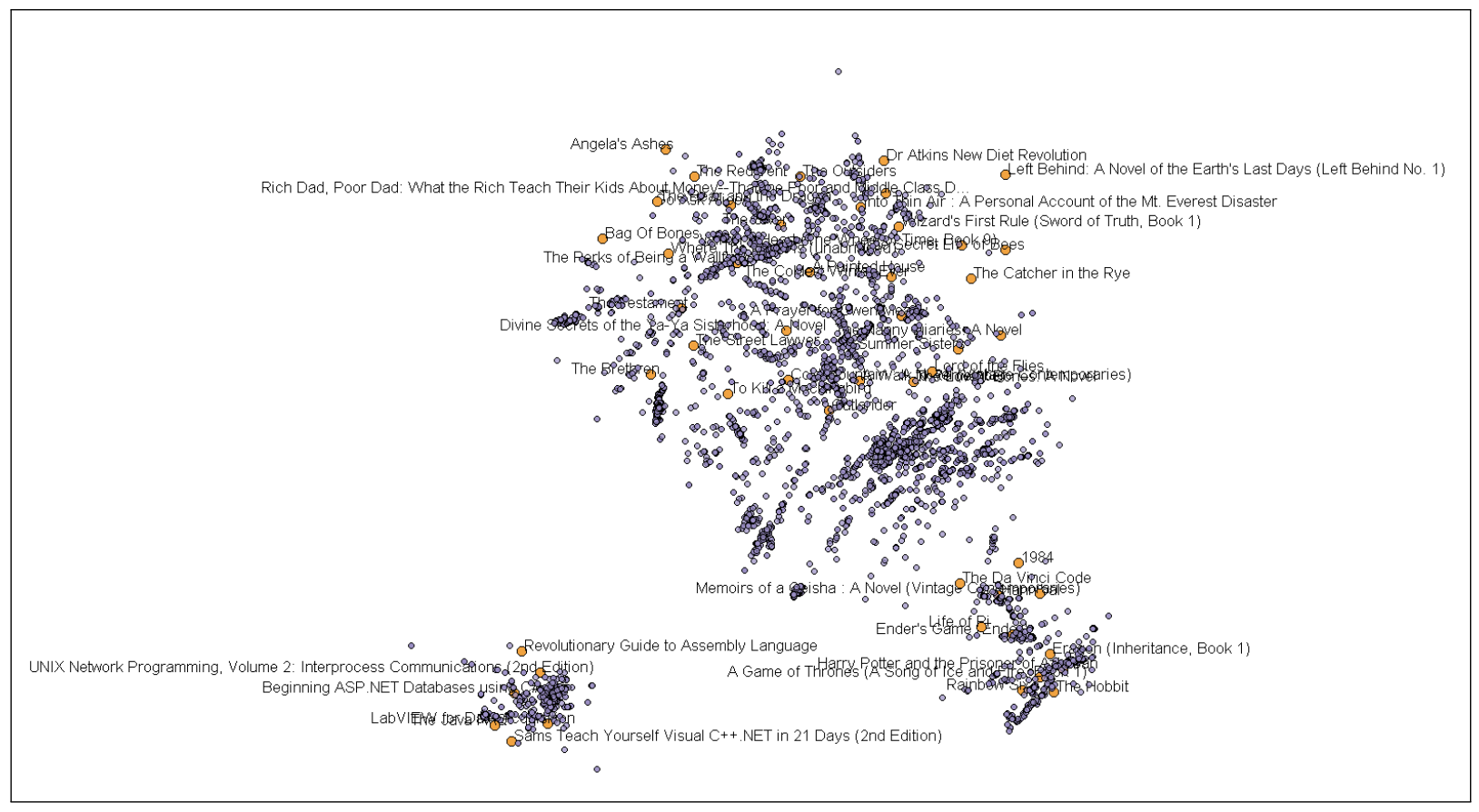

(a) Projeção final de todos os livros relacionados.

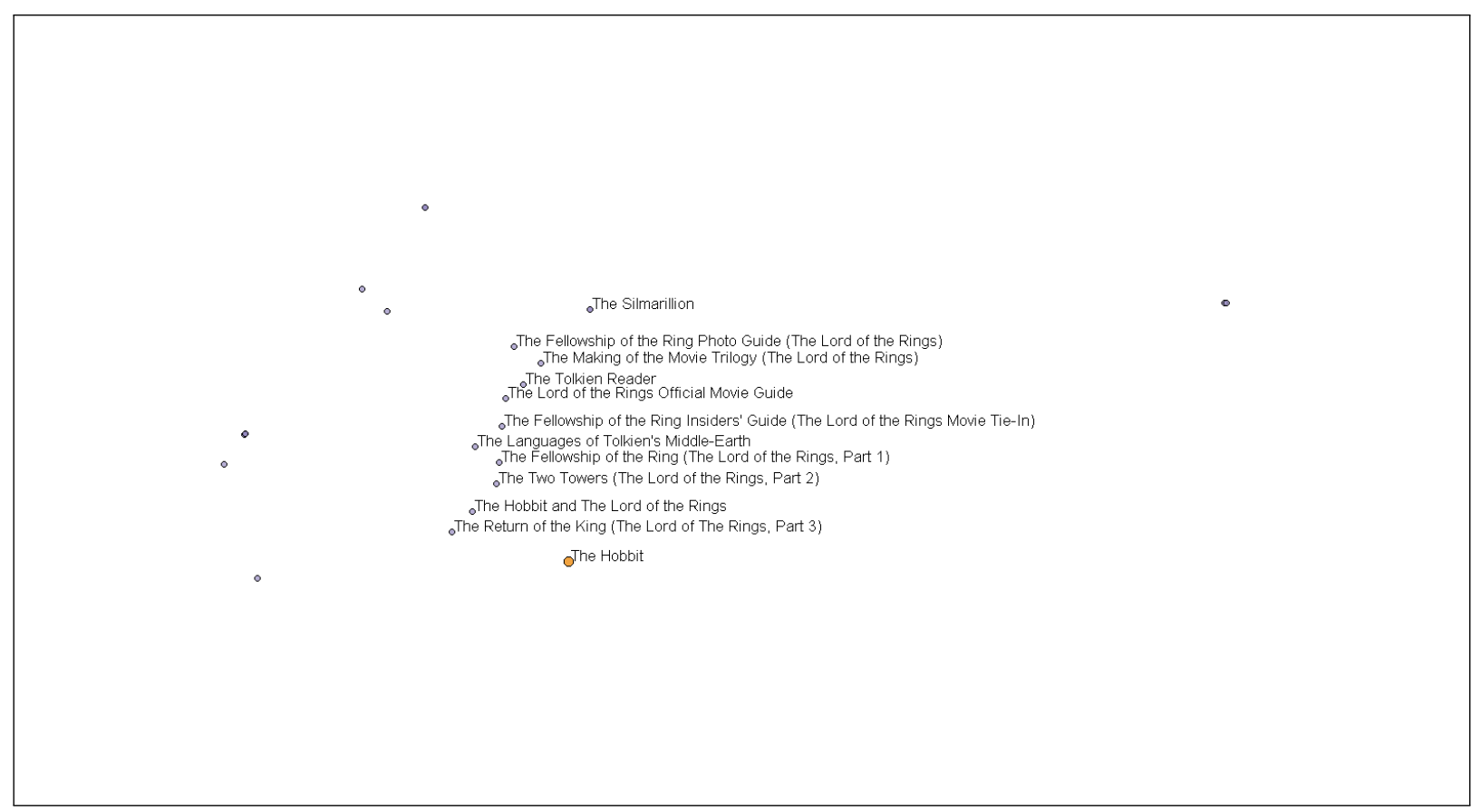

(b) Aproximação visual de uma região de interesse.

Fonte: Elaborada pelo autor. 
Como forma de ilustrar uma aplicação para a abordagem Xtreaming, um estudo de caso foi realizado nesse sentido, buscando-se visualizar o conteúdo de publicações do Twitter durante um período de tempo. Esse período compreendeu os dias entre 14 de abril e 13 de maio, resultando na coleta de 21.089.396 tweets. O período escolhido teve uma motivação especial. Recentemente no Brasil foi iniciado um processo de impeachment da presidente Dilma Rousseff. Esse processo movimentou o cenário político e teve papel de destaque nas mídias e redes sociais.

Para a coleta dos tweets foi utilizada a ferramenta The Streaming APIs, ${ }^{2}$ a qual retorna os tweets que respondem a uma consulta baseada em keywords. Os dados são coletados em tempo real e armazenados em um banco de dados. As keywords utilizadas foram: brasil, corrupção, pt, pmdb, psdb, políticos, deputados, senadores, impeachment, golpe, brasília, congresso, senado, explanada, coxinha, mortadela, temer, dilma, mbl, golpistas e lula.

Após a coleta inicial, os tweets foram filtrados para resultar em uma coleção que apresente apenas tweets relacionados com o objeto em estudo. Para isso, primeiro a frequência de ocorrência das hashtags na coleção foi computada. A Tabela 3 apresenta as 100 hashtags mais frequentes na coleção com suas frequências de ocorrência. Após isso, essas 100 hashtags foram analisadas manualmente de forma a escolher somente as hashtags pertinentes ao processo de impeachment, ou seja, \#impeachmentday, \#stopcoupinbrazil, \#impeachment, \#soscoupinbrazil, \#stopcoupinbrazil, \#temersilveriodosreis, \#mapadoimpeachment, \#golpeaquinãopassa, \#foradilma, \#ficaquerida, \#tchauquerida, \#respeiteasurnas, \#forapt, \#alutacomeçou, \#impeachmentja, \#naovaitergolpe, \#impeachmentjá, \#nãovaitergolpe, \#lulanacadeia, \#dilma, \#impeachj, \#dilmaficagolpesai, \#lavajato, \#decidapelademocracia, \#ocupastf, \#golpe, \#impeachmentdilma, \#dilmanaonu, \#temer, \#belarecatadaedolar, \#foralula, \#foracunha, \#brazilnocorrupt, \#golpeaquinaopassa, \#vaiterimpeachment, \#stopcouplnbrazil, \#brasilcontraogolpe, \#soscoupbrazil, \#dilmaliesattheunitednations, \#elmundocondilma, \#pt, \#lula, \#vaiterluta, \#dilmafica, \#stopcoulpinbrazil, \#mulherescomdilma, \#globogolpista, \#ogolpeéfichasuja, \#alutacontinua, \#grevegeral, \#dilmanaonugolpistanaosecria, \#stopcoupinbrasil, \#gauchaembrasilia, \#traidoresdopovo e \#temersilvériodosreis. Com base nisso, descritores binários foram criados para cada tweet indicando ou não a presença dessas hashtags ou das keywords utilizadas (desconsiderando a keyword 'brasil'). Como resultado, cada tweet é representado por um vetor binário com 75 posições, sendo as 21 primeiras correspondentes às keywords e o restante correspondendo às hashtags. No final, os tweets nulos, isto é, que não apresentam nenhuma keyword ou hashtag, são desconsiderados. Ao final desse processo restaram 13.485.744 tweets.

Para se criar a projeção desses dados é necessário definir uma dissimilaridade entre os tweets. Para isso, o processo de cálculo da dissimilaridade foi dividido entre o cálculo da dissimilaridade entre as keywords e das hashtags, combinando o resultado por meio de uma interpolação linear. Para cada cálculo de similaridade foi usado o coeficiente de Jaccard (TAN

https://dev.twitter.com/streaming/overview 
Tabela 3 - Hashtags mais citadas durante o período de coleta, de 14 de abril de 2016 a 14 de maio de 2016.

\begin{tabular}{|c|c|c|c|}
\hline Hashtag & Frequência & Hashtag & Frequência \\
\hline \#impeachmentday & 286815 & \#dilmaliesattheunitednations & 6459 \\
\hline \#stopcoupinbrazil & 238684 & \#elmundocondilma & 6243 \\
\hline \#impeachment & 99363 & \#lula & 6166 \\
\hline \#internetjusta & 68341 & \#pt & 6063 \\
\hline \#soscoupinbrazil & 54761 & \#política & 6022 \\
\hline \#temersilveriodosreis & 47416 & \#lavajato & 6017 \\
\hline \#golpeaquinãopassa & 43044 & \#jn & 5925 \\
\hline \#ficaquerida & 37777 & \#vaiterluta & 5869 \\
\hline \#brasil & 36223 & \#ccallstars & 5733 \\
\hline \#respeiteasurnas & 36136 & \#dilmafica & 5649 \\
\hline \#alutacomeçou & 31092 & \#rirlisboaampm & 5337 \\
\hline$\# g 1$ & 30565 & \#ocupastf & 5210 \\
\hline \#mapadoimpeachment & 29195 & $\# 1$ & 5096 \\
\hline \#naovaitergolpe & 28632 & \#sqn & 5008 \\
\hline \#forainternetlimitada & 28136 & \#impeachmentdilma & 4957 \\
\hline \#foradilma & 26947 & \#trndnl & 4701 \\
\hline \#tchauquerida & 26078 & \#stopcoulpinbrazil & 4603 \\
\hline \#nãovaitergolpe & 25602 & \#temer & 4423 \\
\hline \#forapt & 18274 & \#mulherescomdilma & 4329 \\
\hline \#impeachmentja & 17535 & \#globogolpista & 4315 \\
\hline \#dilma & 17364 & \#ogolpeéfichasuja & 4283 \\
\hline \#dilmaficagolpesai & 16548 & \#foralula & 4250 \\
\hline \#decidapelademocracia & 15835 & \#alutacontinua & 3994 \\
\hline \#river & 13781 & \#porummundocommais & 3947 \\
\hline \#impeachmentdaanatel & 13470 & \#notícias & 3928 \\
\hline \#golpe & 12779 & \#buyhaironitunes & 3799 \\
\hline \#timbeta & 12470 & \#brazilnocorrupt & 3791 \\
\hline \#operacaobetalab & 12454 & \#raquelmuniz & 3711 \\
\hline \#dilmanaonu & 11910 & \#umrei & 3536 \\
\hline \#estadoislamicolevaomcgui & 11781 & \#grevegeral & 3491 \\
\hline \#belarecatadaedolar & 11494 & \#dilmanaonugolpistanaosecria & 3400 \\
\hline \#trfla & 11401 & \#stopcoupinbrasil & 3344 \\
\hline \#foracunha & 10886 & \#news & 3323 \\
\hline \#seoestadoislamicoatacar & 10823 & \#brazil & 3310 \\
\hline \#sdv & 10167 & \#vaiterimpeachment & 3308 \\
\hline \#golpeaquinaopassa & 10115 & \#eqp & 3270 \\
\hline \#impeachmentjá & 9652 & \#betalab & 3010 \\
\hline \#lulanacadeia & 9275 & \#vergonha & 2980 \\
\hline \#stopcouplnbrazil & 8798 & \#onu & 2941 \\
\hline \#brasilcontraogolpe & 8555 & \#mercados_im & 2907 \\
\hline \#uol & 8075 & \#chaves & 2875 \\
\hline \#soscoupbrazil & 7822 & \#paznobrasil & 2870 \\
\hline \#tomorrowlandnomultishow & 7801 & \#internetlivre & 2821 \\
\hline \#rt & 7734 & \#gauchaembrasilia & 2803 \\
\hline \#obrasilprecisa & 7429 & \#mancuello & 2761 \\
\hline \#badoo & 7070 & \#traidoresdopovo & 2715 \\
\hline \#impeachj & 7042 & \#temersilvériodosreis & 2709 \\
\hline \#podeconfiar & 6793 & \#twibbon & 2694 \\
\hline \#askbelieber & 6655 & \#brasília & 2691 \\
\hline \#tvonline & 6514 & \#feedly & 2651 \\
\hline
\end{tabular}


et al., 2006) de cada sub-vetor. O coeficiente de Jaccard $S_{J}$ indica a proporção de atributos compartilhados entre duas instâncias em relação ao total de atributos dessas duas instâncias. Assim, a dissimilaridade entre dois tweets $S_{T}\left(T_{1}, T_{2}\right)$ é calculada por

$$
S_{T}\left(T_{1}, T_{2}\right)=\left(\alpha \frac{1}{S_{J}\left(T_{k 1}, T_{k 2}\right)+1}+(1-\alpha) \frac{1}{S_{J}\left(T_{h 1}, T_{h 2}\right)+1}\right)
$$

na qual $T_{k i}$ corresponde ao sub-vetor formado pelas keywords e $T_{h i}$ corresponde ao sub-vetor formado pelas hashtags. No estudo conduzido foi utilizado $\alpha=0.25$, o que significa que as hashtags possuem maior influência na determinação da distância.

Para cada dia de coleta criou-se uma partição que foi apresentada à Xtreaming para projeção. Assim, foram projetadas 30 partições de forma incremental. Cada tweet foi classificado como sendo de oposição ao governo, a favor do governo ou neutro, que são aqueles que não puderam ser associados nem à oposição e nem ao governo. Para essa classificação foi feita uma contagem das hashtags manualmente associadas à oposição ou à situação, como ilustrado na Tabela 4, na qual a coluna à esquerda corresponde as hashtags marcadas como oposição. O tweet é classificado de acordo com a maior contagem de hashtags entre oposição e situação, se houver empate é classificado como neutro. A escolha por utilizar hashtags se deu pelo fato de que é possível observar mais hashtags que são utilizadas unicamente por um dos grupos envolvidos no estudo, governo ou oposição, facilitando sua classificação. Já as keywords são mais genéricas, sendo encontradas em tweets de ambos os lados.

A Figura 27 ilustra a projeção correspondente aos tweets do dia 14/04/2016. A cor rosa corresponde aos tweets associados à oposição do governo, a cor verde corresponde aos que são a favor do governo e a cor cinza corresponde aos que não puderam ser associados à oposição ou ao governo. Essas cores são as mesmas e correspondem a essas classes nas demais figuras dessa seção. É possível observar que os tweets classificados como oposição ao governo ficaram mais posicionado à esquerda, enquanto que os classificados como situação ficaram mais à direta e os neutros ficaram mais centrais.

Na Figura 28a são projetados os tweets do dia 14/04/2016 e do dia 15/04/2016, construindo uma projeção de forma incremental pela Xtreaming. O mesmo acontece na Figura 28b, que projeta os tweets dos dois primeiros dias em conjunto com os tweets do dia 16/04/2016. O processo de projeção continua até o último dia, 13/05/2016. Os pontos correspondentes às datas mais antigas vão sendo alterados em relação a um parâmetro $\beta$ que os torna menos opacos com o passar do tempo, sendo dado por

$$
\beta_{t}=\beta_{t-1}+\frac{1-\min }{t-2},
$$

onde $t$ é a quantidade de janelas projetadas, nesse estudo de caso $\min =0.05$. Quando existe apenas uma janela de tempo $\beta=1$. Se existirem duas janelas de tempo, a primeira vai receber $\beta=1$ e a segunda $\beta=0.05$. A partir de três janelas de tempo a Equação (5.3) é utilizada. A janela mais atual sempre terá opacidade total, e a mais antiga recebe $\beta=\min$. A Figura 29 
Tabela 4 - Hashtags classificadas manualmente. À esquerda as que foram associadas a oposição e à direita as que foram assoiadas ao governo.

\begin{tabular}{|c|c|}
\hline Hashtag & Hashtag \\
\hline $\begin{array}{l}\text { \#impeachmentday } \\
\text { \#impeachment } \\
\text { \#stopcoupinbrazil } \\
\text { \#mapadoimpeachment } \\
\text { \#foradilma } \\
\text { \#tchauquerida } \\
\text { \#forapt } \\
\text { \#impeachmentja } \\
\text { \#impeachmentjá } \\
\text { \#lulanacadeia } \\
\text { \#impeachj } \\
\text { \#lavajato } \\
\text { \#ocupastf } \\
\text { \#impeachmentdilma } \\
\text { \#temer } \\
\text { \#foralula } \\
\text { \#brazilnocorrupt } \\
\text { \#vaiterimpeachment }\end{array}$ & $\begin{array}{l}\text { \#stopcoupinbrazil } \\
\text { \#soscoupinbrazil } \\
\text { \#temersilveriodosreis } \\
\text { \#golpeaquinãopassa } \\
\text { \#ficaquerida } \\
\text { \#respeiteasurnas } \\
\text { \#alutacomeçou } \\
\text { \#naovaitergolpe } \\
\text { \#nãovaitergolpe } \\
\text { \#dilma } \\
\text { \#dilmaficagolpesai } \\
\text { \#decidapelademocracia } \\
\text { \#golpe } \\
\text { \#dilmanaonu } \\
\text { \#belarecatadaedolar } \\
\text { \#foracunha } \\
\text { \#golpeaquinaopassa } \\
\text { \#stopcouplnbrazil } \\
\text { \#brasilcontraogolpe } \\
\text { \#soscoupbrazil } \\
\text { \#dilmaliesattheunitednations } \\
\text { \#elmundocondilma } \\
\text { \#lula } \\
\text { \#pt } \\
\text { \#vaiterluta } \\
\text { \#dilmafica } \\
\text { \#stopcoulpinbrazil } \\
\text { \#mulherescomdilma } \\
\text { \#globogolpista } \\
\text { \#ogolpeéfichasuja } \\
\text { \#alutacontinua } \\
\text { \#grevegeral } \\
\text { \#dilmanaonugolpistanaosecria } \\
\text { \#stopcoupinbrasil } \\
\text { \#gauchaembrasilia } \\
\text { \#traidoresdopovo } \\
\text { \#temersilvériodosreis }\end{array}$ \\
\hline
\end{tabular}

ilustra a evolução ao longo dos 30 dias do período de coleta dos tweets. A estrutura geral do layout criado permanece a mesma ao longo do tempo, mostrando que a Xtreaming consegue manter bem a coerência temporal e espacial.

\subsection{Considerações finais}

Nesse capítulo foram apresentados dois estudos de caso com objetivo de ilustrar a utilização das técnicas desenvolvidas. O primeiro estudo de caso apresentou uma aplicação capaz de realizar recomendações de leitura por meio de mapas visuais. A ideia é permitir que o usuário crie grupos de interesse iniciais, formados por livros previamente conhecidos por ele e, a partir desses relacionamentos estabelecidos, livros similares sejam apresentados no mapa visual. As sugestões de leitura são os livros posicionados próximos àqueles selecionados pelo usuário. A manipulação do usuário sobre o conjunto de livros em um passo anterior ao processo final de criação do mapa permite que livros de assuntos diferentes sejam posicionados próximos, 
Figura 27 - Projeção dos tweets coletados no dia 14/04/2016. A cor rosa corresponde aos tweets associados à oposição do governo Dilma, a cor verde corresponde aos que são a favor do governo e a cor cinza corresponde aos que não puderam ser associados à oposição ou ao governo.

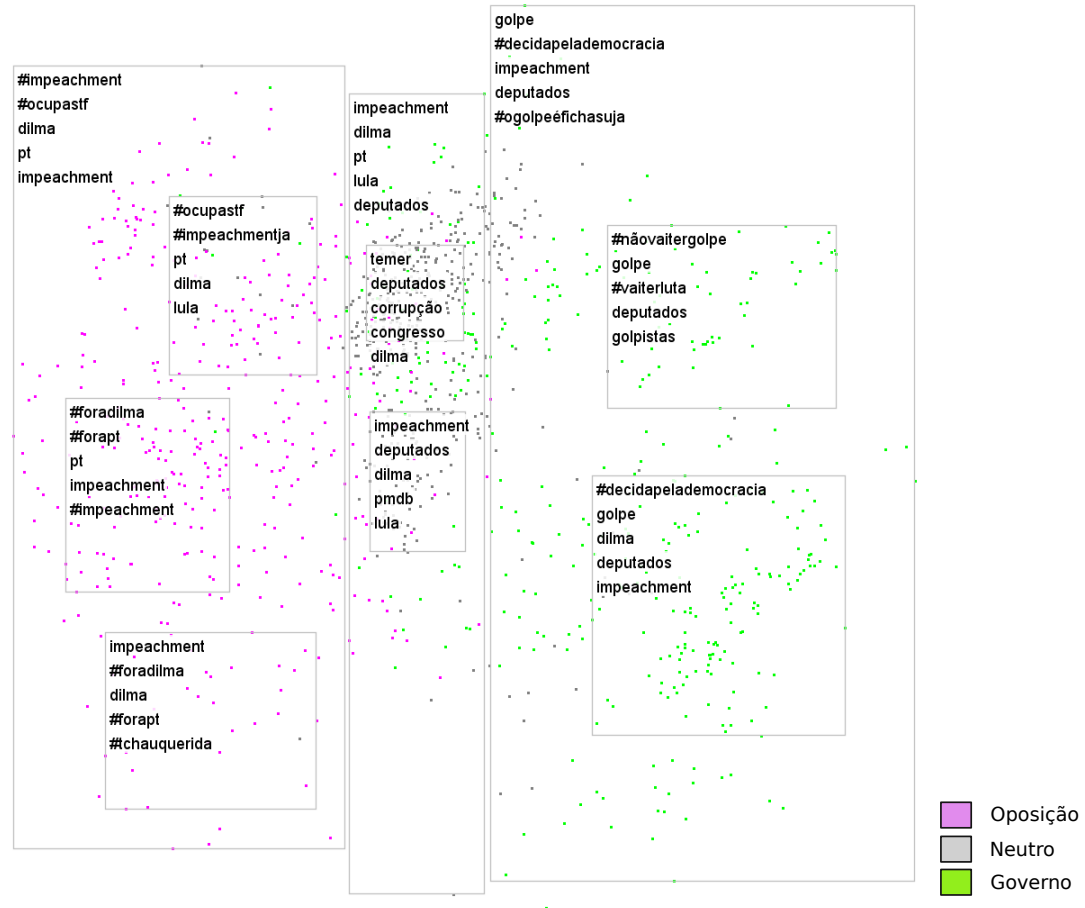

Fonte: Elaborada pelo autor.

Figura 28 - Projeção dos tweets coletados nos dias 14/04/2016 e 15/04/2016 e em seguida dos tweets coletados entre os dias 14/04/2016 e 16/04/2016. A cor rosa corresponde aos tweets associados à oposição do governo Dilma, a cor verde corresponde aos que são a favor do governo e a cor cinza corresponde aos que não puderam ser associados à oposição ou ao governo.

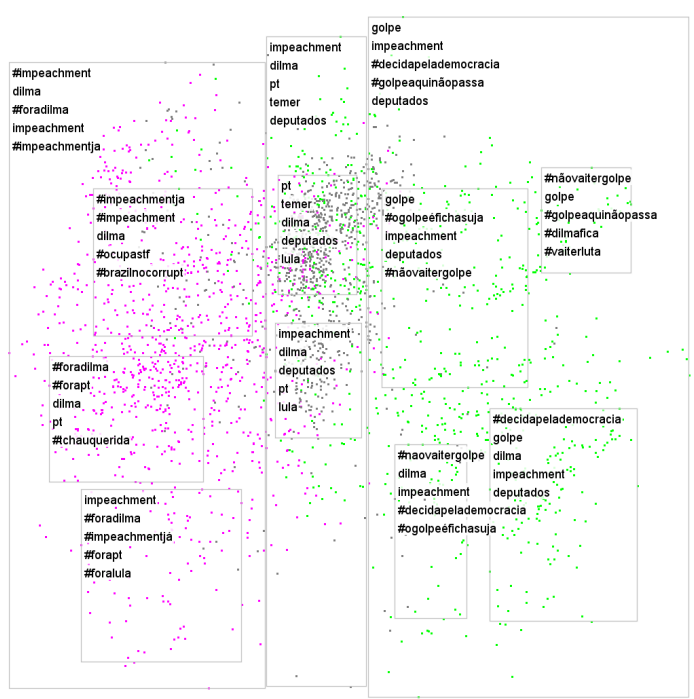

(a) $15 / 04 / 2016$

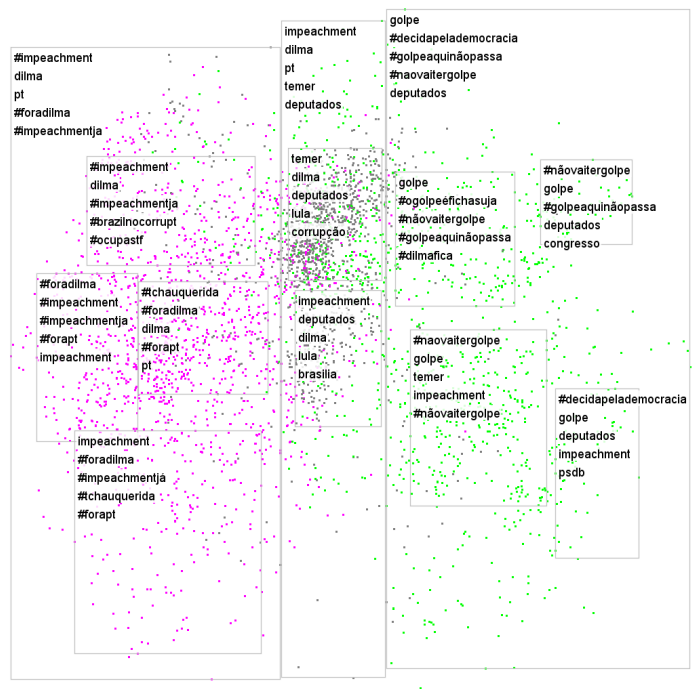

(b) $16 / 04 / 2016$

Fonte: Elaborada pelo autor. 
Figura 29 - Evolução ao longo dos 30 dias que formam o período de coleta dos tweets. A estrutura geral do layout criado permanece a mesma ao longo do tempo, mostrando que a Xtreaming mantém a coerência temporal e espacial.

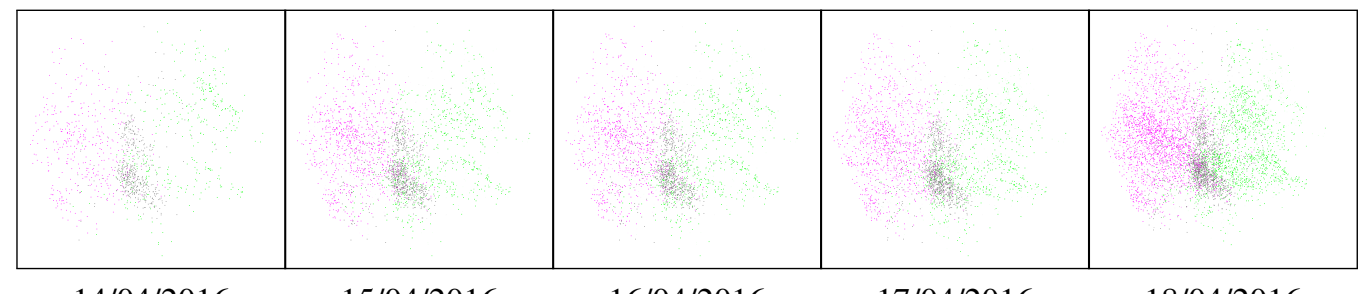
$14 / 04 / 2016$
$15 / 04 / 2016$
$16 / 04 / 2016$
17/04/2016
$18 / 04 / 2016$
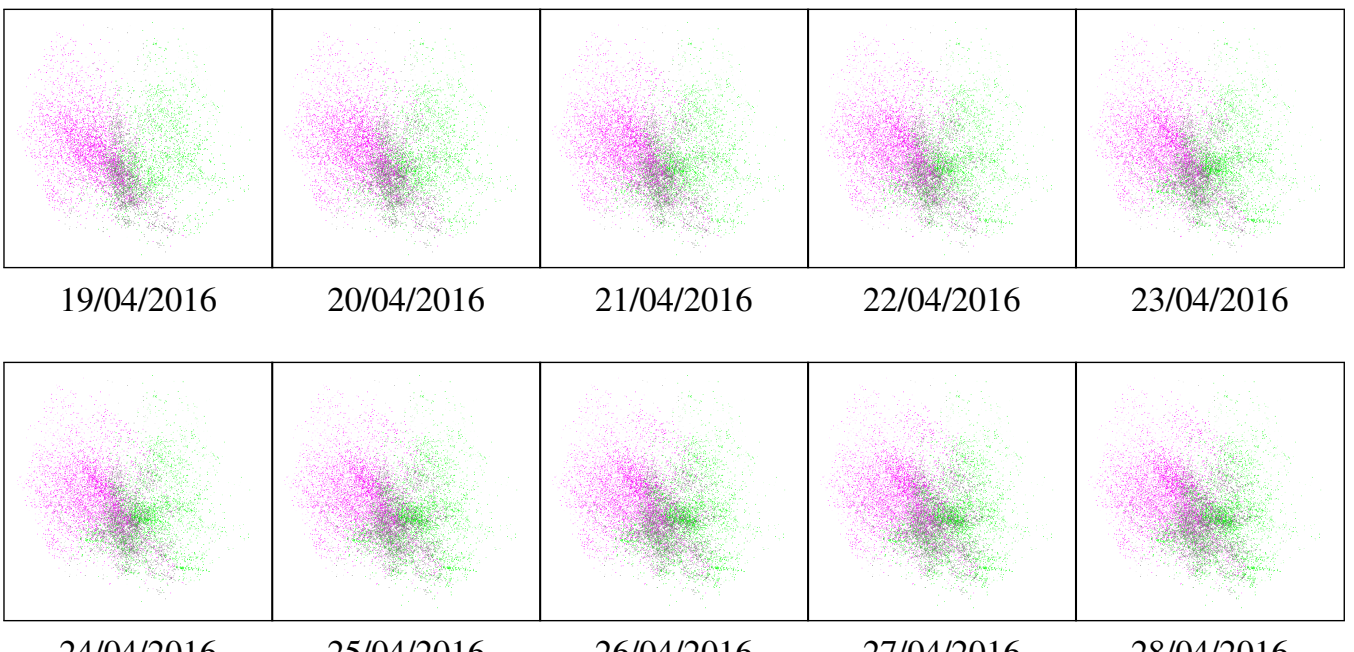

24/04/2016

$28 / 04 / 2016$
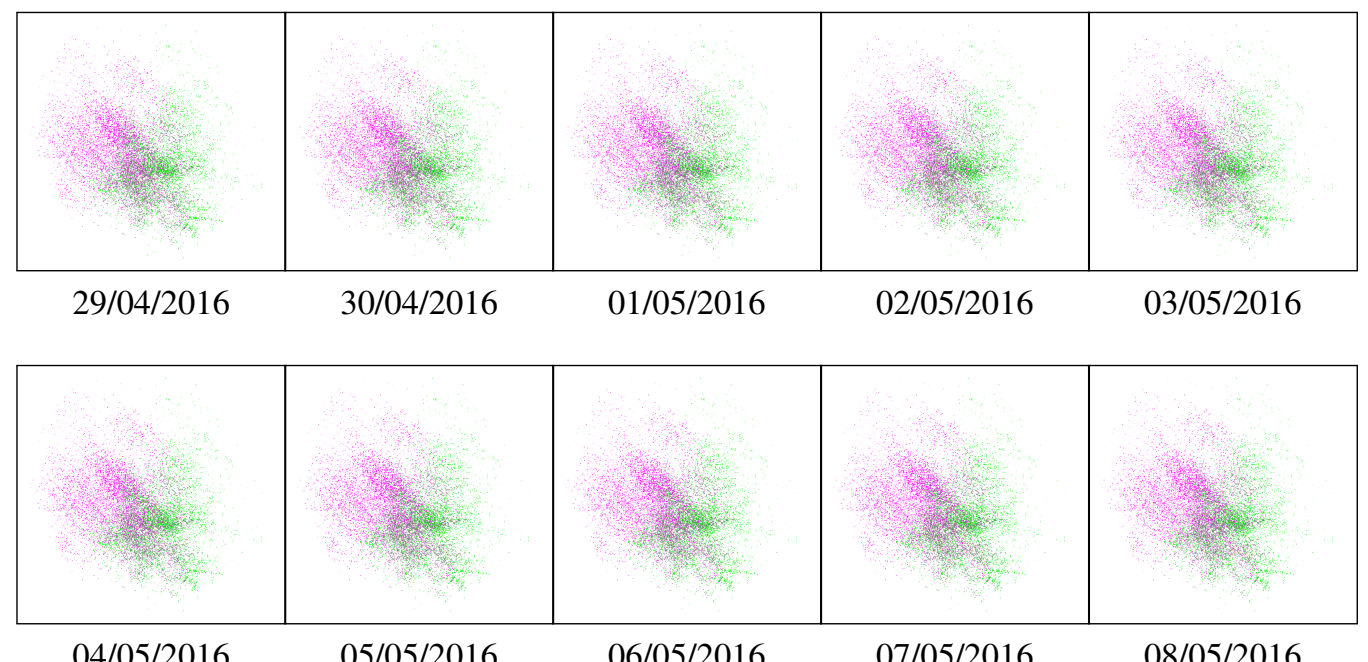
04/05/2016
05/05/2016
$06 / 05 / 2016$
$07 / 05 / 2016$
08/05/2016

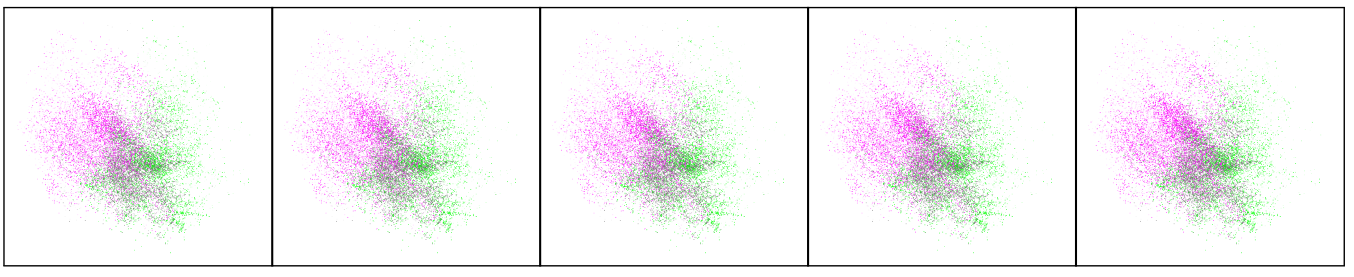

09/05/2016

$10 / 05 / 2016$

$11 / 05 / 2016$

$12 / 05 / 2016$

$13 / 05 / 2016$

Fonte: Elaborada pelo autor. 
refletindo o interesse do usuário.

No outro estudo de caso foi apresentada uma análise do conteúdo de mídias sociais, mais especificamente o Twitter. Durante 30 dias, tweets foram coletados segundo algumas keywords que estavam associadas ao processo de impeachment que ocorreu no Brasil. Esses tweets foram pré-processado e apresentados à Xtreaming para projeção. Além de mostrar um potencial de utilização da abordagem Xtreaming para a análise de conteúdos de mídias sociais, esse estudo de caso evidenciou a capacidade dessa abordagem em prover uma visualização que se adapta ao longo do tempo, mas mantendo a coerência espacial e temporal. 



\subsection{Contribuições}

Nesta tese foram apresentadas diferentes soluções para alguns problemas atuais das técnicas de projeção multidimensionais. Mais especificamente, foram implementadas técnicas que permitem uma maior interação do usuário durante o processo de projeção e um modelo de visualização que pode ser aplicado a fluxos dados, construindo um mapa visual de forma incremental e que se atualiza conforme mudanças na distribuição dos dados são detectadas.

A primeira contribuição desse trabalho foi a técnica User-assisted Projection Technique for Distance Information (UPDis). Ela foi desenvolvida para permitir a intervenção do usuário durante o processo de projeção, agregando o conhecimento prévio ao mapa visual gerado, em cenários nos quais as informações disponíveis para realizar a projeção são apenas as dissimilaridades entre instâncias.

A técnica encontra as coordenadas das amostras representativas no espaço multidimensional e, de posse dessas coordenadas, consegue determinar uma transformação afim, assim como realizada pela LAMP, mas considerando dissimilaridades como entrada. Os resultados comparativos mostram que em termos de preservação de distância e tempos de execução a UPDis é uma das mais eficientes.

Como forma de validar essa técnica, um estudo de caso foi apresentado. Nesse estudo, utilizando distâncias previamente estabelecidas entre diferentes livros e um posicionamento inicial fornecido por meio de uma manipulação realizada pelo usuário, sugestões de leitura são apresentadas na projeção final através dos pontos posicionados próximos àqueles de interesse do usuário. Além dessa aplicação, a UPDis foi bastante importante para o modelo de projeção streaming desenvolvido, uma vez que permite que a projeção seja realizada calculando-se as distâncias entre a instância que está sendo projetada e as amostras representativas apenas.

A segunda, e principal, contribuição foi o modelo de projeção Xtreaming. O modelo 
permite que mapas visuais incrementais sejam criados à medida que conjuntos de instâncias são apresentados para projeção. Além disso, a função de projeção pode ser adaptada à medida que a distribuição dos dados muda.

Para detectar mudanças nos dados, uma ideia simples e rápida foi implementada, a qual verifica se as instâncias selecionadas como candidatas a amostras, na partição que está sendo apresentada, devem ser inseridas no conjunto atual de amostras. Essa verificação se mostrou bem eficiente de acordo com os testes realizados. Entretanto, a ideia é que qualquer técnica que seja capaz de detectar mudanças nos fluxos de dados possa ser utilizada, visto que essa é uma área de pesquisa bastante ativa (PAGE, 1954; AGGARWAL et al., 2003; KIFER; BEN-DAVID; GEHRKE, 2004; BIFET; GAVALDA, 2007; SEBASTIÃO et al., 2010; SÁEZ et al., 2014). O usuário pode escolher aquele que melhor se adapta a sua necessidade fazer essa alteração.

Caso uma mudança seja detectada, a adaptação da função de projeção é realizada. Para garantir que a coerência temporal seja mantida, os pontos previamente posicionados devem ser atualizados para refletir essa mudança, evitando rotações e translações de forma a garantir também a coerência espacial. Isso foi conseguido por meio da aplicação da técnica de Procrustes (GOWER; DIJKSTERHUIS, 2004), que busca encontrar uma matriz de transformação que encaixa uma projeção na outra, da melhor forma possível.

Os resultados mostraram que o Xtreaming consegue atingir uma boa preservação de distância e bons tempos de execução. Também foi apresentado um estudo de caso que ilustrou a utilização do modelo na visualização de um fluxo de dados formado por mais de 13 milhões de tweets. O estudo evidencia o potencial dessa abordagem para a análise de dados que são continuamente coletados e precisam de uma resposta rápida sem a necessidade de manter os dados de forma integral na memória principal.

De forma geral, esse trabalho também contribui para um melhor entendimento das características desejáveis para o processo de projeção nos cenários streaming. Nesse caso específico, é preciso balancear as atualizações do modelo de projeção em relação ao aumento de incoerência temporal e espacial. Atualizações constantes levam a tempos de execução impraticáveis.

\subsection{Limitações}

Embora os resultados apresentados sejam promissores, algumas limitações podem ser observadas:

- O modelo de projeção consegue lidar com uma grande quantidade de instâncias. Mesmo assim, ainda existe uma limitação por conta da quantidade de memória principal disponível, já que ainda é necessário armazenar o posicionamento dos pontos projetados e as informações das amostras representativas.

- Outra limitação importante é a apresentação do mapa visual gerado. Ao posicionar milhões 
de instâncias no plano, é inevitável que ocorra oclusão visual. Assim, a metáfora de pontos posicionados sobre plano pode não ser adequada para a visualização de fluxos de dados. Desenvolver novas metáforas visuais é um dos grandes desafios encontrados pela área de visualização de informação atualmente.

\subsection{Trabalhos futuros}

Os passos para a continuação desse trabalho passam por encontrar soluções para as limitações descritas acima e incorporação de ideias novas ou que surgiram durante a realização do trabalho mas não foram utilizadas. Um exemplo é a implementação da estratégia de doublebuffer, que foi descrita na Seção 4.4, e evitaria o descarte de dados sem o devido processamento por falta de espaço em memória quando a velocidade de aquisição é maior que a velocidade de processamento da abordagem Xtreaming.

Para o problema da limitação de memória principal, uma possível solução é mesclar o uso dessa memória com o uso da memória secundária sempre que a capacidade de armazenamento estiver próxima do máximo. O posicionamento dos pontos podem ficar armazenados em arquivos, sendo lidos apenas no momento da projeção ou da re-projeção.

Com relação a metáfora visual, essa é uma tarefa difícil de ser realizada e alguns estudos ainda precisam ser conduzidos. Alguns trabalhos que podem servir de inspiração inicial foram apresentados por Santos et al. (2013) e Alencar et al. (2012).

\subsection{Artigos}

Os artigos resultantes desse trabalho, publicados ou em fase de submissão, são os seguintes:

1. NEVES, T. T. A. T.; FADEL, S. G.; COIMBRA, D. B.; PAULOVICH, F. V. Análise visual utilizando projeções multidimensionais. Revista de Informática Teórica e Aplicada, v. 22, n. 2, p. 258-288, 2015.

2. NEVES, T. T. A. T.; FATORE, F. M.; FADEL, S. G.; HILASACA, G. M.; PAULOVICH, F. V. UPDis: an user-assisted projection technique for distance information. Submetido a Information Visualization, 2016.

3. NEVES, T. T. A. T.; COIMBRA, D. B.; SIKANSI, F. H. G.; PAULOVICH, F. V. SpMP: Single-pass multidimensional projection. Finalizando a escrita, 2016.

Outros artigos foram publicados durante o período desse trabalho, em colaboração com outros pesquisadores: 
4. COIMBRA, D. B.; MARTINS, R. M.; NEVES, T. T. A. T.; TELEA, A. C.; PAUlOVICH, F. V. Explaining three-dimensional dimensionality reduction plots. Information Visualization, SAGE Publications, v. 15, n. 2, p. 154-172, 2016.

5. OLIVEIRA JR, O. N.; NEVES, T. T. A. T.; PAULOVICH, F. V.; OLIVEIRA, M. C. F. de. Where chemical sensors may assist in clinical diagnosis exploring "big data". Chemistry Letters, The Chemical Society of Japan, v. 43, n. 11, p. 1672-1679, 2014.

6. AOKI, P. H.; ALESSIO, P.; FURINI, L. N.; CONSTANTINO, C. J.; NEVES, T. T. A. T.; PAULOVICH, F. V.; OLIVEIRA, M. C. F. D.; JR, O. N. O. Molecularly designed layerby-layer (lbl) films to detect catechol using information visualization methods. Langmuir, ACS Publications, v. 29, n. 24, p. 7542-7550, 2013. 


\section{REFERÊNCIAS}

ACHLIOPTAS, D. Database-friendly random projections: Johnson-lindenstrauss with binary coins. J. Comput. Syst. Sci., Academic Press, Inc., Orlando, FL, USA, v. 66, n. 4, p. 671-687, 2003. ISSN 0022-0000. Disponível em: <http://dx.doi.org/10.1016/S0022-0000(03)00025-4>. Citado na página 26.

AGGARWAL, C. C.; HAN, J.; WANG, J.; YU, P. S. A framework for clustering evolving data streams. In: Proceedings of the 29th international conference on Very large data bases Volume 29. VLDB Endowment, 2003. (VLDB '03), p. 81-92. ISBN 0-12-722442-4. Disponível em: <http://dl.acm.org/citation.cfm?id=1315451.1315460>. Citado 2 vezes nas páginas 66 e 98.

ALENCAR, A. B.; BÖRNER, K.; PAULOVICH, F. V.; OLIVEIRA, M. C. F. de. Time-aware visualization of document collections. In: ACM. Proceedings of the 27th Annual ACM Symposium on Applied Computing. [S.1.], 2012. p. 997-1004. Citado na página 99.

ANDREWS, D. F. Plots of high-dimensional data. Biometrics, v. 29, p. 125-136, 1972. Citado na página 26.

AOKI, P. H.; ALESSIO, P.; FURINI, L. N.; CONSTANTINO, C. J.; NEVES, T. T. A. T.; PAULOVICH, F. V.; OLIVEIRA, M. C. F. D.; JR, O. N. O. Molecularly designed layer-bylayer (lbl) films to detect catechol using information visualization methods. Langmuir, ACS Publications, v. 29, n. 24, p. 7542-7550, 2013. Citado na página 100.

ARTAC, M.; JOGAN, M.; LEONARDIS, A. Incremental pca for on-line visual learning and recognition. In: Pattern Recognition, 2002. Proceedings. 16th International Conference on. [S.1.: s.n.], 2002. v. 3, p. 781-784 vol.3. ISSN 1051-4651. Citado na página 44.

ASIMOV, D. The grand tour: a tool for viewing multidimentional data. SIAM Journal of Science \& Statistical Computing, v. 6, p. 128-143, 1985. Citado na página 26.

BABCOCK, B.; BABU, S.; DATAR, M.; MOTWANI, R.; WIDOM, J. Models and issues in data stream systems. In: Proceedings of the twenty-first ACM SIGMOD-SIGACT-SIGART symposium on Principles of database systems. New York, NY, USA: ACM, 2002. (PODS '02), p. 1-16. ISBN 1-58113-507-6. Disponível em: <http://doi.acm.org/10.1145/543613.543615>. Citado na página 26.

BACHE, K.; LICHMAN, M. UCI Machine Learning Repository. 2013. Disponível em: <http: $/ /$ archive.ics.uci.edu/ml>. Citado 2 vezes nas páginas 55 e 74.

BASSEVILLE, M.; NIKIFOROV, I. V. et al. Detection of abrupt changes: theory and application. [S.1.]: Prentice Hall Englewood Cliffs, 1993. v. 104. Citado na página 71.

BEDDOW, J. Shape coding of multidimensional data on a microcomputer display. In: Proceedings of the IEEE Visualization 1990 (Vis'90). [S.1.: s.n.], 1990. p. 238-246. Citado na página 26. 
BENEVENUTO, F.; RODRIGUES, T.; CHA, M.; ALMEIDA, V. Characterizing user navigation and interactions in online social networks. Information Sciences, Elsevier, v. 195, p. 1-24, 2012. Citado na página 86.

BIFET, A.; GAVALDA, R. Learning from time-changing data with adaptive windowing. In: SIAM. SDM. [S.1.], 2007. v. 7, p. 2007. Citado na página 98.

BIFET, A.; HOLMES, G.; KIRKBY, R.; PFAHRINGER, B. Data stream mining: A practical approach. [S.1.], 2011. Citado 2 vezes nas páginas 26 e 71.

BISWAS, G.; JAIN, A. K.; DUBES, R. C. Evaluation of projection algorithms. IEEE Transactions on Pattern Analysis and Machine Intelligence, IEEE, n. 6, p. 701-708, 1981. Citado na página 36.

BRANDES, U.; PICH, C. Eigensolver methods for progressive multidimensional scaling of large data. In: SPRINGER. Graph Drawing. [S.1.], 2007. p. 42-53. Citado na página 35.

CARUANA, R.; JOACHIMS, T. Quantum Physics Dataset. 2004. Disponível em: <http:// osmot.cs.cornell.edu/kddcup/datasets.html>. Citado na página 74.

CHALMERS, M. A linear iteration time layout algorithm for visualising high-dimensional data. In: IEEE Visualization. [S.1.: s.n.], 1996. p. 127-ff. Citado na página 36.

CHERNOFF, $\mathrm{H}$. The use of faces to represent points in k-dimensional space graphically. Journal of the American Statistical Association, American Statistical Association, v. 68, n. 342, p. 361368, 1973. ISSN 01621459. Disponível em: <http://dx.doi.org/10.2307/2284077>. Citado na página 26.

CLEVELAND, W. S. Visualizing Data. Summit, New Jersey, U.S.A.: Hobart Press, 1993. Citado na página 26.

COIMBRA, D. B.; MARTINS, R. M.; NEVES, T. T. A. T.; TELEA, A. C.; PAULOVICH, F. V. Explaining three-dimensional dimensionality reduction plots. Information Visualization, SAGE Publications, v. 15, n. 2, p. 154-172, 2016. Citado na página 100.

CORTES, C.; PREGIBON, D. Signature-based methods for data streams. Data Min. Knowl. Discov., Kluwer Academic Publishers, Hingham, MA, USA, v. 5, n. 3, p. 167-182, jul. 2001. ISSN 1384-5810. Disponível em: <http://dx.doi.org/10.1023/A:1011464915332>. Citado na página 66.

COX, T. F.; COX, M. A. A. Multidimensional Scaling. Second. [S.1.]: Chapman \& Hall/CRC, 2000. Citado 3 vezes nas páginas 35, 50 e 54 .

DAURA, X.; JAUN, B.; SEEBACH, D.; GUNSTEREN, W. van; MARK, A. Reversible peptide folding in solution by molecular dynamics simulation. J Mol Biol, v. 280, n. 5, p. 925-32, 1998. Citado na página 66.

DOMINGOS, P.; HULTEN, G. Mining high-speed data streams. In: Proceedings of the sixth ACM SIGKDD international conference on Knowledge discovery and data mining. New York, NY, USA: ACM, 2000. (KDD '00), p. 71-80. ISBN 1-58113-233-6. Disponível em: $<$ http://doi.acm.org/10.1145/347090.347107>. Citado 2 vezes nas páginas 25 e 26.

EADES, P. A heuristics for graph drawing. Congressus numerantium, v. 42, p. 146-160, 1984. Citado na página 36. 
FADEL, S. G.; FATORE, F. M.; DUARTE, F. S.; PAULOVICH, F. V. Loch: A neighborhoodbased multidimensional projection technique for high-dimensional sparse spaces. Neurocomputing, n. 150, p. 546-556, 2014. ISSN 0925-2312. Citado 3 vezes nas páginas 26, 32 e 46.

FALOUTSOS, C.; LIN, K.-I. FastMap: A fast algorithm for indexing, data-mining and visualization of traditional and multimedia datasets. In: Proceedings of the 1995 ACM SIGMOD International Conference on Management of Data. [S.1.]: ACM, 1995. (SIGMOD '95), p. 163-174. ISBN 0-89791-731-6. Citado na página 55.

FARIA, E. R.; GAMA, J. a.; CARVALHO, A. C. P. L. F. Novelty detection algorithm for data streams multi-class problems. In: Proceedings of the 28th Annual ACM Symposium on Applied Computing. New York, NY, USA: ACM, 2013. (SAC '13), p. 795-800. ISBN 978-1-4503-1656-9. Citado na página 71.

FISCHER, F.; MANSMANN, F.; KEIM, D. A. Real-time visual analytics for event data streams. In: Proceedings of the 27th Annual ACM Symposium on Applied Computing. New York, NY, USA: ACM, 2012. (SAC '12), p. 801-806. ISBN 978-1-4503-0857-1. Disponível em: $<$ http://doi.acm.org/10.1145/2245276.2245432>. Citado na página 26.

FLOATER, M. S. Parametrization and smooth approximation of surface triangulations. Computer Aided Geometric Design, Elsevier Science Publishers B. V., Amsterdam, The Netherlands, The Netherlands, v. 14, n. 3, p. 231-250, 1997. ISSN 0167-8396. Citado na página 38.

GAMA, J. A survey on learning from data streams: current and future trends. Progress in Artificial Intelligence, Springer-Verlag, v. 1, n. 1, p. 45-55, 2012. ISSN 2192-6352. Citado 3 vezes nas páginas 26,66 e 80 .

GAMA, J.; GABER, M. Learning from data streams: Processing techniques in sensor networks, a book published by springer verlag. ISBN 3540736786, 9783540736783, 2007. Citado na página 26.

GAMA, J.; RODRIGUES, P. P.; SPINOSA, E. J.; CARVALHO, A. C. P. L. F. de. Knowledge discovery from data streams. In: Web Intelligence and Security - Advances in Data and Text Mining Techniques for Detecting and Preventing Terrorist Activities on the Web. [S.l.: s.n.], 2010. p. 125-138. Citado 2 vezes nas páginas 26 e 65.

GOWER, J. C.; DIJKSTERHUIS, G. B. Procrustes problems. [S.1.]: Oxford University Press Oxford, 2004. v. 3. Citado 3 vezes nas páginas 41, 69 e 98.

GRINSTEIN, G.; TRUTSCHL, M.; CVEK, U. High-dimensional visualizations. In: Proceedings of the 7th Data Mining Conference KDD Workshop. San Francisco, CA: [s.n.], 2001. p. 7-19. Citado na página 26.

GUHA, S.; MEYERSON, A.; MISHRA, N.; MOTWANI, R.; O'CALLAGHAN, L. Clustering data streams: Theory and practice. IEEE Transactions on Knowledge and Data Engineering, IEEE Computer Society, Los Alamitos, CA, USA, v. 15, n. 3, p. 515-528, 2003. ISSN 1041-4347. Citado 3 vezes nas páginas 25, 26 e 65.

GUSTAFSSON, F.; GUSTAFSSON, F. Adaptive filtering and change detection. [S.1.]: Wiley New York, 2000. v. 1. Citado na página 71. 
HAO, M. C.; DAYAL, U.; KEIM, D. A.; SHARMA, R. K.; MEHTA, A. Visual analytics of anomaly detection in large data streams. Visualization and Data Analysis 2009, v. 7243, p. 72430B-72430B-10, 2009. Disponível em: <+http://dx.doi.org/10.1117/12.810945>. Citado na página 25.

HOFFMAN, P. E. Table Visualizations: A formal model and its applications. Tese (Doutorado) - Computer Science Department, University of Massachusetts Lowell, 1999. Citado na página 26.

INGRAM, S.; MUNZNER, T.; OLANO, M. Glimmer: Multilevel mds on the gpu. IEEE Transactionson Visualization and Computer Graphics, IEEE, v. 15, n. 2, p. 249-261, 2009. Citado na página 26.

INSELBERG, A. The plane with parallel coordinates. The Visual Computer - Special Issue on Computational Geometry, v. 1, p. 69-91, 1985. Citado na página 26.

Multidimensional detective. In: Proceedings of IEEE Symposium on Information Visualization 1997 (InfoVis'97). [S.1.: s.n.], 1997. p. 100-107. Citado na página 26.

INSELBERG, A.; DIMSDALE, B. Parallel coordinates: a tool for visualizing multi-dimensional geometry. VIS'90: Proceedings of the 1st Conference on Visualization, p. 361-378, 1990. Citado na página 26.

JACKSON, D. A. Stopping rules in principal components analysis: A comparison of heuristical and statistical approaches. Ecology, Ecological Society of America, v. 74, n. 8, p. 2204-2214, 1993. ISSN 00129658, 19399170. Citado na página 52.

JOIA, P.; COIMBRA, D.; CUMINATO, J. A.; PAULOVICH, F. V.; NONATO, L. G. Local affine multidimensional projection. IEEE Transactions on Visualization and Computer Graphics, IEEE Educational Activities Department, Piscataway, NJ, USA, v. 17, p. 2563-2571, dez. 2011. ISSN 1077-2626. Citado 11 vezes nas páginas 26, 28, 41, 42, 54, 55, 60, 66, 71, 74 e 75.

JOLLIFFE, I. Principal component analysis. In: Encyclopedia of Statistics in Behavioral Science. [S.1.]: John Wiley \& Sons, Ltd, 2005. p. 1580-1584. ISBN 978-0-470-01319-9. Citado 2 vezes nas páginas 34 e 52.

JOURDAN, F.; MELANCON, G. Multiscale hybrid mds. In: IV '04: Proceedings of the Information Visualisation, Eighth International Conference on (IV'04). Washington, DC, USA: IEEE Computer Society, 2004. p. 388-393. ISBN 0-7695-2177-0. Citado na página 74.

KEIM, D. A. Designing pixel-oriented visualization techniques: Theory and applications. IEEE Transactionson Visualization and Computer Graphics, v. 6, n. 1, p. 59-78, 2000. Citado na página 26.

KEIM, D. A.; KREIGEL, H. P. Visdb: Database exploration using multidimensional visualization. IEEE Computer Graphics and Applications, v. 14, n. 5, p. 40-49, September 1994. Citado na página 26.

KEIM, D. A.; KRIEGEL, H. P. Visualizations techniques for mining large databases: a comparison. IEEE Transactions on Knowledge and Data Engineering, v. 8, n. 6, p. 923-936, December 1996. Citado na página 26.

KIFER, D.; BEN-DAVID, S.; GEHRKE, J. Detecting change in data streams. In: VLDB. [S.1.: s.n.], 2004. p. 180-191. Citado na página 98. 
KOHONEN, T. The self-organizing map. Proceedings of the IEEE, Institute of Electrical and Electronics Engineers, v. 78, n. 9, p. 1464-1480, 1998. Citado na página 26.

KRUSKAL, J. B. Multidimensional scaling by optimizing goodness of fit to a nonmetric hypothesis. Psychometrika, v. 1, n. 29, p. 115-129, 1964. Citado 3 vezes nas páginas 35, 46 e 75 .

KULLBACK, S.; LEIBLER, R. A. On information and sufficiency. Ann. Math. Statist., The Institute of Mathematical Statistics, v. 22, n. 1, p. 79-86, 03 1951. Disponível em: <http: //dx.doi.org/10.1214/aoms/1177729694>. Citado na página 43.

LAW, M. H.; JAIN, A. K. Incremental nonlinear dimensionality reduction by manifold learning. IEEE transactions on pattern analysis and machine intelligence, IEEE, v. 28, n. 3, p. 377391, 2006. Citado 2 vezes nas páginas 32 e 45.

LESPINATS, S.; AUPETIT, M. Checkviz: Sanity check and topological clues for linear and nonlinear mappings. Computer Graphics Forum, Blackwell Publishing Ltd, v. 30, n. 1, p. 113-125, 2011. ISSN 1467-8659. Disponível em: <http://dx.doi.org/10.1111/j.1467-8659.2010.01835.x>. Citado na página 46.

MAATEN, L. van der; HINTON, G. Visualizing data using t-SNE. Journal of Machine Learning Research, v. 9, p. 2579-2605, 2008. ISSN 1532-4435. Citado na página 42.

MACQUEEN, J. B. Some methods for classification and analysis of multivariate observations. In: CAM, L. M. L.; NEYMAN, J. (Ed.). Proc. of the fifth Berkeley Symposium on Mathematical Statistics and Probability. [S.1.]: University of California Press, 1967. v. 1, p. 281-297. Citado na página 53.

MARTIN-MERINO, M.; MUNOZ, A. A new sammon algorithm for sparse data visualization. In: Proceedings of the 17th International Conference on Pattern Recognition (ICPR'04). Washington, DC, USA: IEEE Computer Society, 2004. p. 477-481. ISBN 0-7695-2128-2. Citado na página 32.

MORRISON, A.; CHALMERS, M. A pivot-based routine for improved parent-finding in hybrid mds $\dagger$. Information Visualization, SAGE Publications, v. 3, n. 2, p. 109-122, 2004. Citado na página 37.

MORRISON, A.; ROSS, G.; CHALMERS, M. A hybrid layout algorithm for sub-quadratic multidimensional scaling. In: Proceedings of the IEEE Symposium on Information Visualization (InfoVis'02). [S.1.]: IEEE Computer Society, 2002. (INFOVIS '02), p. 152-. ISBN 0-7695-1751-X. Citado 2 vezes nas páginas 37 e 55.

MUTHUKRISHNAN, S. Data streams: Algorithms and applications. [S.l.]: Now Publishers Inc, 2005. Citado na página 25.

NEVES, T. T. A. T.; COIMBRA, D. B.; SIKANSI, F. H. G.; PAULOVICH, F. V. SpMP: Singlepass multidimensional projection. Finalizando a escrita, 2016. Citado na página 99.

NEVES, T. T. A. T.; FADEL, S. G.; COIMBRA, D. B.; PAULOVICH, F. V. Análise visual utilizando projeções multidimensionais. Revista de Informática Teórica e Aplicada, v. 22, n. 2 , p. 258-288, 2015. Citado 2 vezes nas páginas 26 e 99. 
NEVES, T. T. A. T.; FATORE, F. M.; FADEL, S. G.; HILASACA, G. M.; PAULOVICH, F. V. UPDis: an user-assisted projection technique for distance information. Submetido a Information Visualization, 2016. Citado na página 99.

NGUYEN, H.-L.; WOON, Y.-K.; NG, W.-K. A survey on data stream clustering and classification. Knowledge and information systems, Springer, v. 45, n. 3, p. 535-569, 2015. Citado na página 26.

OLIVEIRA JR, O. N.; NEVES, T. T. A. T.; PAULOVICH, F. V.; OLIVEIRA, M. C. F. de. Where chemical sensors may assist in clinical diagnosis exploring "big data". Chemistry Letters, The Chemical Society of Japan, v. 43, n. 11, p. 1672-1679, 2014. Citado na página 100.

OLIVEIRA, M. C. F.; LEVKOWITZ, H. From visual data exploration to visual data mining: a survey. IEEE Transactions on Visualization and Computer Graphics, v. 9, n. 3, p. 378-394, 2003. ISSN 1077-2626. Citado na página 26.

PAGE, E. Continuous inspection schemes. Biometrika, JSTOR, v. 41, n. 1/2, p. 100-115, 1954. Citado na página 98.

PAL, N. R.; BEZDEK, J. C. On cluster validity for the fuzzy c-means model. IEEE Transactions on Fuzzy Systems, v. 3, n. 3, p. 370-379, 1995. ISSN 1063-6706. Citado na página 39.

PAULOVICH, F.; MAKI, R.; OLIVEIRA, M. de; COLHONE, M.; SANTOS, F.; MIGLIACCIO, V.; CIANCAGLINI, P.; PEREZ, K.; STABELI, R.; PERINOTO, A.; OLIVEIRA, O.; ZUCOLOTTO, V. Using multidimensional projection techniques for reaching a high distinguishing ability in biosensing. Analytical and Bioanalytical Chemistry, Springer Berlin / Heidelberg, v. 400, p. 1153-1159, 2011. ISSN 1618-2642. 10.1007/s00216-011-4853-2. Disponível em: <http://dx.doi.org/10.1007/s00216-011-4853-2>. Citado na página 26.

PAULOVICH, F.; NONATO, L.; MINGHIM, R.; LEVKOWITZ, H. Least square projection: A fast high-precision multidimensional projection technique and its application to document mapping. v. 14, n. 3, p. 564-575, 2008. ISSN 1077-2626. Citado 3 vezes nas páginas 26, 38 e 55 .

PAULOVICH, F.; SILVA, C.; NONATO, L. Two-phase mapping for projecting massive data sets. v. 16, n. 6, p. 1281-1290, 2010. ISSN 1077-2626. Citado 7 vezes nas páginas 26, 40, 49, 55, 71, 74 e 75.

PAUlOVICH, F. V.; ELER, D. M.; POCO, J.; BOTHA, C. P.; MINGHIM, R.; NONATO, L. G. Piecewise laplacian-based projection for interactive data exploration snd organization. Computer Graphics Forum, v. 30, n. 3, p. 1091-1100, 2011. Citado 4 vezes nas páginas 39, 55,71 e 74 .

PAVLIDIS, N. G.; TASOULIS, D. K.; ADAMS, N. M.; HAND, D. J. \&\#955;-perceptron: An adaptive classifier for data streams. Pattern Recogn., Elsevier Science Inc., New York, NY, USA, v. 44, n. 1, p. 78-96, jan. 2011. ISSN 0031-3203. Disponível em: <http://dx.doi.org/10. 1016/j.patcog.2010.07.026>. Citado na página 26.

PEKALSKA, E.; RIDDER, D. de; DUIN, R. P. W.; KRAAIJVELD, M. A. A new method of generalizing Sammon mapping with application to algorithm speed-up. In: Annual Conf. Advanced School for Comput. Imag. [S.1.: s.n.], 1999. p. 221-228. Citado 4 vezes nas páginas $36,55,68$ e 74 . 
PICKETT, R. M.; GRISTEIN, G. G. Iconographic displays fos visualizing multidimensional data. In: Proceedings of IEEE Conference on Systems, Man, and Cybernetics. [S.1.: s.n.], 1988. p. 514-519. Citado na página 26.

RAO, R.; CARD, S. K. The table lens: merging graphical and symbolic representations in an interactive focus + context visualization for tabular information. In: CHI '94: Proceedings of the SIGCHI conference on Human factors in computing systems. New York, NY, USA: ACM, 1994. p. 318-322. ISBN 0-89791-650-6. Citado na página 26.

RIDDER, D. D.; DUIN, R. P. Sammon's mapping using neural networks: a comparison. Pattern Recognition Letters, Elsevier, v. 18, n. 11, p. 1307-1316, 1997. Citado na página 36.

ROSE, S.; WONG, P. C. Driftweed - a visual metaphor for interactive analysis of multivariate data. In: Proceedings of IS\&T/SPIE Conference - Visual Data Exploration and Analysis. [S.1.: s.n.], 2000. v. 3960, p. 114-121. Citado na página 26.

ROWEIS, S. T.; SAUL, L. K. Nonlinear dimensionality reduction by locally linear embedding. Science, v. 290, n. 5500, p. 2323-2326, December 2000. Citado na página 26.

SÁEZ, C.; RODRIGUES, P. P.; GAMA, J.; ROBLES, M.; GARCÍA-GÓMEZ, J. M. Probabilistic change detection and visualization methods for the assessment of temporal stability in biomedical data quality. Data Mining and Knowledge Discovery, Springer, p. 1-26, 2014. Citado 2 vezes nas páginas 71 e 98 .

SAMMON, J. W. A nonlinear mapping for data structure analysis. v. 18, n. 5, p. 401-409, 1969. ISSN 0018-9340. Citado 3 vezes nas páginas 26, 35 e 54.

SANTOS, T. S. R.; PAULOVICH, F. V.; MOLCHANOV, V.; LINSEN, L.; OLIVEIRA, M. C. F. de. Visualizing temporal behavior in multifield particle simulations. In: Proceedings of the International Conferenceon Computer Graphics Theory and Applications and International Conference on Information Visualization Theory and Applications. [s.n.], 2013. p. 573-582. Molchanovlinsenvcglsmoothvis. Disponível em: <http://vcgl.jacobs-university.de/ wp-content/uploads/2013/07/VisualizingTemporalBehavior.pdf>. Citado na página 99.

SEBASTIÃO, R.; GAMA, J.; RODRIGUES, P. P.; BERNARDES, J. Monitoring incremental histogram distribution for change detection in data streams. In: Knowledge discovery from sensor data. [S.1.]: Springer, 2010. p. 25-42. Citado na página 98.

SILVA, V. D.; TENENBAUM, J. B. Sparse multidimensional scaling using landmark points. [S.1.], 2004. Citado 3 vezes nas páginas 35, 51 e 55.

SILVA, V. de; TENENBAUM, J. B. Global versus local methods in nonlinear dimensionality reduction. In: BECKER, S.; THRUN, S.; OBERMAYER, K. (Ed.). NIPS. [S.1.]: MIT Press, 2002. p. 705-712. ISBN 0-262-02550-7. Citado 3 vezes nas páginas 38, 55 e 74.

STEINBACH, M.; KARYPIS, G.; KUMAR, V. A comparison of document clustering techniques. In: ACM. Workshop on Text Mining, 6th ACM SIGKDD International Conference on Data Mining (KDD’00). Boston, Massachusetts, USA, 2000. p. 109-110. Citado na página 71.

TAN, P.-N. et al. Introduction to data mining. [S.1.]: Pearson Education India, 2006. Citado na página 91. 
TAN, P.-N.; STEINBACH, M.; KUMAR, V. Introduction to Data Mining, (First Edition). Boston, MA, USA: Addison-Wesley Longman Publishing Co., Inc., 2005. ISBN 0321321367. Citado na página 59.

TEJADA, E.; MINGHIM, R.; NONATO, L. G. On improved projection techniques to support visual exploration of multidimensional data sets. Information Visualization, v. 2, n. 4, p. 218 231, 2003. Citado 2 vezes nas páginas 26 e 31 .

TENENBAUM, J. B.; SILVA, V. de; LANGFORD, J. C. A global geometric framework for nonlinear dimensionality reduction. Science, Department of Psychology, Stanford University, Stanford, CA 94305, USA. jbt@ psych.stanford.edu, v. 290, n. 5500, p. 2319-2323, December 2000. ISSN 0036-8075. Citado 3 vezes nas páginas 26, 37 e 74.

TUTTE, W. T. How to draw a graph. Lodon Mathematical Society, v. 13, p. 743-768, 1963. Citado na página 38.

VENNA, J.; PELTONEN, J.; NYBO, K.; AIDOS, H.; KASKI, S. Information retrieval perspective to nonlinear dimensionality reduction for data visualization. The Journal of Machine Learning Research, JMLR. org, v. 11, p. 451-490, 2010. Citado na página 26.

WHALEN, D.; NORMAN, M. L. Competition data set and description. 2008. 2008 IEEE Visualization Design Contest. Disponível em: < http://vis.computer.org/VisWeek2008/vis/contests. html>. Citado na página 74 .

WILLIAMS, C.; GULATI, G. What is a social network worth? facebook and vote share in the 2008 presidential primaries. In: AMERICAN POLITICAL SCIENCE ASSOCIATION. [S.1.], 2008. Citado na página 86.

YAN, J.; ZHANG, B.; LIU, N.; YAN, S.; CHENG, Q.; FAN, W.; YANG, Q.; XI, W.; CHEN, Z. Effective and efficient dimensionality reduction for large-scale and streaming data preprocessing. IEEE transactions on Knowledge and Data Engineering, IEEE, v. 18, n. 3, p. 320-333, 2006. Citado na página 32.

YOUNG, G.; HOUSEHOLDER, A. S. Discussion of a set of points in terms of their mutual distances. Psychometrika, Springer, v. 3, n. 1, p. 19-22, 1938. Citado na página 35. 